\title{
Full-length review
}

\section{Eye fields in the frontal lobes of primates}

\author{
Edward J. Tehovnik *, Marc A. Sommer, I-Han Chou, Warren M. Slocum, Peter H. Schiller \\ Department of Brain and Cognitive Sciences, Massachusetts Institute of Technology, E25-634, Cambridge, MA 02139, USA
}

Accepted 19 October 1999

\begin{abstract}
Two eye fields have been identified in the frontal lobes of primates: one is situated dorsomedially within the frontal cortex and will be referred to as the eye field within the dorsomedial frontal cortex (DMFC); the other resides dorsolaterally within the frontal cortex and is commonly referred to as the frontal eye field (FEF). This review documents the similarities and differences between these eye fields. Although the DMFC and FEF are both active during the execution of saccadic and smooth pursuit eye movements, the FEF is more dedicated to these functions. Lesions of DMFC minimally affect the production of most types of saccadic eye movements and have no effect on the execution of smooth pursuit eye movements. In contrast, lesions of the FEF produce deficits in generating saccades to briefly presented targets, in the production of saccades to two or more sequentially presented targets, in the selection of simultaneously presented targets, and in the execution of smooth pursuit eye movements. For the most part, these deficits are prevalent in both monkeys and humans. Single-unit recording experiments have shown that the DMFC contains neurons that mediate both limb and eye movements, whereas the FEF seems to be involved in the execution of eye movements only. Imaging experiments conducted on humans have corroborated these findings. A feature that distinguishes the DMFC from the FEF is that the DMFC contains a somatotopic map with eyes represented rostrally and hindlimbs represented caudally; the FEF has no such topography. Furthermore, experiments have revealed that the DMFC tends to contain a craniotopic (i.e., head-centered) code for the execution of saccadic eye movements, whereas the FEF contains a retinotopic (i.e., eye-centered) code for the elicitation of saccades. Imaging and unit recording data suggest that the DMFC is more involved in the learning of new tasks than is the FEF. Also with continued training on behavioural tasks the responsivity of the DMFC tends to drop. Accordingly, the DMFC is more involved in learning operations whereas the FEF is more specialized for the execution of saccadic and smooth pursuit eye movements. (C) 2000 Elsevier Science B.V. All rights reserved.
\end{abstract}

Keywords: Dorsomedial frontal cortex; Supplementary eye field; Frontal eye field; Oculomotor behaviour; Skeletomotor behaviour; Learning; Monkey; Human

\section{Contents}

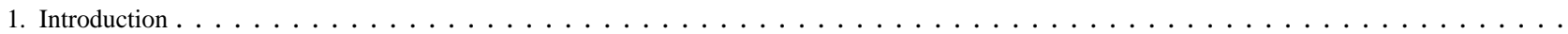

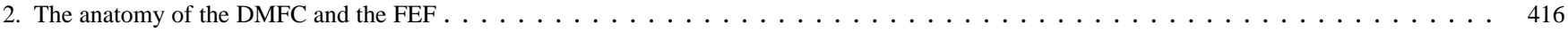

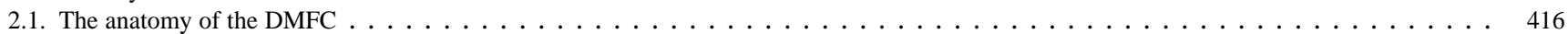

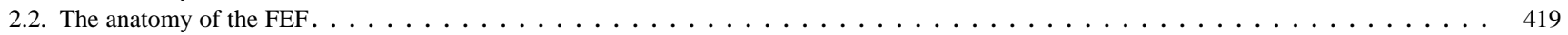

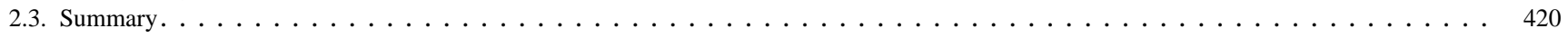

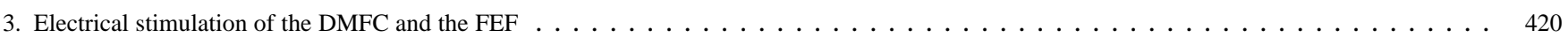

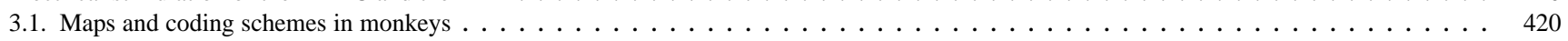

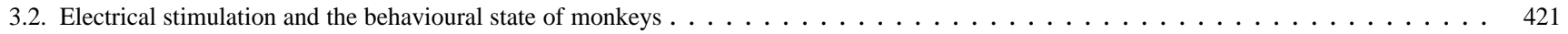

3.3. Skeletomotor responses elicited by electrical stimulation of the DMFC and FEF in monkeys . . . . . . . . . . . . . . . . 4 423

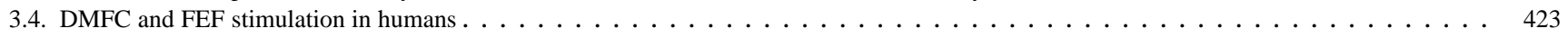

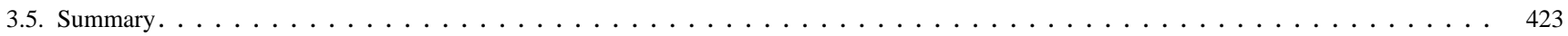

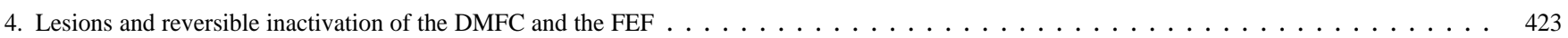

4.1. The effects of lesions and reversible inactivation of the DMFC in monkeys $\ldots \ldots \ldots 423$

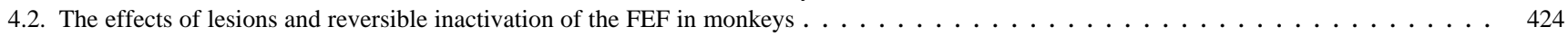

4.3. Direct comparison of DMFC and FEF lesions and inactivation on visually guided eye movements . . . . . . . . . . . . . 426

\footnotetext{
* Corresponding author. Fax: +1-617-253-8943; e-mail: tehovnik@ai.mit.edu
} 


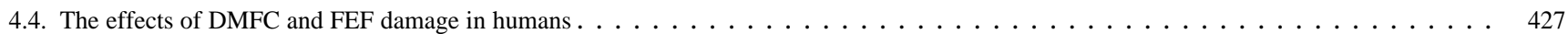

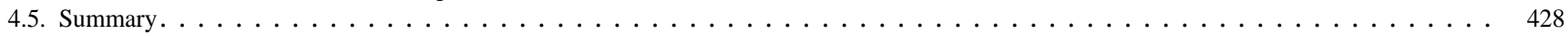

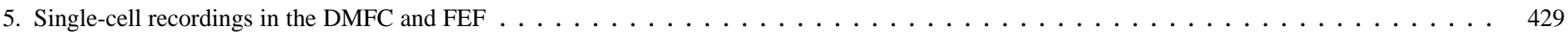

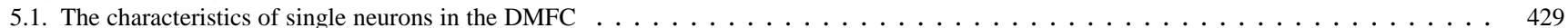

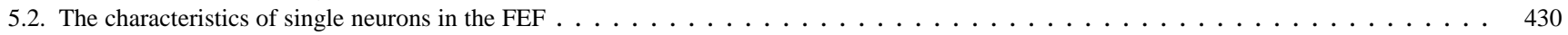

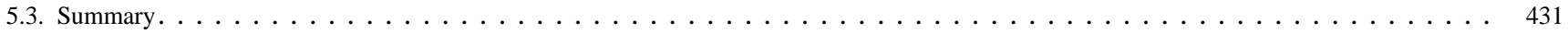

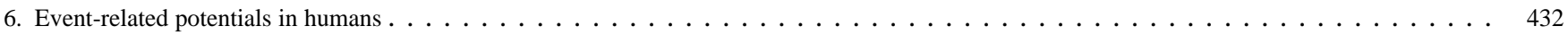

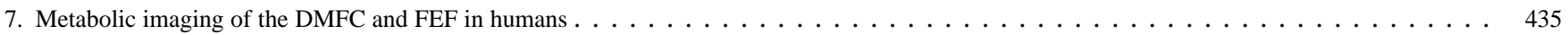

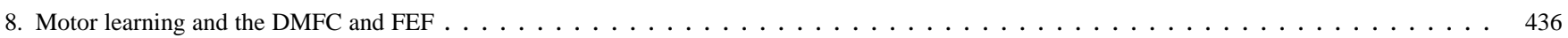

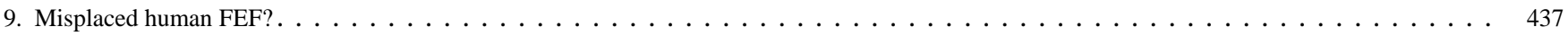

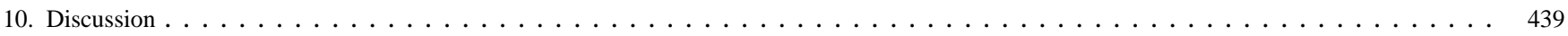

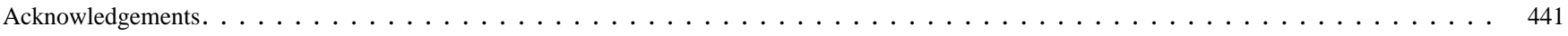

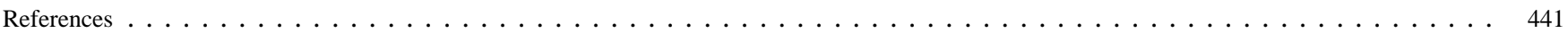

\section{Introduction}

Two areas within the frontal lobes play important roles in eye movement control. One area resides laterally and is known as the frontal eye field (FEF). The other resides medially and dorsally and is often termed the supplementary eye field (see Schall [230]). As will become clear from this review, the size, exact location, and precise function of this second eye field are still under debate; therefore, we refer to it using the anatomical designation, the dorsomedial frontal cortex (DMFC), or more specifically "the eye field within the DMFC', Our examination of the literature suggests that the differences between the two frontal lobe eye fields, the FEF and DMFC, are profound. The FEF plays an important role in generating eye movements, utilizing an eye-centered code, whereas the DMFC integrates oculomotor and skeletomotor behaviour, utilizing predominantly a head-centered code, and is involved in visuo-motor learning.

One of the first investigators to examine the role of the cortex in eye-movement control was Hitzig [106]. Studying patients unable to move their eyes voluntarily, Hitzig found that he could induce eye movements by delivering pulses of direct current through electrodes attached to the skull. Hitzig believed that the eye movements produced were due to excitation of brain tissue. However, the resulting eye movements could have been due to surface conduction to the eye muscles; to resolve this ambiguity, Hitzig needed to stimulate the brain directly. In collaboration with Fritsch, he performed these experiments on dogs. In 1870 they established that neocortical stimulation elicited movement of the extremities, but they failed to produce eye movements [68,307].
Soon thereafter, Ferrier [59] discovered that eye movements could be evoked in monkeys from parts of the frontal, parietal, and temporal lobes, the superior colliculi, and the cerebellum. The frontal lobe eye field that Ferrier described extends from the arcuate sulcus to the midline (Fig. 1A,B). It is remarkable that the only major modification to this eye field since Ferrier's original publication has been a split into two subfields, one wholly within the curve of the arcuate sulcus and the other about a centimeter away, near the midline.

At the end of the 19th century, tissue removal and electrical stimulation were the main techniques used to examine brain function in animals. Interpretation of the former was difficult due to qualitative, irreproducible behavioural testing and post-operative infections [77,107]. Electrical stimulation results, on the other hand, were more unequivocal and enlightening. Beevor and Horsley [10] confirmed Ferrier's findings showing that eye movements could be elicited from both the prearcuate gyrus and the peri-midline cortex in the frontal lobe of monkeys. They further showed that eye movements could be evoked from the lateral frontal convexity of an ape as well [11], and this was confirmed by Grünbaum and Sherrington [92] and Leyton and Sherrington [144] after the turn of the century in orangutans, chimpanzees, and gorillas. However, neither of these groups uncovered the existence of an eye field near the midline of their apes. Subsequently, investigators focused on the prearcuate eye field, which eventually became known as the FEF; the medial eye field representation was essentially ignored for decades.

Neurosurgeons were, in large part, responsible for reviving scientific curiosity about the eye fields in the DMFC. Foerster $[60,61]$ reported that there were two main 


\section{Monkey}

A

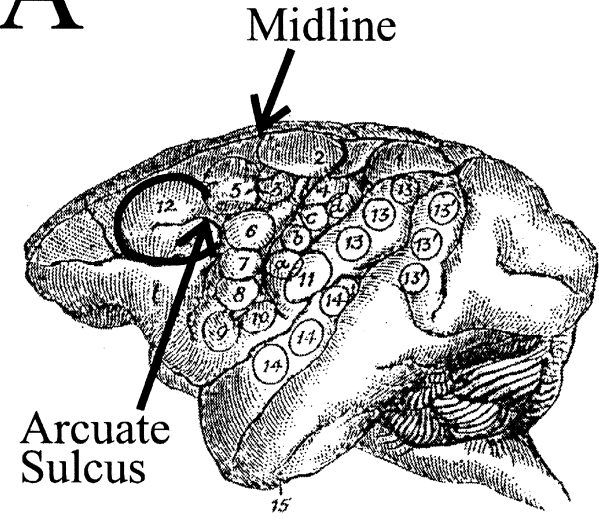

B

(anterior)

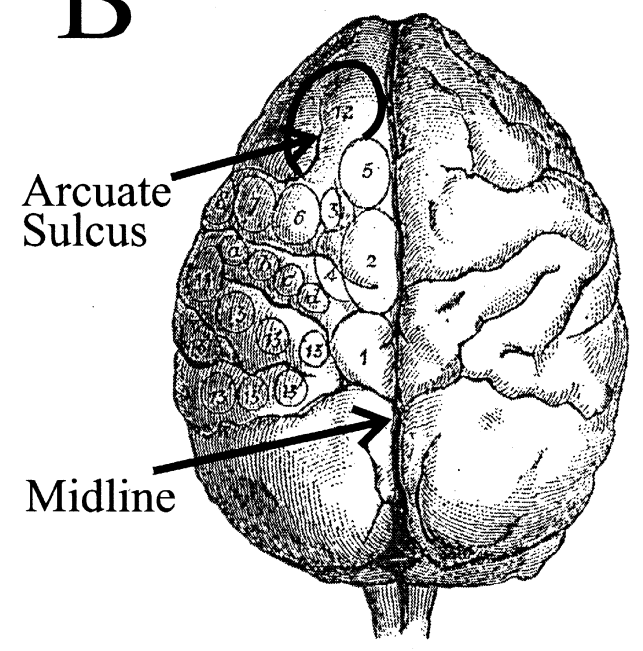

Human

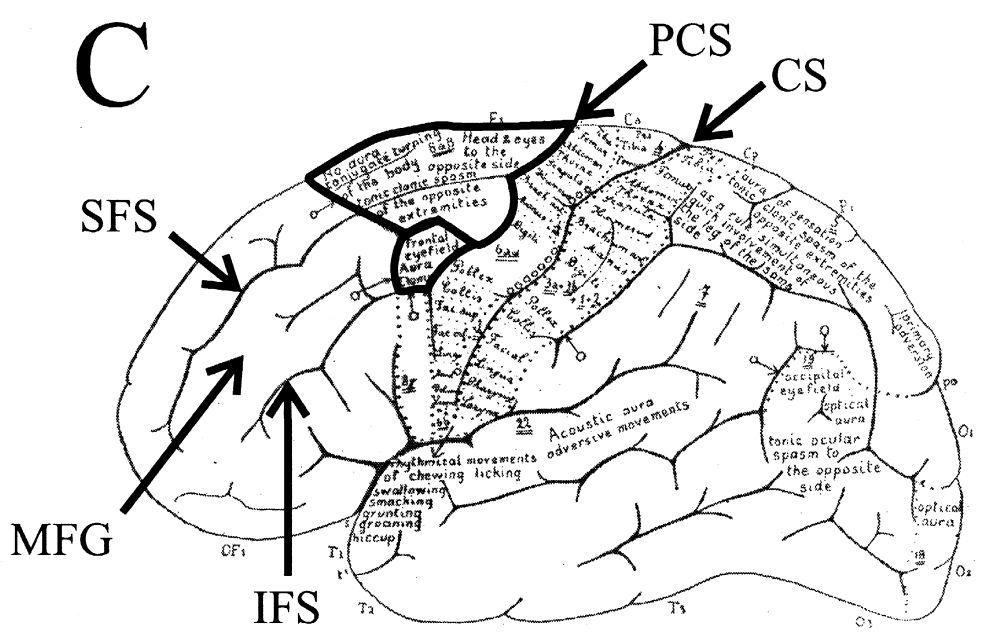

$\mathrm{D}$

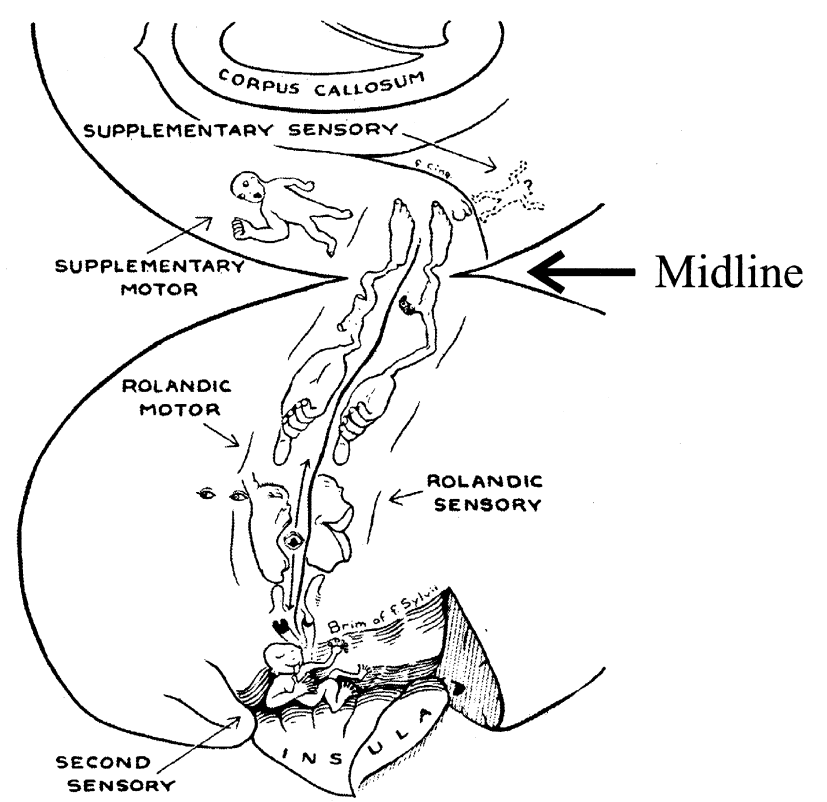

Fig. 1. Classic results in examining the neocortical contribution to eye movements. Anterior is to the left and dorsal to the top unless otherwise noted. (A) Stimulation regions of Ferrier [59], lateral view. In the frontal lobe, eye movements were evoked from region 12 only (border surrounding it is emphasized in bold). Species was Macaca cynomolgus, according to Walker [302], although this was not noted in Ferrier's paper. (B) Dorsal view of Ferrier's stimulation regions (anterior at top). (C) Foerster's map of movements and sensations evoked by electrical stimulation of human brain [60]. The two frontal lobe eye fields he found are outlined in bold. Note, in an apparent attempt to simplify his presentation, he superimposed his functional findings on the cytoarchitectural map of Vogt and Vogt [296]. Human brain landmarks relevant to this review are labeled: IFS, inferior frontal sulcus; MFG, middle frontal gyrus; SFS, superior frontal sulcus; PCS, precentral sulcus; CS, central sulcus (also known as Rolandic sulcus). (D) Map of human peri-Rolandic motor and sensory areas, from Penfield and Jasper [194].

regions from which eye movements could be evoked in the human frontal lobe. One was in the FEF, on the lateral convexity of the cortex (lower bold-outlined region in Fig. $1 \mathrm{C})$, and the other was in Vogts' area $6 \mathrm{a} \beta$, medial to the
FEF (upper bold-outlined region in Fig. 1C). Both regions were anterior to the primary, precentral motor strip. Foerster [60] did not specify what part of Area $6 a \beta$ was related to eye movements. Penfield and Jasper [194] and Penfield 
and Rasmussen [195] clarified the location of the $6 a \beta$ eye field in their subsequent studies of the human brain, localizing it to the rostral part of the supplementary motor area (Fig. 1D). Penfield also confirmed Foerster's finding that the human FEF was on the lateral convexity, anterior to the precentral motor strip (Fig. 1D, lower set of eyes). At about the same time, Woolsey [309] and Woolsey et al. [311] showed in an assortment of animals that the representation of the body was oriented eyes-rostrally and tailcaudally in the DMFC of every animal studied.

Since the 1950s, research directed toward the neural control of eye movements has profited from five major methodological advances: (1) the development of a variety of microelectrodes suitable for single-cell recordings and for microstimulation; (2) the emergence of instrumentation that allowed investigators to accurately measure eye movements; (3) the introduction of behavioral methods that made it possible to train animals to move their eyes in response to sensory stimuli in predictable, reproducible ways; (4) the development of techniques that allowed for making focal brain lesions or for reversibly inactivating selected brain areas using a variety of pharmacological agents; and (5) the application of various imaging procedures to localize areas involved in eye-movement control. This review focuses extensively on research conducted using these methods. We will compare and contrast the function and organization of the two eye fields in the frontal lobes based on research carried out in primates, including humans.

\section{The anatomy of the DMFC and the FEF}

\subsection{The anatomy of the DMFC}

\subsubsection{Monkey DMFC}

In monkeys, the DMFC is situated anterior to the motor cortex. It occupies a region between the superior limb of the arcuate sulcus and the cerebral midline dorsal to the cingulate cortex. Brodmann [29] defined this area as the mesial portion of area 6 . Subsequently, this region was partitioned. Vogt and Vogt [295] divided the DMFC into rostral and caudal zones: $6 \mathrm{a} \beta$ and $6 \mathrm{a} \alpha$, respectively (Fig. 2A). von Bonin and Bailey [297] also partitioned the DMFC into rostral and caudal zones, but the rostral zone was appreciably smaller. Barbas and Pandya [8] divided the DMFC into three regions, a medial region they called MII, a rostrolateral region they called 6DR, and a caudal region they called 6DC. Some have also suggested that the DMFC includes area 8b [147], which is situated immediately adjacent to the anterior border of area 6 [20].

Woolsey et al. [311] observed that the DMFC contains a somatotopic map with the head represented rostrally and the tail represented caudally. Although some have disputed this general topography [305], there is now overwhelming evidence corroborating the original observations of Woolsey [27,64,66,86,110,149,166,228,243,275,308].

Single-unit recording experiments have shown that neurons modulated by eye movements are located rostrally, that neurons modulated by hindleg movements are located

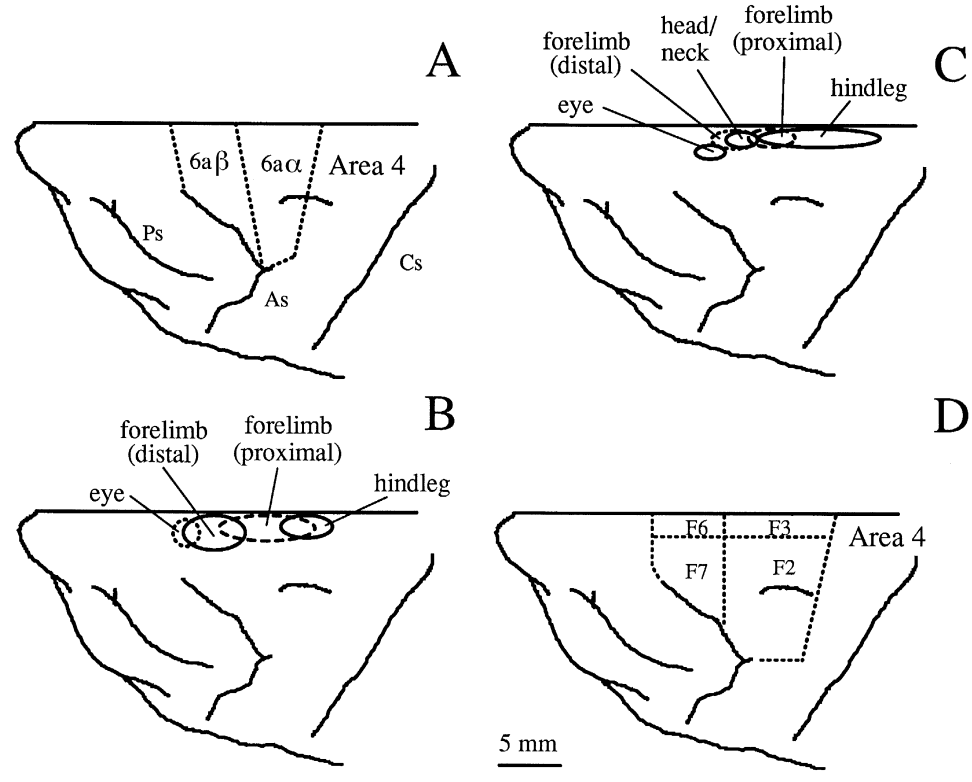

Fig. 2. Monkey DMFC. Each panel shows a top view of one hemisphere of the frontal cortex of a macaque monkey. (A) The DMFC is divided according to the scheme of Vogt and Vogt [295]. (B) Each oval represents a region from the DMFC that contained cells modulated by eye, forelimb, and hindleg movements in the same monkey (Brinkman and Porter [27], monkey SMA-3). (C) Each oval represents a region from the DMFC from which movements could be evoked using electrical stimulation (Luppino et al. [149], monkey MK-7r). (D) The DMFC is divided according to the scheme of Matelli et al. [159]. A scale bar is shown at the bottom. The central sulcus (Cs), arcuate sulcus (As), and principal sulcus (Ps) are indicated in (A). 
caudally, and that neurons modulated by forelimb movement are located in between the rostral and caudal extremes of the DMFC (Ref. [27]; see Fig. 2B). Neurons with responses modulated by distal forelimb movement are found anterior to those modulated by proximal forelimb movements. These findings concur with results obtained using microstimulation (Refs. [149,166]; see Fig. 2C).

\subsubsection{Multiple sub-areas of monkey DMFC}

Based on cytoarchitectonics, Matelli et al. [159] partitioned the DMFC into four regions: F2, F3, F6, and F7 (Fig. 2D). More recently, these regions have been given functional labels now adopted by Tanji and colleagues under the premise that these regions are functionally distinct $[69,161,162,173,254,255,277,279]$. These labels have also been used to organize data from functional imaging experiments carried out on humans [204]. In this nomenclature, F2 corresponds with the premotor area, F3 with the supplementary motor area, F6 with the pre-supplementary motor area, and F7 with the supplementary eye fields.

The subdivisions, F2, F3, F6, and F7, as established by Matelli et al. [159], were based on six macaque monkeys. As sections were taken more rostrally in the DMFC, proceeding from $\mathrm{F} 3$ to $\mathrm{F} 6$ or from $\mathrm{F} 2$ to $\mathrm{F} 7$, the cells in layer $\mathrm{V}$ exhibited a noticeable decrease in size. ${ }^{1}$ Layer $\mathrm{V}$ was thicker in F3 than in F6 and layer V was thicker in F2 than in F7. Progressing from caudal to rostral regions of $\mathrm{F} 3$, a decrease in the frequency of the giant pyramidal cells was observed. Although Matelli et al. [159] suggest that F2 differs from $\mathrm{F} 3$ and that $\mathrm{F} 6$ differs from F7, this is not apparent from their figures. ${ }^{2}$ Based on their illustrations, one would be hard put to establish a difference between F2 and F3 and a difference between F6 and F7. Furthermore, a discrete border between F3 and F6 and between F2 and F7 is hard to discern in their Fig. 3, which depicts horizontal sections including F3 and F6, and in their Fig. 7 which depicts parasagittal sections including F2 and F7. Current anatomical techniques do not convincingly denote marked differences between these areas other than cell size and laminar thickness.

Even though the cytoarchitectonics of the DMFC do not support the subdivisions of Matelli et al. [159], the projections from these regions might favor a segregation such that eye-movement areas only innervate F7 (the supplementary eye fields). The FEF and superior colliculus are connected with area F7 [5,67,108,132,231,257], yet they are also connected with areas F2, F3 and F6 [5,128, $132,231,257]$.

Studies examining the projections between the DMFC and motor cortex show that the entire DMFC (i.e., F2, F3, F6, and F7) sends projections to the forelimb area of the

\footnotetext{
${ }^{1}$ Matelli et al. [159]: their Fig. 6, cf. F3 and F6 and their Fig. 9, cf. F2 and F7.

${ }^{2}$ Compare Fig. 5 with Fig. 8 of Matelli et al. [159].
}

motor cortex [56,79,129,140,146,160]. Motor cortex, however, does not project to F6 and F7 [150], although it does innervate F2 and F3 [140,150]. Thus the cytoarchitectonics and the efferent and the afferent connections of the DMFC do not provide an unambiguous way of subdividing the DMFC according to the scheme of Matelli et al. [159].

\subsubsection{Neuron size and somatotopy of monkey DMFC}

Matelli et al. [159] observed that the thickness of cortex decreases from caudal to rostral DMFC. ${ }^{3}$ The number of cells within a cylinder of constant cross-sectional area of 1 $\mathrm{mm}^{2}$ of cerebral cortex is constant $[16,23,217]$, which makes it understandable why cortical thickness from caudal to rostral portions of the DMFC decreases concurrently with decreases in cell size as illustrated by Matelli et al. [159]. Mitz and Wise [166] show that the number of cells with large diameters (over $600 \mu \mathrm{m}^{2}$ ) also decreases systematically from caudal to rostral DMFC.

It is well-known that there is a direct correspondence between cell size and axon diameter [259] and that the larger the cell, the further the axon tends to project from the cell body $[114,172]$. That cells decrease in size going from caudal to rostral DMFC concurs with the somatotopy of the DMFC. Caudal DMFC, which has been associated with the hindlimbs, projects as far as the lumbar/thoracic cord [99,110]; intermediate DMFC, which has been associated with forelimbs, projects as far as the cervical cord [56,99,110,123,132,151,221]; and rostral DMFC, which has been associated with the eyes and head, projects as far as the brainstem [108,132,142,187,256,257]. Hence, the difference in cell size across the DMFC accords with its general somatotopy.

\subsubsection{Connectivity of monkey DMFC}

As already alluded by the foregoing, the DMFC is innervated by both oculomotor as well as skeletomotor regions of the brain. It innervates the FEF and the superior colliculus $[5,67,108,128,132,231,257]$, both of which are major channels to the saccade generator in the brainstem. Also, it receives robust efferent and afferent projections from the motor cortex $[56,79,129,140,146,150,160]$ and sends fibres to a myriad of brainstem $[108,132,142,187$, $256,257]$ and spinal cord $[56,99,110,123,132,151,221]$ nuclei involved in the execution of eye, head, and limb movements.

In addition, visual centers, such as the lateral intraparietal area and the medial superior temporal area, innervate the DMFC [108,232], and somatosensory areas, such as the superior parietal lobule, send robust projections to it $[113,202]$. Moreover, DMFC is reciprocally connected to prefrontal cortex [108] and innervates various thalamic and striatal sites that have been implicated in oculomotor and

\footnotetext{
${ }^{3}$ Caudal: $F 2$ and F3 $=2162$ and $2157 \mu \mathrm{m}$, respectively. Rostral: F6 and $\mathrm{F} 7=1990$ and $1992 \mu \mathrm{m}$, respectively.
} 
A

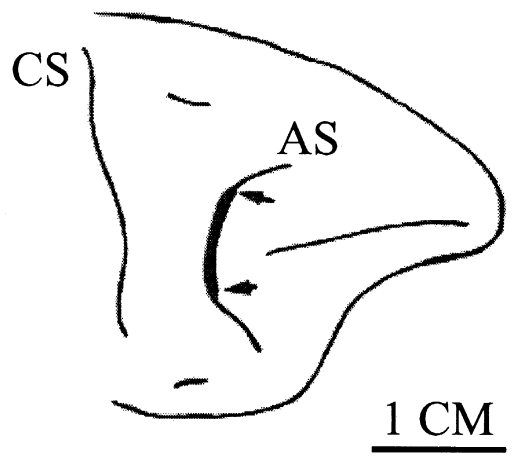

B

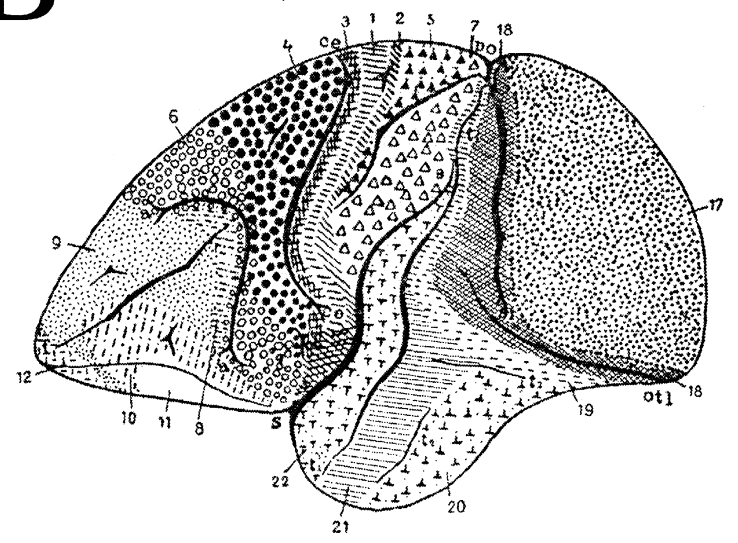

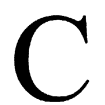

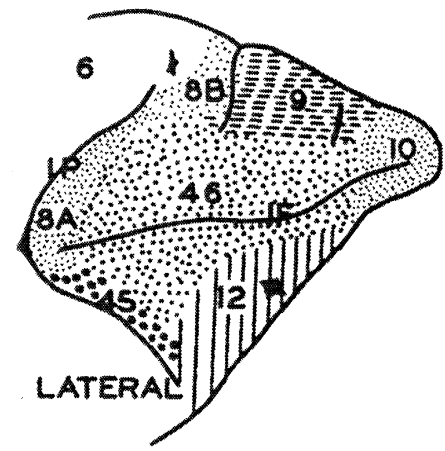

$\mathrm{D}$

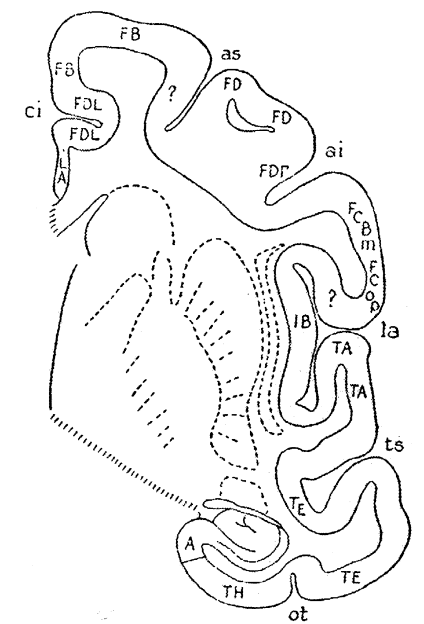

Fig. 3. Monkey FEF. Anterior is to the right for panels A and C, and to the left for panel B. (A) Location of the FEF on a lateral view of monkey frontal lobe, defined using the $<50 \mu \mathrm{A}$ current-threshold criterion (modified from Bruce et al. [31]). Small arrows and shading delimit the mediolateral range of FEF. Most of the FEF, however, extends into the arcuate sulcus and cannot be seen. CS, central sulcus; AS, arcuate sulcus. (B) Monkey cortex as parcellated by Brodmann [29]. Species is presumably Cercopithecus campbelli (see von Bonin and Bailey [297], p. 64). (C) Parcellation of prefrontal cortex by Walker [301]. Species is M. mulatta. (D) Coronal section through the genu of the arcuate sulcus, showing the parcellation of von Bonin and Bailey [297] from mediodorsal (top) to ventrolateral (right). Species is M. mulatta; as, superior branch of arcuate sulcus; ai, inferior branch of arcuate.

skeletomotor functions $[108,125,128,158,187,258]$. Finally, this region sends projections to the red nucleus $[108,257,289]$.

\subsubsection{Human DMFC}

As in monkeys, the DMFC in humans is located immediately anterior to the motor cortex on the dorsal surface of the hemisphere (Fig. 1C,D). The area is situated anterior to the precentral sulcus and is bounded laterally by the superior frontal sulcus and medioventrally by the cingulate cortex [32]. Brodmann [28] has defined this region as mesial area 6 of the agranular cortex and Campbell [32] called it the intermediate precentral area. Vogt and Vogt [295] subsequently divided the region into caudal and rostral zones (i.e., $6 a \alpha$ and $6 a \beta$ ) similar to what they had done in the monkey. Electrical stimulation of this region in humans evokes eye movements from rostral sites and hindleg movements from caudal sites [194,310]. This topographic layout is similar to that observed for the DMFC of monkeys. 


\subsection{The anatomy of the FEF}

\subsubsection{Monkey FEF}

There has been general agreement among electrophysiological studies regarding the gross location of the FEF in the monkey. Ferrier [59] showed that electrical stimulation of the prearcuate gyrus causes contraversive eye movements (Fig. 1A). This central observation has been repeatedly confirmed [262]. The subsequent use of microelectrodes facilitated the establishment of the exact location and extent of the FEF. Bruce and Goldberg [30] functionally defined the FEF as the region from which saccadic eye movements can be evoked with currents of less than $50 \mu \mathrm{A}$. This region lies within the rostral bank of the posterior curve of the arcuate, extending anteriorly over the lip of the arcuate " ... a few millimeters onto the surface of the prearcuate gyrus" (Ref. [31], p. 723), and posteriorly encroaching a few millimeters into the caudal bank [84,85,248]. Mediolaterally, it extends about $10 \mathrm{~mm}$, centered approximately on the arcuate's midpoint as defined by the intersection of the straight extension of the principal sulcus with the arcuate (Fig. 3A). The overall area of the FEF, approximately $100 \mathrm{~mm}^{2}$, is about equal to the area of the DMFC.

The functionally defined FEF does not correspond to any of the classical cytoarchitectural regions defined by anatomists of the 20th century. Brodmann's area 8 [29] is close with respect to its medial and lateral extent (Fig. 3B), but is situated too far rostrally, extending anteriorly to the caudal tip of the principal sulcus and posteriorly only to the lip of the arcuate sulcus (as described by Walker [301]). The functional FEF therefore overlaps with both areas 8 and 6 of Brodmann. Walker's area 8A (Fig. 3C) extends $1 / 2$ to $2 / 3$ of the way down from the lip of the arcuate and hence, like Brodmann's area 8 , also fails to cover the full caudal extent of the FEF. Laterally, Walker picked out another region in the arcuate's rostral bank and called it area 45 (Fig. 3C), but how far this extends into the sulcus was not specified. Thus, in terms of Walker's nomenclature, the functional FEF overlaps with areas 8A and 45 (and encroaches caudally into Brodmann's area 6). von Bonin and Bailey [297] included the medial half of the arcuate's rostral bank in their frontal granular region (FD), but they agreed with Walker that the lateral part differed and called it FD gamma (after the notation of von Economo and Koskinas [299]; Fig. 3D). Other investigators have split the cortex comprising the FEF into even more subfields, upon which we will not elaborate [203,211,295].

Although the functionally defined FEF does not coincide neatly with traditionally defined cytoarchitectonic regions, it does have a distinct, constant anatomical feature. Stanton et al. [267] reported that the functionally defined FEF coincides with a relatively high concentration of large layer V pyramidal cells in the arcuate's rostral bank. This feature is so prominent that Stanton et al. [267] claimed it to be macroscopically evident in tangential sections through the prearcuate gyrus. The layer $\mathrm{V}$ pyramidal cells are thought to be the major conveyors of oculomotor signals from the FEF to the superior colliculus and the pons [247,248,267].

Does any anatomical characteristic of tissue change systematically across the FEF? Successive generations of anatomists have disagreed about which microstructural changes in the FEF are reliable and important. The following changes are worth noting because they have been independently confirmed by the majority of anatomists; ${ }^{4}$ how they relate to function, however, is unknown. From rostral FEF (near the arcuate lip) to caudal (near the fundus), a moderately thick and granular layer IV tapers off, becoming almost invisible at the fundus and into the posterior bank, while radial fascicles become thicker. From medial FEF to lateral, layer III pyramidal cells get bigger and the distinct radial and horizontal myelination patterns that exist in medial FEF become more diffuse.

The FEF makes profuse reciprocal connections [109] with the lateral intraparietal area, with area 46, with the contralateral FEF, and with the eye field in the DMFC. Subcortically, the FEF is reciprocally and heavily connected with the lateral sector of the mediodorsal nucleus of the thalamus and, to a lesser extent, with thalamic regions lateral and anterior to this [76,268]. The FEF projects directly to the superior colliculus and to brainstem regions fundamental to saccade generation [141], and the FEF receives reciprocal input from the superior colliculus via a disynaptic pathway relayed by the thalamus [153]. The FEF also projects to the striatum $[187,268]$; this projection may be reciprocated through a polysynaptic loop to substantia nigra pars reticulata, thalamus, and back to FEF $[3,153]$.

\subsubsection{Human FEF}

The anatomy of human FEF is an enigma. The most recent conclusions about the gross location of human FEF come from experiments using positron emission tomography (PET) imaging or functional magnetic resonance imaging (fMRI), and from these studies, it appears that the human FEF lies within the precentral sulcus $[43,148,189]$ just caudal to the middle frontal gyrus. The human FEF seems to be placed surprisingly far back in the frontal lobe; it is within, or attached to, the precentral motor strip. In monkeys, by contrast, the FEF is distinctly rostral to the precentral motor strip. The human and monkey FEF are dissimilar in terms of their microstructures, as well. In monkeys, as already noted, a striking characteristic of the FEF is that, within it, layer IV changes rostrocaudally from being thick and granular to being nearly non-existent. In humans, however, the FEF lies entirely in agranular cortex (Fig. 4A). The major thalamic input to monkey FEF is the

\footnotetext{
${ }^{4}$ To our knowledge, modern myelin staining has been performed in the FEF by only one laboratory [211]. Therefore, our myelination conclusions are based on a single report and one might consider them tentative.
} 


\section{A cytoarchitecture}
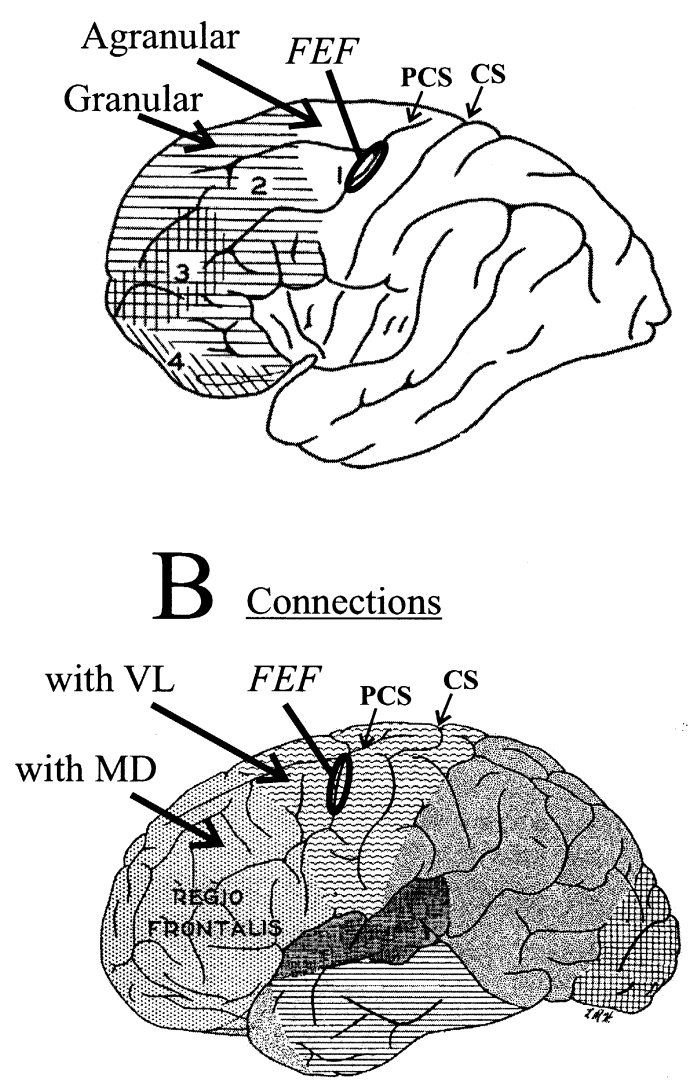

Fig. 4. Human FEF. Anterior is to the left and dorsal is to the top. Ellipses show the approximate locations of human FEF as determined by imaging studies. (A) Basic cytoarchitecture of human frontal lobe. Region 2 is the extent of granular frontal cortex; caudal to that, region 1, in white, is agranular frontal cortex (the granularity of regions caudal to the central sulcus (CS) is not considered). Imaging studies place the human FEF in the precentral sulcus (PCS), totally in agranular cortex. Derived from Walker [301], who based his figure on the human brain study of von Economo and Koskinas [299]. (B) Connections of the human brain with respect to thalamus. The "regio frontalis" is connected primarily with the mediodorsal (MD) nucleus of the thalamus; the region caudal to that is connected primarily with the ventrolateral (VL) thalamic nucleus. Modified from Bailey and von Bonin [7].

mediodorsal nucleus, as noted above. In humans, the general layout of thalamic projections to the cortex has been estimated [7] by analyzing retrograde degeneration subsequent to prefrontal leucotomy or lobectomy $[65,165]$ and by extrapolating results from monkeys [300]. According to this mapping, it is doubtful that the human FEF receives substantial mediodorsal thalamus input (Fig. 4B). Rather, like its neighbor, the precentral motor strip, the human FEF appears to receive its primary afferents from more ventrolaterally located nuclei.

The human FEF, as determined by imaging methods, therefore, is strikingly different from the monkey FEF. Imaging investigators recognize this conflict and have offered a number of explanations for it $[43,148,189]$. We will return to this topic later in the review.

\subsection{Summary}

Two distinct areas involved in eye-movement control have been discerned in the frontal lobe, the FEF and the eye fields in the DMFC. In the monkey, the FEF is located in a well-defined region of the arcuate sulcus. The FEF receives extensive projections from area 46, the intraparietal sulcus, the DMFC, and the contralateral FEF; layer V cells in the FEF project extensively to subcortical centers including the superior colliculus and the brainstem.

The exact size and location of the eye field in the DMFC are not as clearly defined as in the FEF. However, it is evident that the size of cells increases antero-posteriorly in the DMFC and that the projections from the anterior regions terminate mostly in the brainstem while those from the posterior regions have projections that reach the spinal cord. The DMFC innervates regions that mediate both oculomotor and skeletomotor responses.

The two eye fields have also been identified in the human. The FEF in the human is located more closely to the central sulcus than it is in the monkey. The inputs to these areas and their outputs are less well-known in humans than in monkeys.

\section{Electrical stimulation of the DMFC and the FEF}

\subsection{Maps and coding schemes in monkeys}

In 1969, Robinson and Fuchs [216] showed that electrical stimulation of the FEF elicited fixed-vector saccadic eye movements such that the size and direction of the elicited saccades were largely invariant with the initial position of the eyes in orbit. They also noted an orderly arrangement of stimulation-elicited saccades in the FEF (which was first alluded to by the work of Beevor and Horsley [10]): in the ventrolateral regions, small-amplitude saccades were evoked, whereas stimulation of the dorsomedial regions yielded large-amplitude saccades (Fig. 5A). Robinson and Fuchs [216] also found that when long trains of stimulation were delivered to the FEF, a staircase of saccades was elicited with alternating saccades and fixations, so that each saccade had a similar vector (Fig. 5B, right). Bruce et al. [31] confirmed the FEF's map of saccadic amplitudes, and also found that the direction of saccades varied as a function of the depth of stimulation in the arcuate sulcus. Numerous other studies have confirmed these basic findings [6,80,157,229,233,282,284].

Electrical stimulation of the DMFC yields notably different results from those obtained in the FEF. It has been known since 1987 [243] that saccades evoked by electrical stimulation from most sites within the DMFC tend to shift the center of gaze to a particular location of craniotopic 


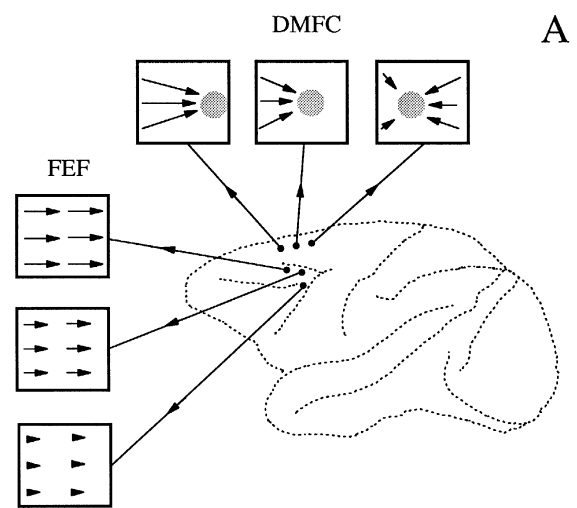

B

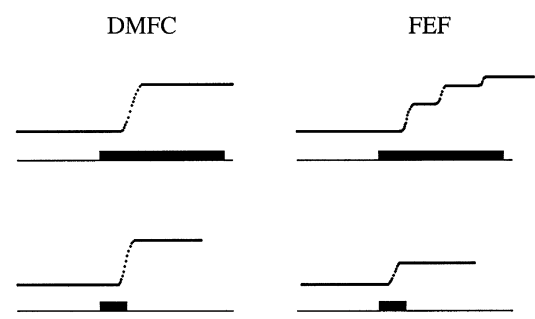

Fig. 5. Coding schemes. (A) Cranio- and retinocentric coding schemes described for the DMFC and FEF, respectively, are shown. A side-view of the macaque monkey brain is depicted. Each box represents the visual space in front of a monkey with head fixed. The right side of a box represents contralateral craniotopic space and the left side represents ipsilateral craniotopic space (i.e., with respect to the side of stimulation). The arrows within each box represent saccades starting from different fixation positions. The top boxes show the types of saccades evoked from sites situated along the rostrocaudal axis of the DMFC. A shaded circle represents the termination zone of the saccades evoked from a given site. The boxes aligned at left show the types of saccades evoked from sites situated along the mediolateral axis of the FEF. (B) Horizontal eye traces are shown of saccades evoked from the DMFC and FEF. Below each eye trace is a black bar which represents the onset and duration of electrical stimulation. (Top) When a 400-ms train of stimulation was delivered to the DMFC, a single saccadic eye movement was evoked and when such a train of stimulation was delivered to the FEF, a series of saccadic eye movements was evoked. (Bottom) When a 70-ms train of stimulation was delivered to the DMFC or FEF, a single saccadic eye movement was evoked.

space. This finding has been confirmed by the present authors laboratory $[139,156,264,282,283,285,286]$ as well as by others $[19,229]$. The orbital position reached by the eye upon stimulation has subsequently been named the termination zone [282]. The location of a termination zone corresponds to the location of the fixation fields of neurons in the stimulated area [19]. Further work revealed that the DMFC contains an orderly topographic map representing different termination zones [139,264,282,283,285,286]: stimulation of rostral sites in the DMFC elicits saccades that shift the direction of gaze into contralateral craniotopic space, whereas stimulation of caudal sites shifts gaze into central or ipsilateral craniotopic space (Fig. 5A [139]); stimulation of medial and lateral sites direct the eyes to lower and upper craniotopic space, respectively. When the head is displaced with respect to the trunk or when the head is tilted with respect to the vertical axis, the location of a termination zone remains fixed to the head [285]. When long trains of stimulation are delivered to the DMFC, only one saccadic eye movement is typically produced (Fig. 5B, left) $[229,243,282,284]$ after which the eyes remain fixated in the termination zone for the duration of stimulation, thereby inhibiting any subsequent eye movements [282,283]. These results suggest that the DMFC, unlike the FEF, contains a craniocentric (or headcentered) code for the execution of saccadic eye movements.

In conflict with these reports is a study by Russo and Bruce [222] who found that stimulation in the DMFC produces saccadic eye movements similar to those found in the FEF: the size and direction of the saccadic eye movements did not vary remarkably with respect to the starting position of the eye. There could be several reasons for this difference. First, it is possible that area DMFC is not homogeneous; different subregions may carry different codes. Second, it is possible that stimulation at certain sites in the DMFC antidromically activated axon collaterals from the FEF. Consistent with this hypothesis, our experience has been (Ref. [264] and unpublished observations) that fixed vectors can be evoked from the DMFC at about $4 \%$ of sites ( $N=53$ penetration), but only within narrowly defined depths; stimulation a few hundred microns above or below these sites again yields craniocentric saccades. Ablation or inactivation of the FEF during stimulation of the DMFC could test the hypothesis that fixed-vector saccades elicited from the DMFC occur by virtue of activating the collaterals of FEF neurons. The third possible reason that Russo and Bruce obtained what look like fixed-vector saccades is that they used only short-duration stimulation trains of $70 \mathrm{~ms}$. Under such conditions, the saccades elicited from the DMFC often do not reach their full extent [284]. An example of this is shown in Fig. 6, demonstrating that the amplitude of stimulation-elicited saccades increases with increasing train duration. In the experiments of Russo and Bruce, low current levels were used which may have also contributed to the execution of truncated saccades. This, however, cannot be the entire explanation since others have managed to evoke convergent saccades from the DMFC using low currents $[19,229,243]$. For more details regarding these issues, see Schall [230] and Tehovnik [280,281].

\subsection{Electrical stimulation and the behavioural state of monkeys}

It has been shown in many experiments that the probability of evoking a saccadic eye movement with electrical brain stimulation is influenced by the behavioral state of an animal. Such factors as state of alertness and intent to fixate or to carry out a specific task can significantly alter the size, direction, or latency of saccadic eye movements or affect the current threshold at which saccades are 


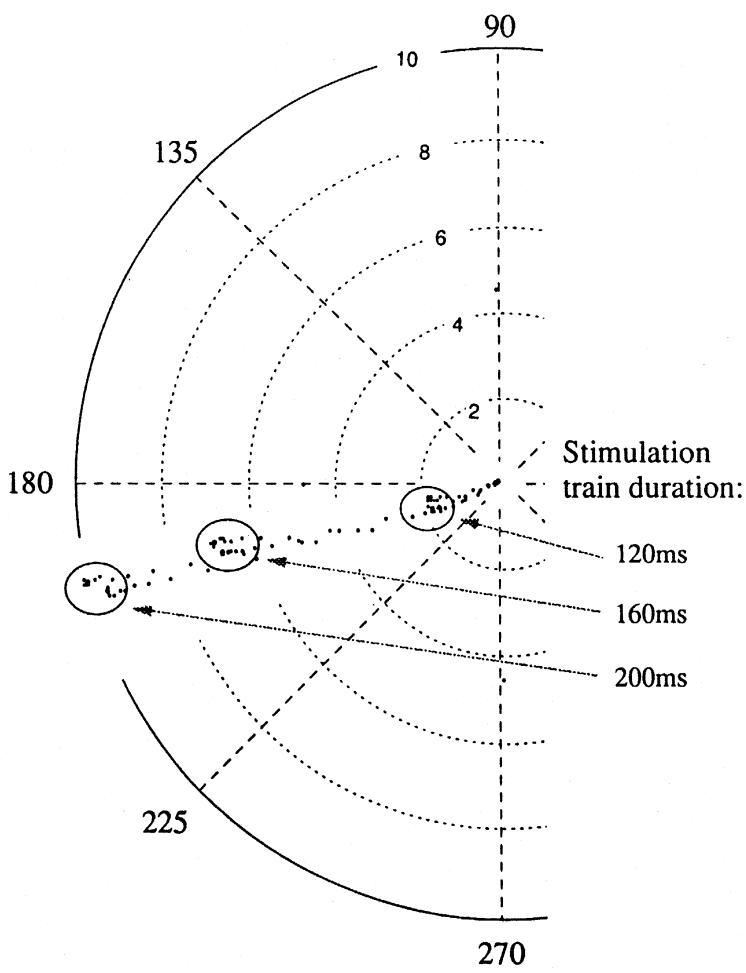

Fig. 6. Effect of train duration on saccades evoked from the DMFC. The left hemifield, out to $10^{\circ}$, is shown for a monkey. The animal fixated a target located in central craniotopic space. Electrical stimulation was delivered to one site in the DMFC to evoke saccades contralateral to the side of stimulation. The arrows point to the end points of the elicited saccades when using stimulation trains of 120, 160, and $200 \mathrm{~ms}$. Notice that the amplitude of the saccades increased systematically with increases in train duration.

produced $[19,69,82,131,157,186,237,253,266]$. A recent examination of the effectiveness of stimulation in the frontal lobes has shown that the behavioural state of animals has a much greater effect on saccadic eye movements evoked electrically from the DMFC than from the FEF [284]. Monkeys were required to fixate a visual target for $600 \mathrm{~ms}$ after which a juice reward was given. Electrical stimulation was delivered at various times during and after fixation. When stimulating the DMFC early during the fixation period, 16 times as much current (Fig. 7A) was required to evoke saccades than when current was delivered after termination of the fixation spot (Fig. 7C). When the same manipulations were carried out in the FEF, only three times as much current (Fig. 7B) was required to evoke saccades early during fixation as compared with stimulation after the fixation spot was turned off (Fig. 7C). This finding for the FEF concurs with the results of Goldberg et al. [82]. The probability of evoking saccades from the DMFC was also noticeably decreased when the duration of active fixation was decreased or when the delivery of juice reward was delayed; stimulation-elicited saccades from the FEF were much less affected by these variables. These results, along with the finding that low currents (e.g. $<50 \mu \mathrm{A}$ ), short train durations (e.g., $<70$ $\mathrm{ms}$ ), and high pulse frequencies (e.g., $>300 \mathrm{~Hz}$ ) are more effective in evoking saccades from the FEF than from the DMFC, suggest that the FEF, compared to the DMFC, is more closely connected to the saccade generator in the brainstem [284,286].
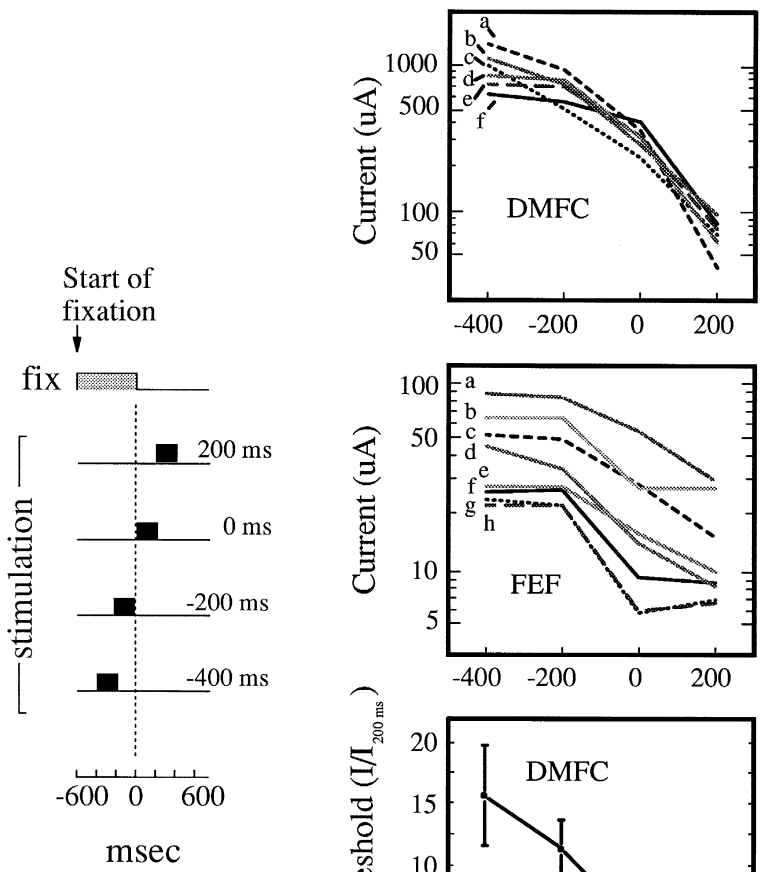

A

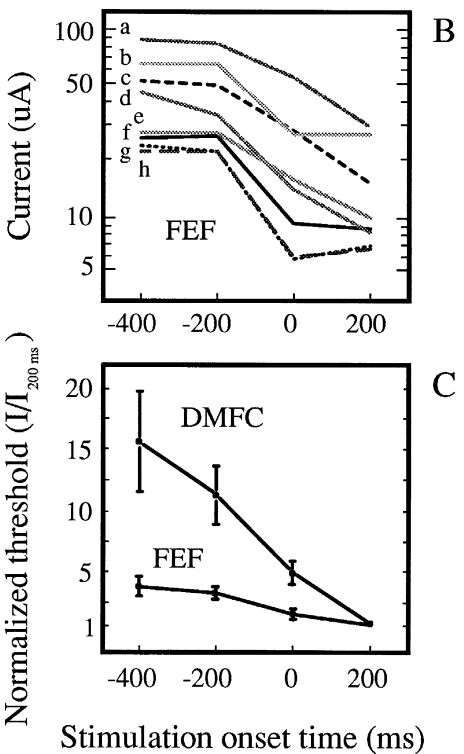

Fig. 7. Current threshold for eliciting saccades on $70 \%$ of stimulation trials is plotted as a function of stimulation onset time for the (A) DMFC and (B) FEF. Curves " $a$ " through " $f$ " in (A) represent the current thresholds for evoking saccades from sites in the DMFC, and curves " $a$ " through " $h$ " in (B) represent the current thresholds for evoking saccades from sites in the FEF. Stimulation was delivered $200 \mathrm{~ms}$ after the termination of the fixation spot $(200 \mathrm{~ms}), 0 \mathrm{~ms}$ after the termination of the fixation spot $(0 \mathrm{~ms}), 200 \mathrm{~ms}$ before the termination of the fixation spot $(-200 \mathrm{~ms})$, or $400 \mathrm{~ms}$ before the termination of the fixation spot $(-400 \mathrm{~ms})$. The left panel shows the method. The top grey bar represents the duration of fixation (fix), which was $600 \mathrm{~ms}$, and the black bars represent onset and duration of stimulation which was $200 \mathrm{~ms}$. Juice was delivered immediately after the fixation spot was terminated as long as the animal remained fixated for the $600 \mathrm{~ms}$. No juice was delivered if the animal broke fixation during this period, whether the break was self-initiated or stimulation-induced. (C) A normalized threshold ratio is plotted as a function of stimulation onset time for the DMFC and FEF. The ratio was computed by dividing the mean current required to evoke saccades at a given stimulation onset time by the mean current required to evoke saccades at a stimulation onset time of $200 \mathrm{~ms}$. Standard errors are indicated. Pulse duration and pulse frequency were $0.2 \mathrm{~ms}$ and $200 \mathrm{~Hz}$, respectively. Data from Tehovnik et al. [284]. 


\subsection{Skeletomotor responses elicited by electrical stimula- tion of the DMFC and FEF in monkeys}

As indicated earlier, the DMFC, within which the supplementary motor area resides, contains a topographic map of the body. Stimulation of rostral sites tends to evoke eye movements, whereas stimulation of caudal sites tends to evoke hindlimb movements; stimulation of intermediate sites tends to evoke forelimb movements (Fig. 2C). Other responses that have been evoked from the DMFC include ear and neck movements, as well as eyelid blinking $[20,243]$. In contrast, skeletomotor responses are not readily triggered from the FEF $[31,157,216,233,237,239]$.

\subsection{DMFC and FEF stimulation in humans}

It has been known for some time that electrical stimulation delivered to either the DMFC or the FEF in humans evokes eye movements [60]. Such stimulation of the human DMFC has disclosed a somatotopic map similar to that observed in the monkey [194,310]. These findings have recently been replicated [66,78]. Penfield and Welch [196] found that stimulation of some sites in the DMFC evoked a contralateral gaze shift that was accompanied by an arm movement coincident with the change in the direction of gaze (represented by cartoon in supplementary motor area of Fig. 1D). These findings suggest that the DMFC may be involved in hand-eye coordination and that forelimb and eye have a common termination position that is laid out in a topographic fashion in this structure [282]. Penfield and Welch [196] also found that stimulation delivered to the DMFC often inhibited the execution of movements. These findings are in consonance with the already noted finding that in the monkey, visually evoked saccades are inhibited when the eyes are already positioned in the termination zone [282,283].

\subsection{Summary}

Saccadic eye movements can be elicited with electrical stimulation from both the FEF and the DMFC. The nature of the saccadic eye movements produced, however, is quite different in the two areas.

In the FEF, the saccadic eye movements elicited have constant vectors; the amplitude and direction of a saccade at each site stimulated are largely unaffected by initial eye position. Prolonged stimulation produces a staircase of equal-size saccades. There is a clear topographic order in the FEF, with large amplitude saccades represented in medial portions and small amplitude saccades represented in lateral portions of the anterior bank of the arcuate.

In the eye fields of the DMFC, electrical stimulation at most sites elicits saccadic eye movements that bring the eyes to a specific orbital position. Prolonged stimulation holds the eye in place at that position. There is a topographic order in the DMFC eye field area representing different terminal positions. At some sites in this region, one can also elicit eye movements with constant vectors. More posteriorly in the DMFC, electrical stimulation can produce skeletomotor responses. Such responses are somatotopically ordered.

In general, eye movements can be produced more reliably and with lower currents in the FEF than in the DMFC. This is especially true when an animal is actively fixating.

\section{Lesions and reversible inactivation of the DMFC and the FEF}

\subsection{The effects of lesions and reversible inactivation of the DMFC in monkeys}

Many groups have studied the effect of DMFC lesions on forelimb movement tasks (e.g., Refs. [25,26,35,147, $188,227,255,288,306])$. In 1984, Brinkman [26] made lesions of various portions of the DMFC confined to the mesial bank (Fig. 8A). The animals were tested on two tasks. In the first, a unimanual task, monkeys were required to remove small morsels of food embedded in slots cut into a board. The orientation of each slot was different, requiring the animal to orient his fingers appropriately to extract the food item. In the second task, a bimanual one, monkeys were required to use both hands to obtain the food morsels. One hand was needed to push the food item through a slot and the other to grab it. Shortly after unilateral DMFC lesions, monkeys were impaired on both of these tasks; they no longer adjusted the orientation of their hands to extract the food in the unimanual task. Both hands showed impairment. On the unimanual task, the deficit disappeared after 2 weeks. In contrast, the poor performance on the bimanual task persisted even 1 year after the lesion.

Lucchetti et al. [147] found that following a lesion of the DMFC that included anterio-lateral regions (Fig. 8B), a monkey was impaired at reaching toward visual objects presented in contralateral space. This deficit subsided after 1 month, however.

In another set of experiments, Thaler et al. [288] and Chen et al. [35] made bilateral lesions of the DMFC that included both the mesial and lateral regions of the area (Fig. 8C). Monkeys were trained on several tasks. In the first, they had to displace one lever at the onset of a visual stimulus and then displace another lever upon the termination of the stimulus. In the second task, monkeys were trained to delay the movement of a joystick by having them activate the joystick 5-8 s after the onset of a visual stimulus. In the third task, the animals had to shift the joystick to the left and then forward after the visual stimulus appeared. In the fourth task, reversal learning was assessed by making reward contingent on repeatedly pressing the joystick to the left and then, after 27 trials, to the 

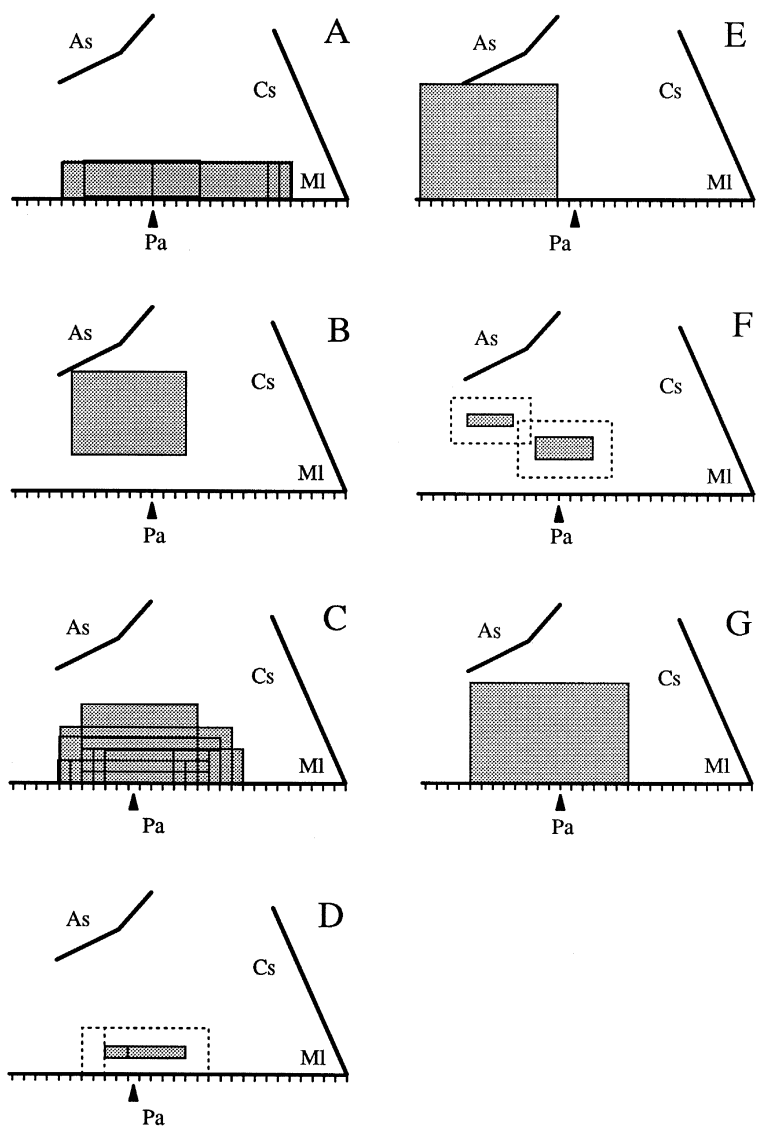

Fig. 8. DMFC lesions in monkeys. The method of Tehovnik [280] was used to determine the size and location of DMFC lesions across various studies. The rostrocaudal and mediolateral extents of a lesion were determined in millimeters and the location of a lesion was determined with respect to the cerebral midline (Ml) and posterior tip of the arcuate sulcus $(\mathrm{Pa})$. In each panel, the tick marks along the midline axis are spaced by $1 \mathrm{~mm}$. (A) The overlapped rectangles show the location of the chronic lesions of monkeys used in the study of Brinkman [26]: monkeys SMX1, SMX2, M6, M7, M9. Lesions were all unilateral. (B) The rectangle shows the extent and location a chronic lesion of a monkey used by Lucchetti et al. [147]. The lesion was unilateral. (C) The overlapped rectangles show the location of the chronic lesions of monkeys used in the study of Thaler et al. [288] and Chen et al. [35]: monkeys $62,63,64,65,66,67,83,84,85$. Lesions were bilateral. (D) The shaded rectangles represent the sites injected with muscimol in monkeys BT and PS of Shima and Tanji [255]. The dotted rectangle represents the maximal spread of the muscimol which was estimated to be $2.0 \mathrm{~mm}$ from the cannula tip [255]. All injections were bilateral. (E) The rectangle represents the location and size of a cooling probe used in the study of Sasaki and Gemba [227]. Cooling probes were situated bilaterally. (F) The shaded rectangles represent the sites injected with lidocaine in the study of Sommer and Tehovnik [264]. The anterior-most rectangle represents the injection sites of Monkey L and the posterior-most rectangle represents the injection sites of Monkey I. The dotted rectangle represents the maximal spread of the lidocaine. Each injection was estimated to spread $1.5 \mathrm{~mm}$ from the cannula tip [287]. All injections were unilateral. (G) The rectangle shows the extent and location of a typical chronic lesion in the study of Schiller and Chou [234]: monkey 3. Lesions were typically unilateral.

right; the number of trials required for successful reversal was assessed. Damage to the DMFC had little effect on the performance of these tasks. The last two tasks did show a minor deficit, but continued training rapidly reinstated pre-operative performance. One additional task was used in which monkeys were required to break a photobeam with their forelimbs in order to obtain a reward. The animals were exposed to this task for $30 \mathrm{~min} /$ day. On this task, 3 weeks after a DMFC lesion, monkeys were still deficient. However, due to limited testing (only four occasions), these results are difficult to evaluate.

Using reversible inactivation methods, Shima and Tanji [255] showed that the learning of a sequential task, which required animals to move a manipulandum to successive positions (by a push, pull, or turn), was disrupted when muscimol was injected bilaterally into various regions of the DMFC (Fig. 8D). The severity of the deficit decreased with the repetition of a particular sequence, however. When the monkeys were required to execute the movements in the presence of visual cues, no deficit was observed following inactivation.

In another reversible inactivation experiment in which a large portion of the DMFC was cooled both unilaterally and bilaterally (Fig. 8E), Sasaki and Gemba [227] showed that performance was disrupted on a task that required the lifting of a lever when a visual stimulus appeared. They found that the latency with which the animals lifted the lever upon the appearance of the visual stimulus increased when tissue was cooled. The effect, however, was transitory; after 2 months of continued testing, the response latencies were no longer affected by cooling. When a similar experiment was performed on the motor cortex, the disruptive effect of cooling on lever lifting never faded [226]. Corroborating the amelioration of deficits with repeated cooling is a study by Miyashita et al. [168], who have shown that after extensive training, inactivation of the DMFC becomes ineffective.

Only a few studies have examined the effects of DMFC inactivation and lesions on oculomotor responses. Since these studies compared directly the effects of DMFC and FEF lesions or inactivation, they will be considered in a separate section below.

\subsection{The effects of lesions and reversible inactivation of the FEF in monkeys}

The effects of FEF ablations and inactivation have been extensively studied. Investigators who have examined the execution of saccadic eye movements to singly appearing stationary visual targets report that after FEF ablation or inactivation, the deficits are moderate. There is a small decrease in saccadic velocities and an increase in saccadic latencies; this has been reported both with lesions and with reversible inactivation using lidocaine or muscimol [52, 54,234,238,240,263]. After FEF ablation, there is relatively rapid recovery in both saccadic velocities and saccadic latencies. Time for recovery is longer for saccades made to visual targets appearing at relatively large eccentricities $\left(10^{\circ}-20^{\circ}\right)[235,236]$. Reversible inactivation studies also 
show that monkeys have difficulty in acquiring targets that appear beyond $15^{\circ}$ of eccentricity from straight ahead and to then maintain fixation on them [263]. This deficit has its counterpart in the fact that there is a decrease in saccadic amplitude that is especially notable for large saccades following FEF ablations. These deficits recover at about the same rate as does the deficit in saccadic latency $[235,236]$.

In contrast to the relatively mild and short-lasting deficits in the latency and amplitude of saccades made to visual targets and in maintained fixation, ablation or inactivation of the FEF (Figs. 9 and 10A,B,C,D) dramatically affects the execution of single saccades generated to remembered target positions. FEF lesions (Fig. 10A,B,E) also interfere with two successive saccades made in response to two successively presented targets. Deficits in generating such "'memory-guided saccades" persist even 4 months after an FEF ablation (Fig. 10C).

The effects of FEF lesions (Fig. 10F) on the execution of smooth pursuit eye movements elicited by moving targets have also been examined. Deficits in pursuit have been reported both with lesions and inactivation [152,251]. Pursuit deficits typically occur for targets moving in a direction ipsilateral to the side of the lesion. Deficits in pursuit are still apparent beyond 10 weeks after an FEF ablation [120]. To obtain clear deficits in visually guided pursuit, the deeper portions of the arcuate, including the fundus and portions of the posterior bank, must be ablated or inactivated [154]. The deficits in pursuit so obtained are in consonance with two related findings [84,85,154]: (1) there are neurons in the depth of arcuate sulcus, including
A

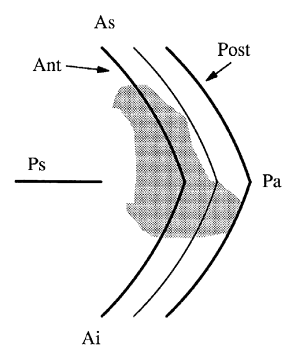

B
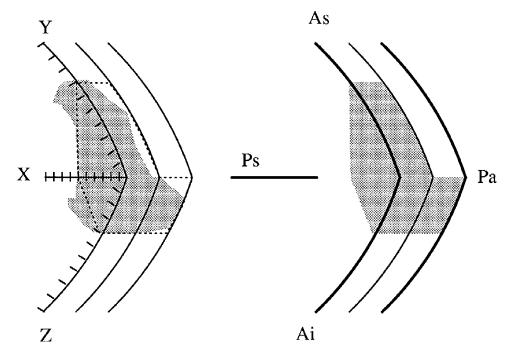

Fig. 9. Size and location of FEF lesions in monkeys. (A) The size and location of an FEF lesion were determined by noting the extent of a lesion with respect to the superior (As) and inferior (Ai) limbs of the arcuate and with respect to an axis originating at the posterior tip of the arcuate $(\mathrm{Pa})$ and extending anteriorly toward the principle sulcus (Ps). The anterior (ant) and posterior (post) portions of the arcuate sulcus are also shown so that the depth of the lesion into each bank can be assessed. The shaded area is a hypothetical FEF lesion. (B) The length of each axis $(Y, X$, and $Z$ ) was set to 1 . For the hypothetical lesion shown in " $\mathrm{A}$ ", the length of the $\boldsymbol{Y}$ vector is 0.7 , the $\boldsymbol{X}$ vector is 0.6 , and the $\boldsymbol{Z}$ vector is 0.4. (C) By joining the endpoints of each vector (dotted line in B) in combination with the borders of the lesion into the anterior and posterior bank, the size and location of an FEF lesion are described.
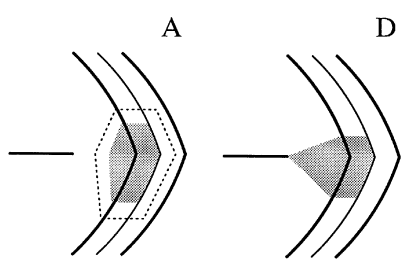

D
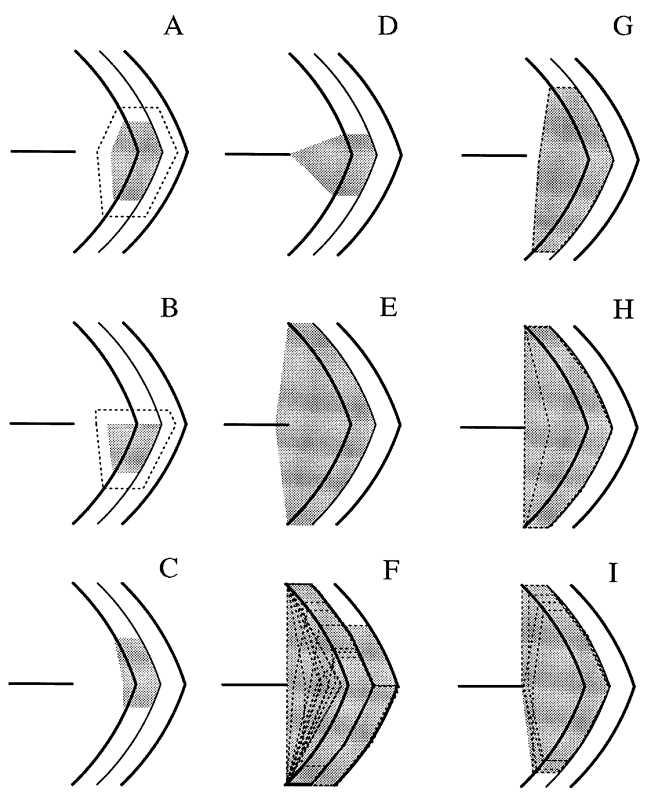

Fig. 10. FEF lesions in monkeys. The size and location of FEF lesions are shown for various studies investigating oculomotor and skeletomotor behaviour. The shaded area represents the lidocaine injection sites of (A) Monkey L and (B) Monkey I in Sommer and Tehovnik [263,264]. The dotted area represents the maximal effective spread of lidocaine. Each injection was estimated to spread $1.5 \mathrm{~mm}$ from the cannula tip [287]. All injections were unilateral. (C) The shaded area represents the extent of the chronic lesion in the monkey used by Deng et al. [52]. The lesion was unilateral. (D) The shaded area represents the chronic lesion of a monkey used by Funahashi et al. [70]: monkey YM. The lesion was unilateral. (E) The shaded area represents a typical chronic lesion in the study of Schiller and Chou [234]: monkey 3. The lesions were usually unilateral. (F) The overlapped dotted regions show the location of chronic lesions of monkeys used in various studies: Keating [120]: monkeys Big1, Big2, SML; Keating [121]: monkey S1, S2, S3; Keating et al. [122]: monkey 3; Lynch [152]: monkey R5; MacAvoy et al. [154]: monkey 420. (G) The shaded area represents the chronic lesion of a monkey used by Schiller et al. [240]: monkey Bn. The lesion was bilateral. (H) The overlapped dotted regions show the location of chronic lesions of monkeys used by van der Steen et al. [291]: monkeys F1, F2, F3. Lesions were unilateral. (I) The overlapped dotted regions show the location of chronic lesions of monkeys used by Halsband and Passingham [95]: monkeys FEF33, FEF34. Lesions were bilateral. For other details, see Fig. 9.

the fundus, that are modulated during smooth pursuit; and (2) electrical stimulation of this region evokes smooth pursuit eye movements.

A number of studies have also investigated the effect of FEF ablations on visually guided forelimb movements [46,95,214,240,291]. Schiller et al. [240] trained monkeys to pick apple pieces from slots imbedded in a board. The slots in the board spanned $60^{\circ} \times 60^{\circ}$ of visual space. Immediately after a bilateral FEF lesion (Fig. 10G), monkeys were impaired at retrieving apple pieces from the board; complete recovery was evident by the fourth postoperative week. van der Steen et al. [291] trained monkeys to press, within $1 \mathrm{~s}$ following its illumination, a button which was presented at one of 19 positions spaced at $5^{\circ}$ intervals over a horizontal $90^{\circ}$ arc in front of an animal. 
Two days after a unilateral FEF lesion (Fig. 10H), monkeys failed to push the illuminated target that appeared anywhere contralateral to the side of the lesion. Thirty-five days after the lesion, monkeys were still impaired at contralateral locations beyond $30^{\circ}$. Monkeys had difficulties in making large gaze shifts which were compensated by the animals making head movements of increased amplitude.

In another set of experiments, Halsband and Passingham [95] trained monkeys on a conditional motor task. The animals had to push a sphere when a green light came on and a cube when the light turned orange. The position of the sphere and the cube was randomized. Following bilateral lesions of the FEF (Fig. 10I), monkeys did very poorly and failed to relearn the task; they were exposed to 3500 trials over a 3-month period. Unoperated controls mastered the task within 1 month and 1200 trials.

\subsection{Direct comparison of DMFC and FEF lesions and inactivation on visually guided eye movements}

Only two sets of experiments have compared the effects on eye movements of lesions or reversible inactivation of the DMFC and FEF in monkeys. In the first set of experiments, the DMFC or FEF was reversibly inactivated with lidocaine or muscimol (Figs. 8F and 10A,B [263,264]) while monkeys performed various eye movements. Inactivation of the DMFC did not interfere with the ability to fixate visual targets in different parts of visual space or to execute saccadic eye movements to single visual targets or to remembered target locations [264]. However, inactivation of the FEF, as already noted, had dramatic effects on these tasks; the most pronounced deficits were obtained under conditions when animals had to make saccadic eye movements to remembered target locations [263]. When monkeys were required to generate a sequence of two saccades to two remembered targets, both DMFC and FEF inactivation produced deficits [263,264]. Monkeys were often unable to generate saccades to either the first or the second target. The magnitude of the impairment was much greater after FEF inactivation than it was after DMFC inactivation.

The second set of experiments compared eye-movement performance after FEF and DMFC ablations [234] and reported similar deficits to those found during reversible inactivation. DMFC lesions produced a mild impairment that recovered within weeks on the execution of successive saccadic eye movements made to sequentially presented targets. FEF lesions, on the other hand, produced a much more dramatic deficit on this task that lasted even after 2 years of continued testing. The areas lesioned are depicted in Figs. 8G and 10E.

In addition to these tasks, the study comparing FEF and DMFC lesions used a test in which two identical targets were presented, with one appearing in each hemifield [234]. Monkeys were rewarded for choosing either target. This task was similar to the one used in clinical studies that explore the extinction phenomenon $[46,124,147,214$, 291,304]. In addition to having the targets appear simultaneously, they were also presented with various temporal onset asynchronies. This enabled the investigators to determine how choice of the targets shifted as a function of the temporal offset between them. In normal animals, the equal probability point at which the frequency of left and right target choices was similar occurred close to the time when they appeared simultaneously. However, after a unilateral DMFC or FEF lesion, a major shift arose in choice preference. The temporal shift was much greater and longer-lasting after an FEF lesion than after a DMFC lesion. To get equal probability choices for the left and right targets, a temporal asynchrony of more than $110 \mathrm{~ms}$ had to be introduced 2 weeks after removal of the FEF, with the target in the hemifield contralateral to the lesion having to appear first. The temporal offset for equal probability choice 2 weeks after a DMFC lesion was only 31 ms. Recovery, after the DMFC lesion, was complete after 4 months; after FEF lesions, even a year later, more than a 60-ms offset was necessary for equal probability choice. Fig. 11 shows data on this task.

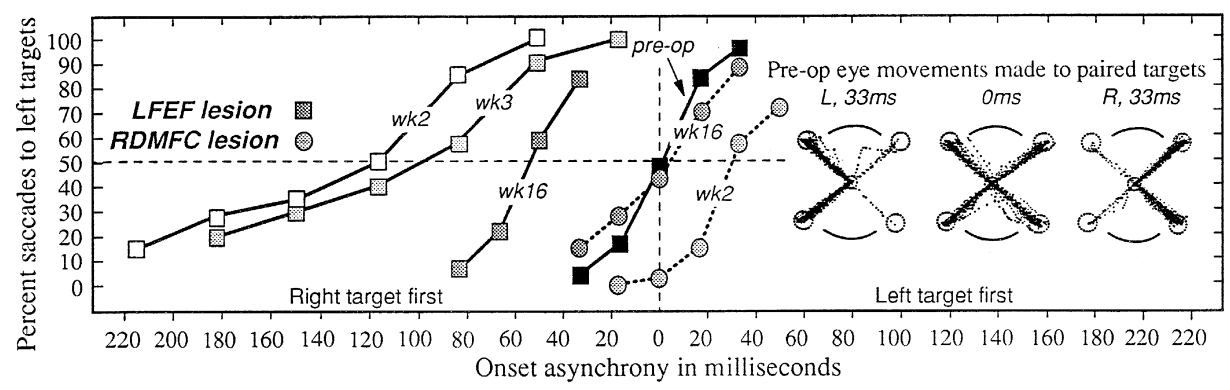

Fig. 11. Target selection. Data obtained from two monkeys are shown as obtained with paired targets presented with varied temporal asynchronies. Plotted is the percent of saccades made to the left target as a function of temporal offset between the paired targets. Data are shown at various times after recovery from a left FEF (LFEF) or right DMFC (RDMFC) lesion as well as pre-operatively (pre-op). Squares and solid lines depict data from the animal with the FEF lesion; circles and dotted lines depict data from the animal with the DMFC lesion. Records of saccadic eye movements made to paired targets with various temporal offsets in the intact animal appear as an inset. For each of the post-operative weeks plotted (wk2-wk16), data were collected for five or six successive days. Data from Schiller and Chou [234]. 
One interpretation of these effects after unilateral ablation is that the lesions affect temporal discrimination during target selection. To test this, monkeys were trained to discriminate temporal differences in target onset [234]; they had to select the target in an array that came on various times prior to the other similar stimuli. The animals were rewarded only for making a saccadic eye movement to the target that had appeared first. This task revealed major deficits in making temporal discriminations after FEF lesions and mild but significant deficits after DMFC lesions. Thus, one major effect of FEF lesions, and to a lesser extent of DMFC lesions, is to impair temporal discrimination.

One animal in this study was also examined after both the DMFC and the FEF had been removed. The deficits after such paired lesions were of about the same magnitude as single lesions to the FEF $[235,236]$. These lesions did not produce any deficits in smooth pursuit eye movements, probably because the FEF lesion did not include damage to the fundus and posterior bank of the arcuate.

\subsection{The effects of DMFC and FEF damage in humans}

\subsubsection{Deficits on oculomotor tasks}

Effects of frontal lobe damage on the oculomotor behaviour of humans have been studied widely (e.g., Refs. [24,73,74,93,100,170,190,205-207,213]). Unfortunately, the brain damage in such patients is usually not restricted to the FEF or DMFC; it often includes damage to several other regions. In considering the effects of damage to the DMFC and FEF, we focused on results obtained from patients whose lesions did not extend well beyond either the FEF or DMFC (Fig. 12). In the human, the FEF is generally considered to be in or near the precentral sulcus (e.g., Ref. [189]) and the DMFC straddles the midline with significant overlap into the mesial bank. Most of our FEF cases included damage to regions rostral to, but also including, the precentral sulcus. The findings may be summarized as follows.

(1) Patients with lesions of either the FEF or DMFC could generate saccades as well as normal subjects to visual targets. The lesions are depicted in Fig. 13A.

(2) Patients with a unilateral FEF lesion (Fig. 13B, left) trained to make saccades to remembered target positions in total darkness (typically a 2-s delay) generated hypometric saccades to targets appearing contralateral to the side of the lesion; saccade reaction times were much longer than those exhibited by normal subjects. In contrast, DMFC patients (Fig. 13B, right) were not at all impaired on this task.

(3) Patients with a unilateral FEF lesion (Fig. 13C, left) trained to generate saccades to a remembered target position in total darkness after head and body rotation showed no impairment. Similar tests after DMFC lesions (Fig. $13 \mathrm{C}$, right) revealed that patients undershot the location of

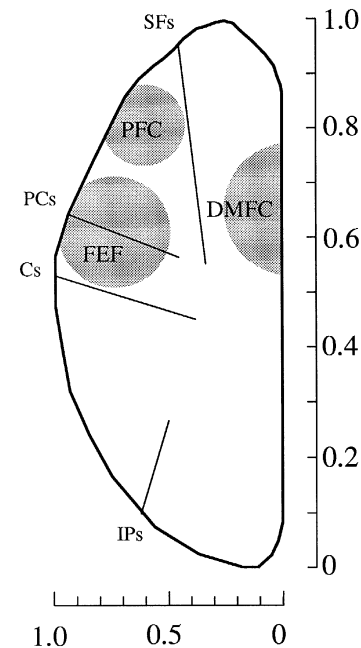

Fig. 12. Size and location of DMFC or FEF lesions in humans. Shown is a diagrammatic horizontal slice through the top portion of one hemisphere of the human cerebral cortex. To determine the location and size of a lesion centered on the dorsomedial frontal cortex (DMFC) or frontal eye field (FEF), the length and width of the cerebral cortex were set to 1.0. According to this scheme, the DMFC is situated between 0.5 and 0.8 units along the length dimension and between 0.0 and 0.3 units along the width dimension; the FEF is situated between 0.5 and 0.75 units along the length dimension and between 0.5 and 0.9 units along the width dimension. In Figs. 13 and 14, this measuring scheme was used to determine the borders and location of lesions confined to the FEF and DMFC of various studies. The prefrontal cortex (PFC), superior frontal sulcus (SFs), precentral sulcus (PCs), central sulcus (Cs), and intraparietal sulcus (IPs) are indicated.

the remembered target position for targets appearing both in the hemifield ipsilateral and contralateral to the lesion.

(4) One patient with a unilateral FEF lesion (Fig. 13D, left) showed deficits in making successive saccades to two remembered target positions in total darkness; on $20 \%$ of trials, saccades were executed in the wrong order. Another patient with a DMFC lesion tested in a similar manner showed error rates of less than 10\%; this performance was comparable to that of normal control subjects (Ref. [73], case 1).

(5) Three of five DMFC patients (Fig. 13D, right) tested on a three-target task failed to successfully generate saccades to the remembered target positions in the same order the targets were presented. These three patients were tested between 26 and 54 days following the lesion. Two of the five patients, tested between 38 and 84 days, did not exhibit any deficits.

(6) Patients with unilateral FEF (Fig. 13E, left) or DMFC (Fig. 13E, right) lesion trained to generate "antisaccades" that forced them to shift their gaze into the hemifield opposite to where the target had appeared, performed on the task as well as did normal subjects. However, in patients with infarcts that included the prefrontal cortex, a significant deficit was observed on this task [207]. 

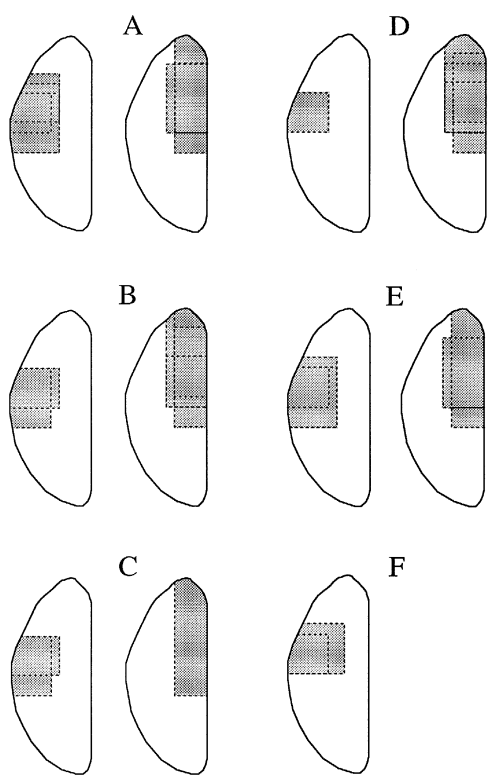

Fig. 13. DMFC or FEF lesions in humans performing oculomotor tasks. Shown are horizontal slices through the cerebral cortex. Within each slice, the grey area represents the size and location of many lesions combined from different patients. (A) Left plate shows lesions confined to the FEF of 19 patients from Braun et al. [24] (cases 1 to 6), Pierrot-Deseilligny et al. [207] (cases 1 to 10), and Rivaud et al. [213] (cases 1 to 3). Right plate shows lesions confined to the DMFC of 13 patients from Braun et al. [24] (cases 13 to 15), Gaymard et al. [73] (cases 1), and Pierrot-Deseilligny et al. [207] (cases 1 to 9). (B) Left plate shows lesions confined to the FEF of eight patients from Pierrot-Deseilligny et al. [205] (cases 1 to 5) and Rivaud et al. [213] (cases 1 to 3). Right plate shows lesions confined to the DMFC of seven patients from Gaymard et al. [74] (cases 1, 3, 4, and 5) and Pierrot-Deseilligny et al. [206] (cases 1 to 3, with right-sided lesion). (C) Left plate shows lesions confined to the FEF of five patients from Pierrot-Deseilligny et al. [205] (cases 1 to 5). Right plate shows lesions confined to the DMFC of three patients of Pierrot-Deseilligny et al. [205] (cases 1 to 3). (D) Left plate shows lesions confined to the FEF of one patient from Rivaud et al. [213] (case not specified). Right plate shows lesions confined to the DMFC of five patients from Gaymard et al. [73] (case 1) and Gaymard et al. [74] (cases 1, 3, 4, and 5). (E) Left plate shows lesions confined to the FEF of 13 patients from Pierrot-Deseilligny et al. [207] (cases 1 to 10) and Rivaud et al. [213] (cases 1 to 3). Right plate shows lesions confined to the DMFC of 10 patients from Gaymard et al. [73] (case 1) and Pierrot-Deseilligny et al. [207] (cases 1 to 9). (F) The plate shows lesions confined to the FEF of six patients from Morrow et al. [170] (cases 1 to 3) and Rivaud et al. [213] (cases 1 to 3). See Fig. 12 for other details.

(7) Patients with unilateral FEF lesions (Fig. 13F) tested on smooth pursuit were all impaired for ipsilaterally directed motion relative to the lesion but not for contralaterally directed motion.

\subsubsection{Deficits on forelimb movement tasks}

Few studies have looked at the effect of DMFC or FEF damage on the execution of forelimb movements in patients (e.g., Refs. [94,293]). Viallet et al. [293] trained patients with DMFC lesions (Fig. 14A) on a bimanual forelimb movement task. At the onset of a tone burst, patients were required to remove a weight from the forelimb contralateral to the lesion with the other hand. Nor- mally, under such conditions after the hand releases the load, the forelimb exhibits a slight flexion response. After a DMFC patient's hand released the load, a larger flexion response than normal was observed, suggesting that the DMFC in humans is involved in bimanual postural adjustments.

Halsband and Freund [94] trained patients with frontal lobe damage on a task wherein a particular visual stimulus had to be associated with a specific forelimb movement. At the onset of a stimulus, a patient was required to produce a correct movement (e.g., after stimulus onset, a patient had to put the right hand on the right shoulder unfolding it through about $90^{\circ}$ downward). Of the patients studied, two had lesions confined to the DMFC (Fig. 14B) and one had a lesion confined to the FEF (Fig. 14C). All the patients had a deficit in learning the association task but had no difficulty imitating forelimb movements by visual example or from memory; nor did they have problems in evoking visually guided reaching movements toward different positions in visual space.

\subsection{Summary}

The nature of deficits induced by ablation of the DMFC and FEF is quite different both in kind and in magnitude. After DMFC lesions, deficits are common both in limb and eye movement control with the latter quite mild, whereas after FEF lesions, there are no deficits in limb movements but impairment in some aspects of eye-movement control are sizeable and long-lasting. Such sizeable and long-lasting deficits following FEF ablation have been observed for the selection of two simultaneously presented targets, for the execution of sequences of eye movements to successive targets, and for eye movements made to briefly presented stimuli. DMFC lesions produced only mild deficits on these tasks that recovered within a few months. Lesions of the posterior bank and fundus of the arcuate, but not of the DMFC, produce deficits in pursuit eye movements. The impairment observed in limb movements after DMFC lesions is most pronounced when a bimanual task is employed. The deficits documented in the FEF and DMFC

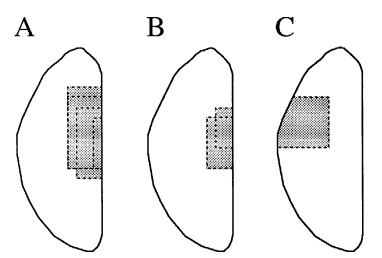

Fig. 14. DMFC or FEF lesions in humans performing skeletomotor tasks. Shown are horizontal slices through the cerebral cortex. Within each slice, the grey area represents the size and location of many lesions combined from different patients. (A) Lesions confined to the DMFC of four patients from Viallet et al. [293] (cases 1, 3, 4, and 5). (B) Lesions confined to the DMFC of two patients from Halsband and Freund [94] (cases 1 and 9). (C) Lesion confined to the FEF of one patient from Halsband and Freund [94] (case 5). See Fig. 12 for other details. 
upon reversible inactivation are similar to those found with lesions. Human studies for the most part are consistent with the findings reported in monkeys: lesions of the FEF or DMFC do not disrupt visually guided saccades; lesions of the FEF, but not the DMFC, impair saccades made to one remembered target position; lesions of the FEF or DMFC affect saccades generated to two or more remembered target positions; lesions of the FEF interfere with smooth pursuit eye movements; and finally, lesions of the DMFC disrupt bimanual movements.

\section{Single-cell recordings in the DMFC and FEF}

\subsection{The characteristics of single neurons in the DMFC}

\subsubsection{Eye and forelimb movements}

Accumulating evidence suggests that neurons throughout the full extent of the DMFC are modulated by forelimb movements (Fig. 15A). Limb movements that are associated with neuronal activity include the displacement of a manipulandum, reaching toward and pressing buttons, and wrist extension or flexion. Unfortunately, many studies examining limb movements have not recorded and studied the eye movements that are an integral part of coordinated limb movements. Since Schlag and Schlag-Rey [242] have shown that the anterior DMFC (anterior to the posterior tip of the arcuate) contains neurons that respond in association with eye movements, it is possible that the neuronal responses interpreted to occur with limb movements may be, at least in part, due to eye movements or the combined action involved in hand-eye coordination (Fig. 15B).

Cells that respond in association with eye movements typically have been shown to be located in anterior DMFC, but a few studies have found such cells further back, in regions a few millimeters caudal to the posterior tip of the arcuate (Fig. 15B). Some studies have measured both eye and forelimb movements while recording from the DMFC [18-20,156,173,228]. Of these, only Mushiake et al. [173] have dissociated the contribution of eye movement from the contribution of forelimb movement. In this study, a monkey was trained to reach to and look at a visual target. Units were examined under three conditions: (1) execution of eye movements in the absence of limb movements; (2) execution of limb movements in the absence of eye movements; and (3) execution of both movements together. Of 12 cells studied in anterior DMFC, all exhibited their best response when the eyes and forelimb movements occurred together. Chou and Schiller [37,38] used a paradigm similar to that of Mushiake et al. [173] while recording from hundreds of units located within the full rostrocaudal extent of the DMFC. They found that the vast majority of cells responded under the above noted three conditions, albeit to different degrees. These findings suggest that most neurons in this area are not dedicated to the execu-
A

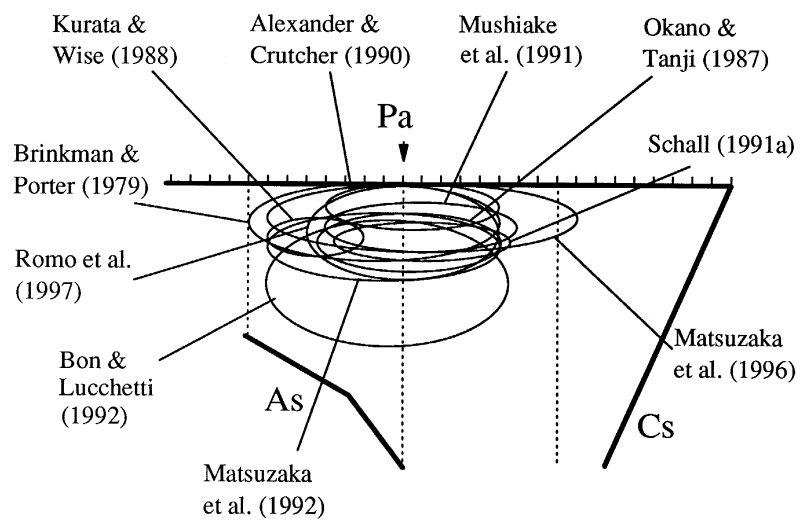

B

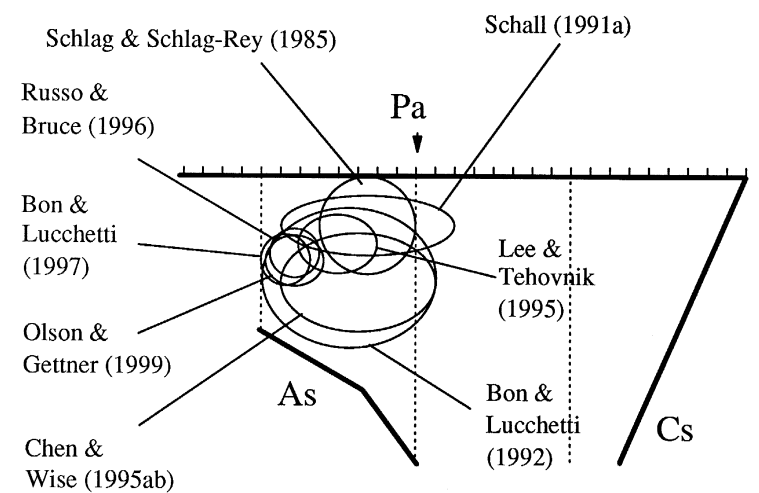

Fig. 15. Location of unit recording sites in monkeys. (A) Top view of one side of the DMFC showing regions from which units were recorded by investigators who studied monkeys as they performed a forelimb movement task. The cerebral midline is represented by the horizontal line. Each tick mark on this line is spaced by $1 \mathrm{~mm}$. The arcuate sulcus (As) and central sulcus (Cs) are indicated. The posterior tip of the arcuate sulcus $(\mathrm{Pa})$ is shown. Each oval represents the size and location of the region from which units modulated by a given forelimb movement task were found. The length and width of an oval and its center were determined using the method of Tehovnik [280]. Studies pertaining to a particular recording zone are listed. (Also see Ref. [130]). (B) Top view of one side of the DMFC showing regions from which units were recorded by investigators who studied monkeys as they performed an oculomotor task.

tion of a single, specific motor act. These neurons may in fact be involved in hand-eye coordination.

\subsubsection{Eye movements}

Neurons within the DMFC are modulated by saccadic and pursuit eye movements [19,101,105,139,156,223, 228,241-243] and discharge during the presentation of visual stimuli [223,228,243]. A large proportion of cells within the anterior DMFC also respond vigorously when the animal engages in active fixation $[17,19,21,139,180$, 244]. Neurons at rostral sites respond best when the center of gaze is directed toward contralateral craniotopic space, whereas neurons at caudal sites respond best when gaze is directed toward ipsilateral craniotopic space [139]. At lat- 
eral sites, responses are best for upward gaze and at medial sites, for downward gaze. Recently, the rostrocaudal topographic order has been alluded to by the work of Bon and Lucchetti [21]. Here, a monkey was required to remain fixated and to displace a lever to detect the color change of a peripherally located visual target. Cells in rostral DMFC tended to respond to such target changes occurring in contralateral craniotopic space, whereas cells in caudal DMFC tended to respond to such changes occurring in ipsilateral craniotopic space. A population of neurons in rostral DMFC also seems to be modulated differentially according to what side of an object a monkey generates an eye movement $[180,181]$. Thus, DMFC neurons, especially those in anterior DMFC, discharge during saccadic eye movements, during smooth pursuit eye movements, during active fixation, and during the onset of visual stimuli. The region contains a topographic map for the representation of various gaze positions.

\subsubsection{Anterior vs. posterior DMFC}

Considerable evidence has been presented suggesting that the anterior and posterior regions of the DMFC are functionally distinct [69,161,162,173,254,274,277,279]. Matsuzaka et al. [161] found that neurons in the anterior DMFC are modulated differently from neurons in the posterior DMFC. In their experiment, monkeys faced a panel containing two switches. A light over either the left or right switch was illuminated briefly. A visual trigger then signalled the monkey to press the illuminated switch. Compared to cells in the anterior DMFC, cells located more caudally discharged best immediately before, during, and after the execution of the forelimb movement. In contrast, cells in anterior DMFC were more vigorously modulated when the light was on as well as during the period between the termination of the light and the onset of the target that triggered the forelimb movement. That cells in anterior DMFC are more readily modulated by visual stimuli and respond less at the time of the forelimb movement should not be surprising, since the region contains many cells that discharge to the presentation of visual stimuli [223,228,243]. When tactile rather than visual stimuli were used to initiate forelimb movement, no difference was observed in the modulation of cells in anterior and posterior DMFC [220]. Thus, to reveal a difference between the anterior and posterior regions of the DMFC, a visual task must be employed.

Tanji and Shima [279] found that 54 out of 206 units located in posterior DMFC were modulated by a specific sequence of three movements (push-pull-turn) of a manipulandum guided by visual memory. Mushiake et al. [174] found that a small proportion of cells (21/328) located throughout the DMFC was modulated by a specific sequence of button presses. With the push-pull-turn paradigm of Tanji and Shima [279], a larger proportion of cells in anterior DMFC $(64 / 251)$, as compared to posterior DMFC (6/385), exhibited a diminution of responsivity during the continued execution of a movement sequence under visual guidance [254]. At this time, it is not known whether the sequencing-specific properties of cells in posterior DMFC would also diminish after prolonged task repetition. This question arises because it has been demonstrated that cells in posterior DMFC become quite unresponsive after overtraining on a simple key-press task [1].

One of the problems with the studies just described is that in none of them were eye movements under continuous measurement. This is of concern because the pattern of saccadic eye movements changes when animals learn a task that requires forelimb movements [167]. Another problem is that these studies have not mapped the receptive fields ${ }^{5}$ or fixation fields of neurons before they were tested on any sequencing task. Issues of overtraining, eye movement control, and visual receptive field characteristics will need to be addressed before one can fully accept claims that go beyond anterior DMFC having a visual bias and posterior DMFC having a skeletomotor bias $[161,162]$.

\subsection{The characteristics of single neurons in the FEF}

In 1968, Bizzi [14] found that neurons in the FEF respond during fixation and during and after the execution of saccadic eye movements. Subsequently, it was shown that cells in FEF also discharge in response to visual stimuli and before saccadic eye movements [15,30, $81,169,271]$. Some cells in this region are also responsive during active fixation [270]. In addition, cells have been discovered in deeper portions of the bank of the arcuate that are modulated during ipsilaterally directed pursuit [154]. Finally, the FEF appears to be topographically organized such that neurons in dorsomedial sites discharge best for large-amplitude saccades, whereas neurons in ventrolateral sites discharge best for small-amplitude saccades [31].

Identifying neurons by antidromic activation, Segraves and Goldberg [248] described the basic properties of FEF cells that project to the superior colliculus. Using similar methods, Segraves [247] also characterized the FEF neurons that project to the pons. Both projections were found to relay primarily saccadic and fixation-related discharges, and they rarely had only visual responses. Recently, Sommer and Wurtz [265] presented the first description of FEF neurons that may receive input from the superior colliculus. Some FEF neurons could be activated via synapses by electrical stimulation in the superior colliculus, presumably driven via a tectothalamocortical route [153]. These FEF input neurons all had visual responses, and half had presaccadic bursts as well. Taken together with the results of

\footnotetext{
${ }^{5}$ Tolias et al. [290] describes a method to map the entire receptive field of cortical cells within the context of the behavioural paradigm, a method that could be employed when studying sequencing behaviour in visual areas.
} 
Segraves and Goldberg [248], this provides the first evidence that FEF receives visual signals at its input and produces saccade commands at its output (as predicted by Bruce and Goldberg [30]).

Segraves and Park [249] determined that movement-related presaccadic FEF neurons begin their discharge approximately $150 \mathrm{~ms}$ before saccadic onset and show peak activity approximately $13 \mathrm{~ms}$ before the onset of the saccade. These neurons can have multiple phases of activity: prelude activation and a burst that occurs later. Hanes et al. [96] performed an analysis of activity in the FEF and DMFC to determine the onset time of neural activity. For presaccadic neurons in both the FEF and DMFC, the onset time of the burst was more tightly coupled to the beginning of the saccade, as opposed to the time that the instructional trigger signal was presented. On average, FEF neurons began bursting $28 \mathrm{~ms}$ (S.D. $=3.3 \mathrm{~ms}$ ) before saccades. Presaccadic neurons in the DMFC, on the other hand, started to burst earlier than FEF neurons, and they showed greater variance in burst time $($ mean $=135$, S.D. $=6.6 \mathrm{~ms}$ ). Also the prelude activity in the DMFC occurred earlier and with a greater variance in onset time than it did in the FEF.

Lee [138] trained monkeys to generate saccades to visual targets presented within a region of $60^{\circ} \times 40^{\circ}$ of visual space. The monkeys were required to maintain fixation for $1000 \mathrm{~ms}$ after which they generated a saccade to a randomly selected target position. It was found that a higher percentage of cells in the DMFC than FEF was modulated during active fixation but that a higher percentage of cells in the FEF than DMFC was modulated during saccade execution. Also unlike cells in the DMFC that are modulated during both eye and forelimb movements [18, $37,38,156,173]$, cells in the FEF are modulated exclusively during eye movements [173].
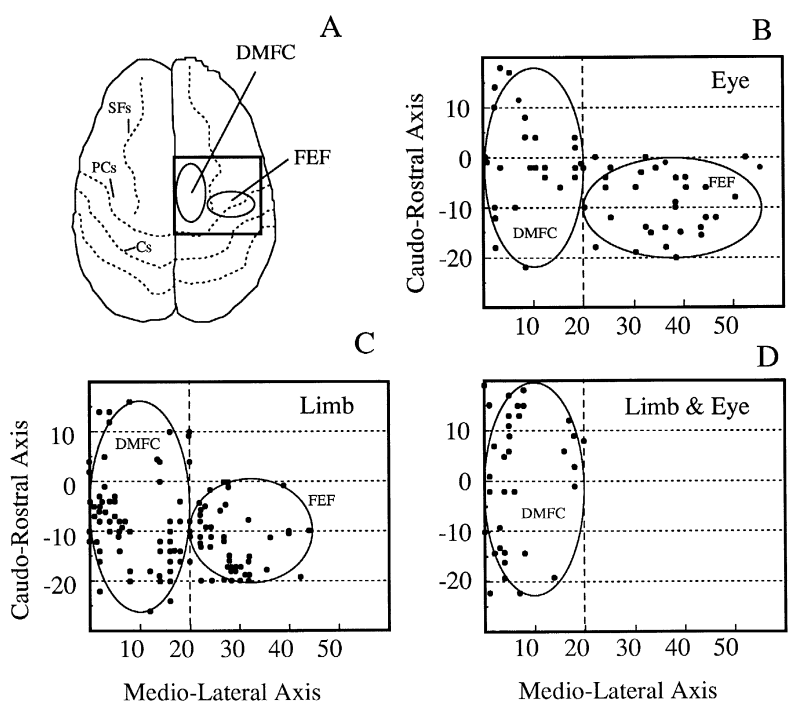

\subsection{Summary}

Neuronal responses associated with eye and limb movements are common in the DMFC and many single cells respond to both, indicating that these cells do not mediate a specific motor act. Cells in anterior portions of the DMFC tend to be more responsive to visual stimuli and the execution of saccadic eye movements whereas in posterior regions, cells are more responsive to limb movements. Cells that discharge during fixation and smooth pursuit eye movements have also been reported.

Fig. 16. Imaging studies and the DMFC and FEF. (A) Shown is a top view of the human cerebral cortex. The box depicts the region from which studies located maximal-activity points measured with PET or fMRI while subjects executed saccadic eye movements or smooth pursuit eye movements. The approximate location of the DMFC and FEF is represented by the ellipses. The central sulcus (Cs), precentral sulcus (PCs), and superior frontal sulcus (SFs) are indicated. (B) The graph shows the location of maximal-activity points in Brodmann's area 6 observed with PET or fMRI while human subjects performed tasks involving the generation of saccadic or smooth pursuit eye movements. Each dot within the figure represents a maximal-activity point plotted in Talairach and Tournoux [273] coordinates along the caudorostral and mediolateral axes. A dot is based on an average from 5 to 12 subjects. The subtraction method was used to determine a maximal-activity point. Typically, the baseline behaviour used for the subtraction method was fixation of a visual target, or resting with eyes open or closed. Data were obtained from the following studies: Anderson et al. [4], Doricchi et al. [55], Kawashima et al. [119], Luna et al. [148], O’Driscoll et al. [178], Paus et al. [191,192], Petit et al. [197,198], and Sweeney et al. [272]. The ellipses represent the distribution of maximal-activity points along the caudorostral and mediolateral axes. The DMFC and FEF were divided according Paus [189] and Roland and Zilles [219]. (C) The graph shows the location of maximal-activity points in the DMFC of Brodmann's area 6 while human subjects performed forelimb movement tasks that did not engage the eyes. Movements could involve displacement of the shoulder, elbow, hand, or fingers or some combination of each. A dot is based on an average of 6-16 subjects. Typically, the baseline behaviour used for the subtraction method was the total immobility of the body; often this immobility was conducted in total darkness with the eyes closed. Data were obtained from the following studies: Colebatch et al. [41], Deiber et al. [51], Dettmers et al. [53], Jahanshahi et al. [111], Jenkins et al. [112], Jueptner et al. [115,116], Paus et al. [192], Playford et al. [209], Schlaug et al. [245], Stephan et al. [269], and van Mier et al. [292]. The ellipse represents the distribution of maximal-activity points along the caudorostral and mediolateral axes. Activation in the FEF ellipse is presumably from the arm area of the motor and premotor cortical areas. See B for other details. (D) The graph shows the location of maximal-activity points in the DMFC of Brodmann's area 6 while humans subjects performed forelimb movement tasks that engaged the eyes. The movements could involve a key press, pointing movements, or movements of a manipulandum whose displacement was represented visually on a monitor. A dot is based on an average of 6-24 subjects. Typically, the baseline behaviour used for the subtraction method was fixation of a visual target. Data were obtained from the following studies: Corbetta et al. [42], Grafton et al. [87-90], Kawashima et al. [117,118], Paus et al. [192], Sakai et al. [224], and Sergent et al. [250]. The ellipse represents the distribution of maximal-activity points along the caudorostral and mediolateral axes. See B for other details. 
In the FEF, neurons have not been found that respond specifically to skeletal movement. Several populations of cells have been discerned: some have visual receptive fields, some discharge before, during and after saccadic eye movements, and some respond in association with fixation as well as smooth pursuit eye movements. The saccade-associated responses of many cells are tightly time-locked to saccade execution, suggesting that these cells contribute centrally to the initiation of eye movements.

For both the DMFC and FEF, recording studies support the topographic layout of saccadic eye movements as revealed by electrical stimulation.

\section{Event-related potentials in humans}

When human subjects make self-initiated finger or hand movements, a DC shift in cortical potential can be recorded from scalp electrodes placed over the frontal lobes prior to these movements. This potential was first termed "bereitschaftpotential", or "readiness potential" by Kornhuber and Deecke [127]. It emanates primarily from rostromedial recording locations in the frontal lobe (electroencephalogram (EEG) electrode locations $\mathrm{Cz}, \mathrm{C} 3$, and C4) and is evident as a slow increase in surface negativity before self-initiated movements.

The readiness potential has been divided into different phases $[50,252]$. The first component is associated with a slow bilateral buildup of negativity. This buildup generally occurs up to 1-2 $\mathrm{s}$ before the initiation of a voluntary movement as measured by the onset of EMG activity, and is most prominent over the midline. Approximately $400 \mathrm{~ms}$ prior to EMG onset, the negative potential increases in slope and becomes more pronounced in the hemisphere contralateral to the hand being used [49]. This marks the second component.

Based on differences in the location of their maxima, the two components were posited to emanate from different cortical areas [49]. Since the first component was most prominent over the vertex, and was bilaterally distributed, it was proposed that its source was bilateral activation of the DMFC. The second component was centered more caudally and contralateral to the hand being used. This corresponded roughly with the hand region of motor cortex. Thus, it was proposed that the second component has its source primarily in contralateral motor cortex.

This hypothesis of bilateral DMFC activation followed by contralateral primary motor cortex activity was consistent with single-unit recording evidence showing that DMFC, but not motor cortex, was organized bilaterally [278], and that it was activated earlier than was motor cortex $[2,276]$.

The DMFC motor cortex hypothesis was challenged in humans, however, by the failure to localize the early component to the DMFC. Modeling the overall potential by fitting different possible dipole sources, some studies did not find a stable solution with DMFC as the exclusive source of the early component [22]. An alternate hypothesis was formulated that attributed both components to the
A
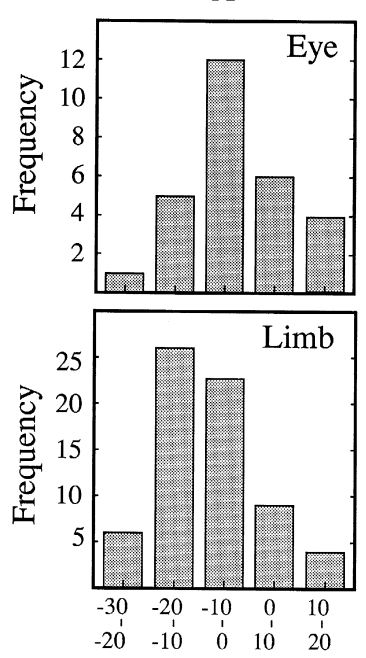

Caudo-rostral axis

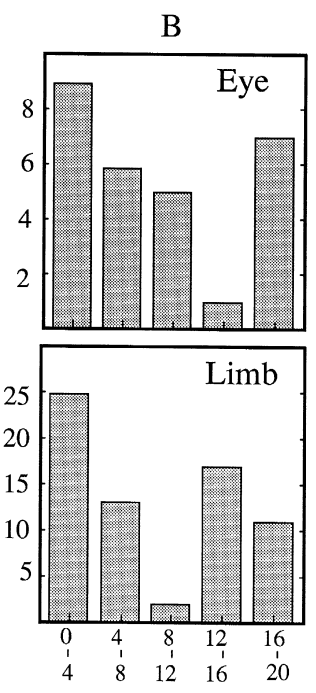

Medio-lateral axis
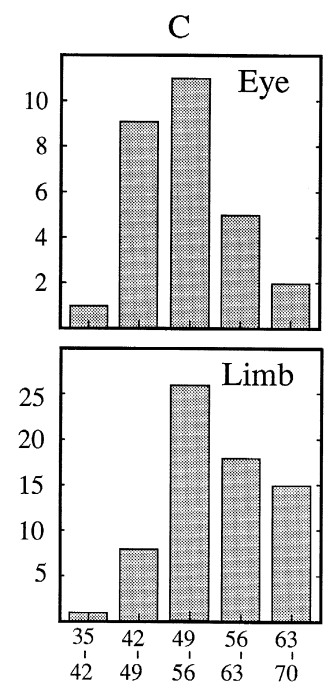

Ventro-dorsal axis

Fig. 17. Eye movements vs. forelimb movements and DMFC activity. The frequency of maximal-activity points for a given location in the DMFC along the caudorostral (A), mediolateral (B), and ventrodorsal (C) axes is shown for imaging experiments that studied eye movements (Eye) and forelimb movements (Limb). The data for the eye movement and forelimb movement studies are based on the data in Fig. 16B and C, respectively. Values along each ordinate are expressed in Talairach and Tournoux [273] coordinates. Statistical tests were conducted to determine whether the center of the eye field differed from the center of the forelimb field. Along the caudorostral axis, the center of the eye field was anterior to the center of the forelimb field $(t(27)=3.2, p<0.01)$; along the mediolateral axis, the center of the eye field was not different from the center of the forelimb field $(t(27)=0.006$, $p>0.05)$; along the ventrodorsal axis, the center of the eye field was ventral to the center of the forelimb field $(t(27)=3.1, p<0.01)$. See Fig. 16 for other details. 
motor cortex, with early bilateral activation followed by exclusively contralateral activation. Other studies using different recording techniques have also failed to observe consistent early activation of the DMFC. For example, Neshige et al. [176] found a clear signal in motor cortex just prior to movement, but found only weak evidence for early DMFC activity using subdural electrodes in epileptic patients. Researchers have also failed to observe the readiness potential over the DMFC using magnetoencephalography (MEG). Countering these claims is a report by Cheyne and Weinberg [36], who suggested that these negative findings were a product of the recording technique of MEG; they proposed instead that symmetric bilateral activation of both DMFCs would lead to mutually canceling dipoles. Lang et al. [134] tested this hypothesis by recording from a patient with a unilateral DMFC lesion and found that a dipole was indeed consistently localized over the intact DMFC.

Several studies have shown activation of DMFC as well as motor cortex during self-paced movements using PET $[155,218]$ but the poor temporal resolution of this technique does not make it possible to distinguish between early and late components of activation. Thus, the evidence is mixed regarding the role of the DMFC in the generation of the readiness potential.

If the DMFC is the source of the readiness potential, the potential should be modulated by tasks that involve the DMFC to various degrees. Functions that have been at-
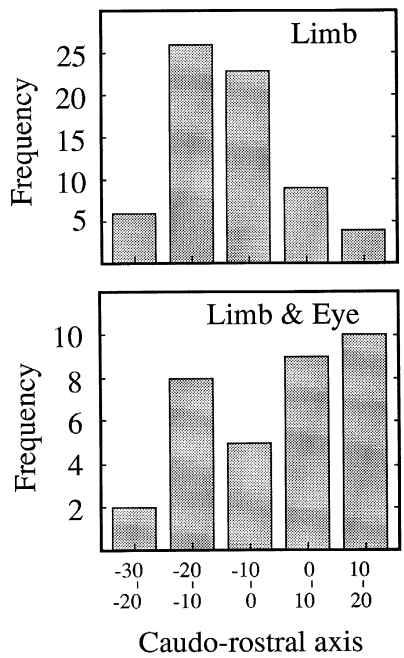

Fig. 18. Eye movements vs. eye and forelimb movements and DMFC activity. The frequency of maximal-activity points for a given location in the DMFC along the caudorostral axis is shown for the imaging experiments that studied limb movements (Limb) and limb and eye movements (Limb and Eye). The data for Limb and Limb and Eye are based on the data in Fig. 16C and D, respectively. Values along each ordinate are expressed in Talairach and Tournoux [273] coordinates. A statistical test was conducted to determine whether the center of the eye and forelimb field differed from the center of the forelimb field. Along the caudorostral axis, the center of the eye and forelimb field was anterior to the center of the forelimb field $(t(27)=3.5, p<0.01)$. See Fig. 16 for other details.
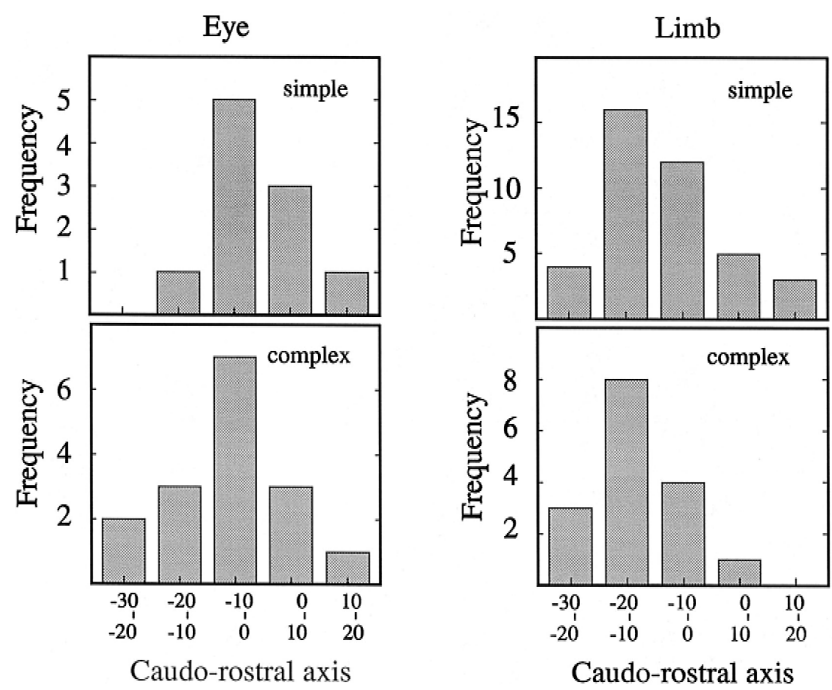

Fig. 19. Simple vs. complex tasks and DMFC activity. The frequency of maximal-activity points for a given location in the DMFC along the rostrocaudal axis is shown for the imaging experiments that studied eye movements (Eye) and forelimb movements (Limb), sorted according to whether the movements were simple (simple) or complex (complex). The data for Eye and Limb are based on the data in Fig. 16B and C, respectively. For the eye movement experiments, simple movements included self-paced saccades, visually guided saccades, or visually guided pursuit, and complex movements included memory-guided saccades, anti-saccades, or conditional saccades (e.g., visual object/saccade direction associations or go/nogo saccade tasks). For the forelimb movement experiments, simple movements included tactile- or auditory-triggered finger, hand, or shoulder movements, movements of a joy stick, or self-paced forelimb movements, and complex movements included antifinger flexion movements (e.g., to move the finger next to the one stimulated), sequential movements of the fingers or joy stick, or conditional forelimb movements (e.g., to move a particular finger according to the auditory tone delivered). Only data from experiments in which subject were over trained are included. Values along each ordinate are expressed in Talairach and Tournoux [273] coordinates. Statistical tests were conducted to determine whether the center of the eye and forelimb fields differed depending on whether the task performed was simple or complex. The center of the eye field for simple and complex tasks did not differ $(t(9)=1.3, p>0.05)$. Also, the center of the forelimb field for simple and complex tasks did not differ $(t(15)=1.64, p>0.05)$. See Fig. 16 for other details.

tributed to the DMFC are sequencing of multiple movements and also the learning of motor tasks. The magnitude of the readiness potential does seem to reflect the complexity of the task being performed and is greater prior to sequences of movements as opposed to single movements [48]. As previously discussed, one class of movements that the DMFC is thought to be specialized for is bimanual coordination. Lang et al. [136] showed that the magnitude of the readiness potential was not only greater when subjects performed a bimanual coordination task as compared to a unimanual one but it was also modulated by the difficulty of the task. They recorded from trained musicians performing both an easy and a difficult bimanual rhythm and found that the readiness potential had a greater magnitude when subjects performed the difficult task. 
A
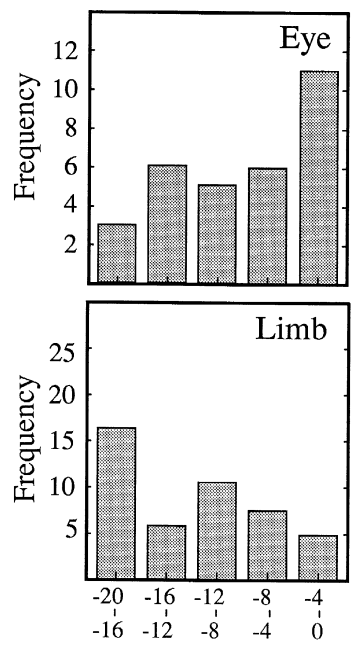

B
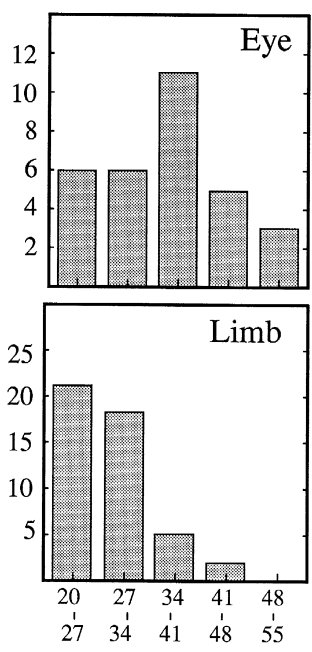

Medio-lateral axis
$\mathrm{C}$
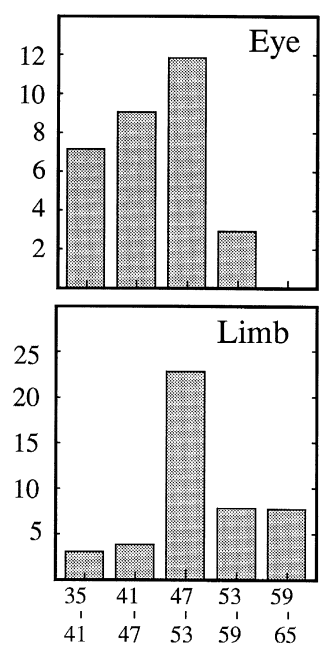

Caudo-rostral axis

Fig. 20. Eye movements vs. forelimb movements and FEF activity. The frequency of maximal-activity points for a given location in the FEF along the rostrocaudal (A), mediolateral (B), and ventrodorsal (C) axes is shown for imaging experiments that studied eye movements (Eye) and forelimb movements (Limb). The data for the eye movement and forelimb movement studies are based on the data in Fig. 16B and C, respectively. Values along each ordinate are expressed in Talairach and Tournoux [273] coordinates. Statistical tests were conducted to determine whether the center of the eye field differed from the center of the forelimb field. Along the caudorostral axis, the center of the eye field was anterior to the center of the forelimb field $(t(30)=2.6, p<0.01)$; along the mediolateral axis, the center of the eye field was lateral to the center of the forelimb field $(t(30)=4.3, p<0.01)$; along the ventrodorsal axis, the center of the eye field was ventral to the center of the forelimb field $(t(30)=4.9, p<0.01)$. See Fig. 16 for other details.

The readiness potential is also modulated during motor learning. Several studies have observed a change in the magnitude of the readiness potential over the course of learning of a difficult motor task, such as mirror tracing [48,135,177].

Although the majority of studies examining the readiness potential have used hand or finger movements, a readiness potential can also be seen prior to saccadic eye movements [9,57,126] and speech [91]. These findings suggest that the readiness potential is a generalized premovement signal. Because of the low spatial resolution of EEG recording, it is not known whether the pre-movement signals all emanate from one source, or from several sources close to each other. The readiness potential observed before arm, eye, foot or mouth movements could actually be emanating from each of the respective representations in the topography known to exist in the DMFC. Experiments using finer resolution techniques, such as MEG or subdural recording, will be required to resolve this question.

In monkeys, correlates of the readiness potential have been observed using a variety of techniques. Field potential recordings revealed a slow potential prior to movements [97], particularly during learning of new movements [75,225]. At the single-cell level, many studies have observed a preponderance of neurons in DMFC that discharge in advance of movement. Such discharge before arm movements has been termed "preparatory set" [2,179]. Early pre-movement activity has also been observed prior to saccadic and smooth pursuit eye movements [105,
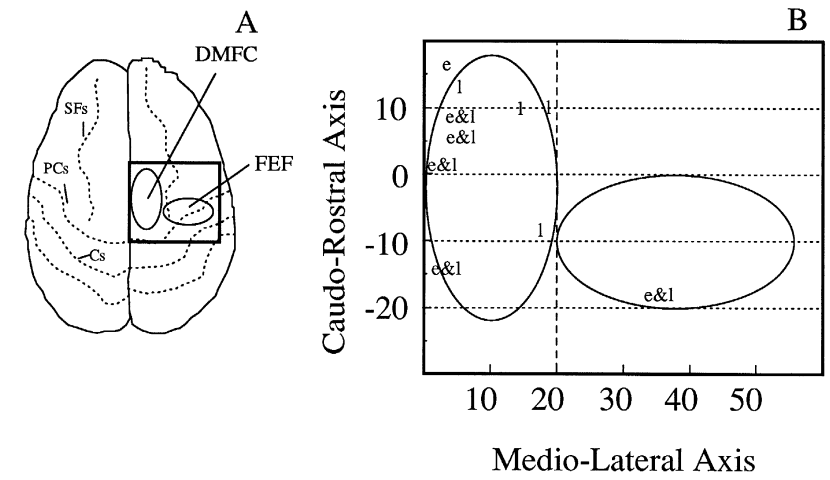

Fig. 21. Effects of learning on DMFC and FEF activity. (A) Shown is a top view of the human cerebral cortex. The approximate location of the DMFC and FEF is represented by the ellipses. The central sulcus (Cs), precentral sulcus (PCs), and superior frontal sulcus ( $\mathrm{SFs}$ ) are indicated. (B) The graph shows the location of maximal-activity points in Brodmann's area 6 observed with PET or fMRI while human subjects learned eye movement (e), limb movement (1), or eye and limb movement (e \& 1) tasks. Each symbol within the figure represents the location of a maximal-activity point plotted in Talairach and Tournoux [273] coordinates. A maximal activity point is based on the average of 6-12 subjects. The subtraction method was used to determine a maximal-activity point. Typically, the baseline behaviour used for the subtraction method was the performance of a task that resembled the learned task in terms of the types of movements executed except that there was no change in performance over trials. Data were obtained from the following studies: for eye movements experiments (e): Kawashima et al. [119]; for limb movement experiments (1): Jenkins et al. [112]; Jueptner et al. [115,116]; for eye and limb movement experiments (e and 1): Grafton et al. [88,89]; Sakai et al. [224]. The vertically oriented ellipse represents the approximate location of the DMFC and the horizontally oriented ellipse represents the approximate location of the FEF. See Fig. 16 for other details. 
228,243]. It remains to be seen whether such activity is truly analogous with human readiness potentials, and if it is modulated by the same factors.

In conclusion, the readiness potential has been observed over the DMFC of both humans and monkeys. There is some question as to whether the DMFC is the true source of this potential. The magnitude of this potential is affected by motor learning, task difficulty, and whether the task is bimanual or unimanual. The readiness potential has been studied mainly using forelimb-movement tasks, and to a lesser degree, oculomotor tasks. The somatotopic map
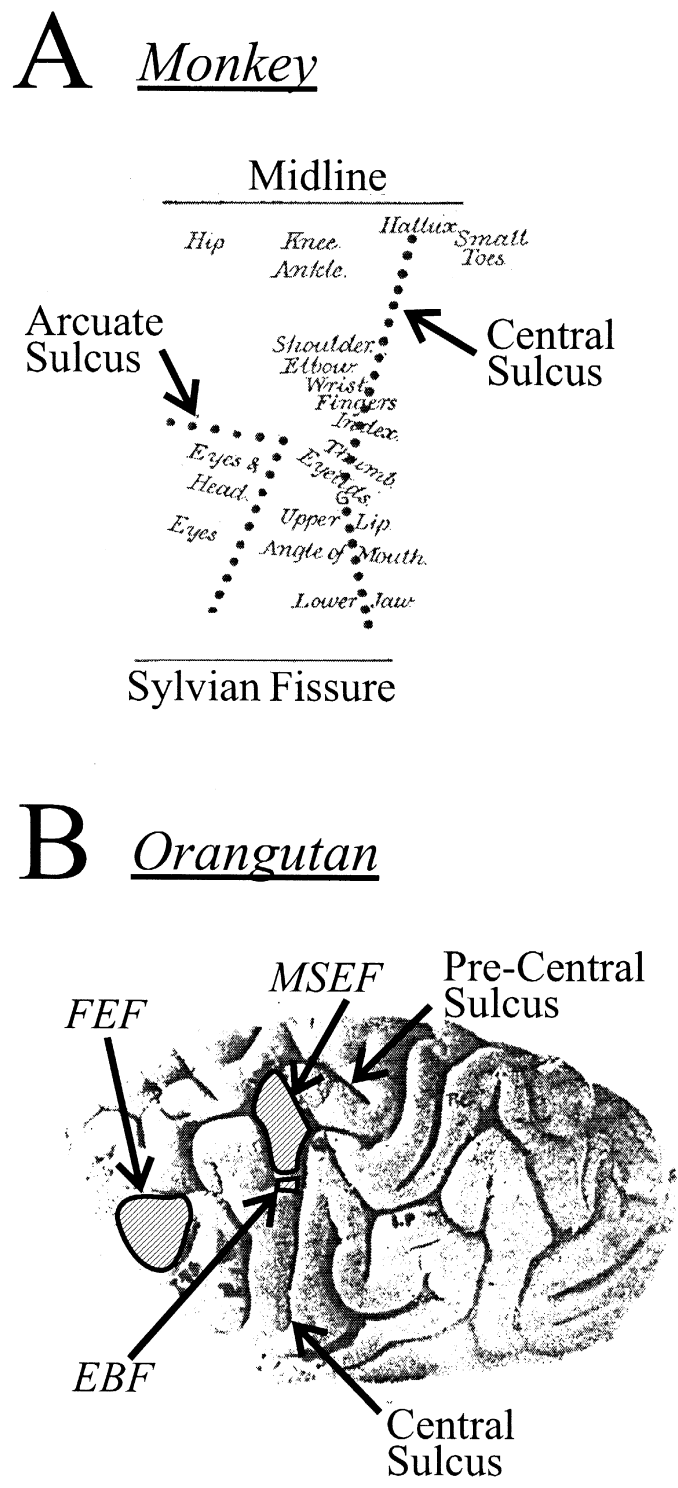

described for the DMFC has yet to be verified using EEG recordings.

\section{Metabolic imaging of the DMFC and FEF in humans}

PET and fMRI have been used on humans to measure the metabolic activity of the cortex as subjects performed eye and forelimb movement tasks. The metabolic activity is assumed to reflect neuronal activity. A large region of
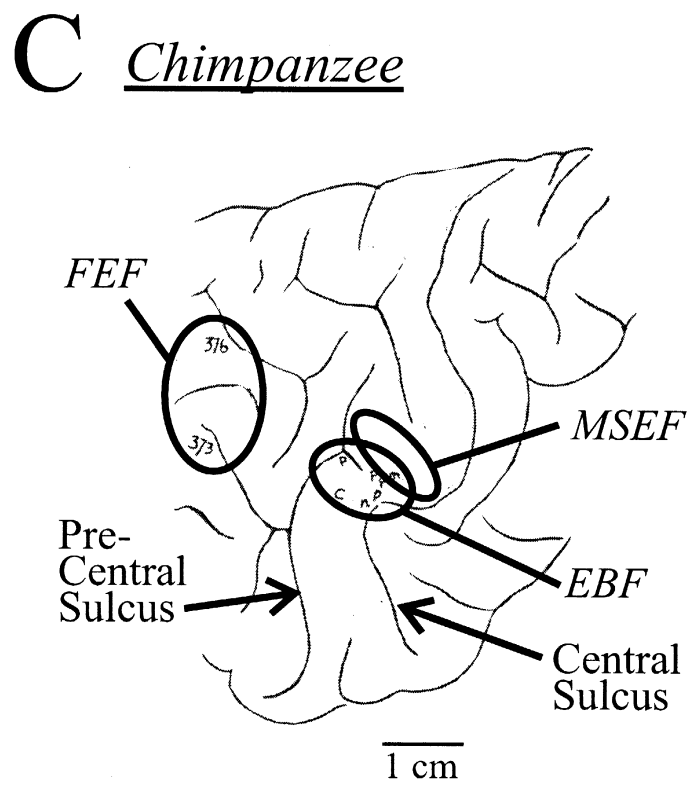

D Gorilla

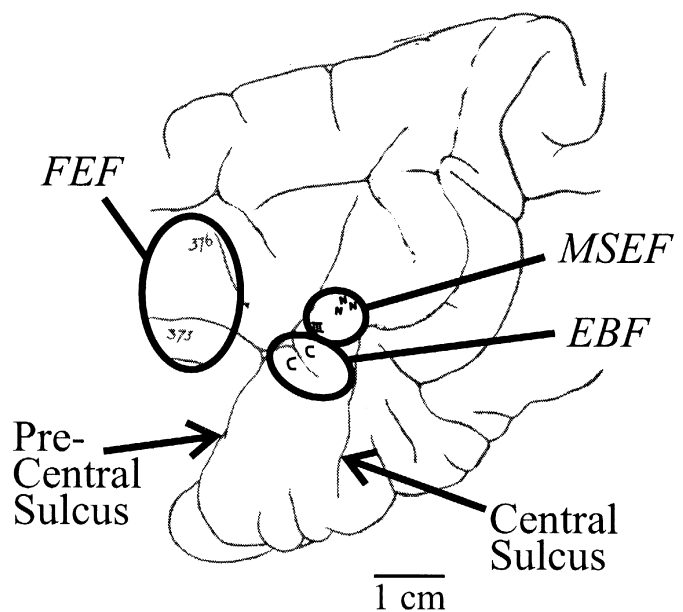

Fig. 22. Monkey and ape frontal lobe functional maps. All panels show lateral views, with anterior to the left and dorsal at the top. (A) Schematic of monkey frontal lobe and the movements elicited by stimulation from each region [11]. Note that eye movements are represented in the curve of the arcuate sulcus, but eyelid blinking is represented caudally, in the motor strip. (B) Photograph of the orangutan brain studied by Beevor and Horsley [11]; the stippling they used to show functional areas has been modified to hatched areas for clarity. FEF, frontal eye field; EBF, eyelid blinking field; MSEF, motor strip eye field. (C) A representative chimpanzee brain, modified from a figure by Leyton and Sherrington [144]. In this particular animal, the MSEF was not found, but the general location of this region in other chimpanzees is indicated. (D) A representative gorilla brain [144]. Sites from both hemispheres pooled together. In panels $\mathrm{C}$ and $\mathrm{D}$, eye rotation was the primary movement evoked at sites 373 and 376; eyelid closing was the primary movement evoked from sites c, p, m, and n; and eye rotation occasionally accompanied the movements (head turnings) that were primarily evoked from sites $\mathrm{N}$ and III. 
Brodmann's area 6 becomes active when subjects generate saccadic or smooth pursuit eye movements (Fig. 16A). The medial portion of this region is presumed to be the DMFC, and the lateral portion is presumed to be the FEF (Fig. 16B $[189,219])$. Here, we review imaging studies and compare the locations of the center of activation for eye movement tasks and forelimb movement tasks.

In the DMFC of monkeys, the eye field overlaps with the forelimb field (see Fig. 15). Fig. 16B, C, and D show the distributions of maximal activity points obtained from imaging studies conducted on the DMFC of humans as they performed eye movements alone, or forelimb movements alone, or eye and forelimb movement together. The distributions (Fig. 16B and C) suggest that the eye and forelimb fields of the human DMFC are overlapped. Despite this overlap, the center of the eye field in the DMFC was situated anterior to the center of the forelimb field (Fig. 17A). This result is consistent with the somatotopy of the DMFC of monkeys, and is also consistent with earlier observations made in humans [64]. Furthermore, the center of the DMFC's eye field was ventral to the center of forelimb field (Fig. 17C). This is due to the fact that the surface of the frontal lobes in humans curves downward as one advances rostrally. Finally, there was no difference in the location of the center of the eye field in the DMFC as compared with the center of the forelimb field along the mediolateral dimension (Fig. 17B).

In most studies so far, comparisons have been based on experiments that studied either eye movements with no forelimb involvement or forelimb movements with no eye involvement. When comparisons were made between the center of a field based on forelimb movements that engaged the eyes and the center of a field based on forelimb movements that did not engage the eyes, it was found that the center of the former, the limb and eye case, was anterior to the center of the latter, the limb-only case (Fig. 18). This indicates that by engaging the eyes during a forelimb movement task, the center of the activity field within the DMFC shifts rostrally.

A recent review by Picard and Strick [204] have suggested that the performance of complex tasks activates anterior regions of the DMFC and that the performance of simple tasks activates more posterior regions of the DMFC [204]. We compared the centers of activity within the DMFC for simple and complex tasks that involved the eyes only and forelimbs only (see caption of Fig. 19 for details). For both behaviours, there was no tendency for the performance of complex tasks to activate regions anterior to those activated for the performance of simple tasks; if anything, the center of activity was situated somewhat more caudally during the performance of complex tasks (Fig. 19). Only experiments in which subjects were overtrained on the task were considered here, since studies have shown that learning a new task greatly augments the activity of the DMFC when compared to the overtrained condition [224].
Maximal activity points for the eye and forelimb fields of the human FEF region were compared (Fig. 16B and C, FEF). ${ }^{6}$ It was found that forelimb tasks activated more caudal and medial locations of the FEF region, whereas eye movement tasks activated more rostral and lateral regions (Fig. 20A and B). Consistent with this was the observation that the forelimb tasks activated more dorsal sites in the cortex and the eye movement tasks activated more ventral sites (Fig. 20C). This can be explained by the fact that the surface of the frontal lobes in humans curves downward moving rostrally and laterally.

To summarize, the eye and forelimb fields of the human DMFC are highly overlapped, with the center of the eye field being somewhat more anterior to the center of the forelimb field. For comparison, the eye field within the FEF region is also situated more anterior to the forelimb field of this region, although the forelimb field here represents the forelimb area of the premotor and motor cortices. Contrary to the findings of Picard and Strick, we do not find evidence for the idea that the anterior DMFC mediates "complex" tasks and that the posterior DMFC mediates "simple" tasks. When forelimb movements are accompanied by eye movements, the center of the activity field within the DMFC shifts rostrally. This concurs with the general topographic order of human as well as monkey DMFC.

\section{Motor learning and the DMFC and FEF}

Imaging experiments performed on human subjects have disclosed that the DMFC becomes very active during the learning of new tasks (Fig. 21 [88,89,112,115,116,119, 224]). Learning tasks that engage both the eyes and limbs tend to similarly activate anterior and posterior sites of the DMFC $[88,89,224]$. One study has been done on the learning of an eye movement task, and in this case, the anterior DMFC was activated [119]. As for the FEF, one site only has been identified that is maximally active during the learning of an eye or forelimb movement task. This difference between the DMFC and FEF is quite revealing given that in all these studies, neuronal activity was assessed over both the DMFC and FEF.

Sakai et al. [224] found that once human subjects master the performance of a task, the activity of the DMFC drops. They trained subjects to depress a set of buttons in a particular order using visual guidance. The DMFC was more active during the performance of an underlearned task as compared to the performance of an overlearned task. Also, the readiness potential that has been attributed to the DMFC was found to exhibit a decrease in amplitude once human subjects were overtrained $[133,177]$.

\footnotetext{
${ }^{6}$ Limb-related activation in the FEF region presumably is due to neurons of the primary motor cortex and premotor cortex, which abuts human FEF.
} 
Chen and Wise $[33,34]$ found that cells in the DMFC of monkeys were more readily modulated during the learning of an object-saccade association task than were cells in the FEF. For this task, a monkey was required to fixate a spot where an object stimulus was subsequently presented. Following the dousing of the object stimulus and fixation spot, the monkey was required to generate a saccade to one of four identical targets. Making a saccade to one of the four targets produced a reward. Through trial and error, the animal had to determine which of four saccade directions (i.e., up, down, left, or right) yielded a reward for a given object stimulus. Neurons in the DMFC, as compared with neurons in the FEF, more often changed their firing rate with changes in the performance of the object-saccade association task.

Aizawa et al. [1] found that training a monkey for 1 year to press two keys in response to a visual target resulted in fewer DMFC units than normal being modulated by the task. Only two units of 1120 tested were modulated after 1 year of training, compared with the normal rate of $40 \%$ observed after 1-4 months of training [278]. Also more cells in the DMFC of monkeys are modulated during the performance of a new task than during the performance of an overlearned task [175]. As mentioned previously, once monkeys are overtrained on a task, inactivation of the DMFC is no longer disruptive $[168,227]$.

Any area of the brain that participates in the learning of motor tasks, as the DMFC seems to, should be influenced by reward delivery given that it is usually reward that motivates subjects to learn. Cells in the DMFC are modulated while monkeys fixate different positions in craniotopic space for a juice reward, but not when monkeys look about freely and obtain no reward $[19,139]$. Mann et al. [156] observed that cells in the DMFC respond to the delivery of juice only when the juice is delivered as a reward for task execution but not when delivered outside of task execution (e.g., as during the intertrial interval). Also while monkeys learned an object-saccade association task for juice reward, many cells within the DMFC were modulated immediately before and after the reward period. Of the seven cells illustrated by Chen and Wise [33] showing changes in responsivity with changes in task performance, five cells showed clear changes in modulation during the reward period.

That the DMFC has access to a reward signal should not be surprising given that the substantia nigra of monkeys sends a rich dopaminergic projection to this cortical area $[12,13,63,72,143,210]$, an input that is more robust than that to the FEF/prefrontal region and other cortical areas $[13,71,143]$. Like the DMFC $[1,33,34,133,175,177$, 224], the substantia nigra is maximally active during the early stages of learning a motor task [145,246].

In short, the DMFC seems more involved in motor learning than the FEF. This conclusion is based on imaging data from humans and on single-unit recording data from monkeys. It is apparent that the activity of the DMFC drops with protracted training on a variety of motor tasks. After such training, lesions of the DMFC are no longer disruptive. The DMFC has a substantial dopaminergic input that might mediate motor learning.

\section{Misplaced human FEF?}

PET and fMRI studies have found that the human FEF is in the precentral sulcus, abutting or lying within the primary motor strip. These results differ from the location of the FEF in monkeys. The key to reconciling this difference may lie in a consideration of behavioural methods used by imaging investigators, who assume that their images reflect neuronal activity related to moving the eyes. To obtain these images, data derived during control scans (i.e., while subjects fixate or are at rest) are subtracted from data derived during saccadic test scans. ${ }^{7}$ This is intended to localize brain areas related to moving the eyes, because this is the only movement that supposedly differentiates the test scans from the control scans. However, another action has been well-documented to occur with saccades: eyelid blinking [58,62,298,303]. Unless subjects are specifically instructed to inhibit blinking, it is common for blinking to occur when saccades are made. In contrast, subjects blink less frequently during steady fixation or during rest. Subjects rarely blink during task-related saccades (those made toward a visual target, for instance) but they compensate by blinking with high likelihood during "return" saccades in the intertrial interval [58,62,303]. Blinking is particularly common for saccades greater than $10^{\circ}$ in amplitude [303], which means that blinking may have frequently accompanied saccades during test scans in six of the eight PET studies reviewed recently (Paus [189]: Refs. $[4,64,137,178,191,199])$, in four out of the five published fMRI studies (Refs. [43,47,171,197]; the exception is Luna et al. [148]), and even in the original ${ }^{133} \mathrm{Xe}$ regional cerebral blood flow study that started the era of FEF imaging [164]. No oculomotor imaging study, to our knowledge, has mentioned instructing the subjects not to blink, nor has any used control scans in which subjects blinked at similar rates as detected during test scans. Accordingly, most imaging studies have probably mislocated the FEF caudally, toward the motor strip which contains a region that mediates blinking responses (an eyelid blinking field) as well as another region that medi-

\footnotetext{
${ }^{7}$ Recently [43], the method of fMRI has made it possible to compare data from different epochs of a task with each other ("epoch 1", image-"epoch 2" image). The problems discussed in this section are still relevant.
} 
ates eye movements in humans (a motor strip eye field) (Fig. 22 and Fig. 23A-C). ${ }^{8}$

Only a single imaging study that examined saccade generation failed to find the FEF near the expected precentral sulcus location [119]. In this study by Kawashima et al., subjects made a series of seven successive saccades to visual targets, each saccadic period lasting a second, and then subjects rested for a second, on average. The saccades were of relatively short amplitude ${ }^{9}$ and nearly all saccades were task-related, such that blinking was probably inhibited until the intertrial period, when "return" saccades were allowed $[58,62,303]$. This intertrial period only occurred for about $1 \mathrm{~s}$ out of approximately every $9 \mathrm{~s}$. It would seem that blinking once every $9 \mathrm{~s}$ or so is about the rate expected to occur during fixation, as well. Therefore,

\footnotetext{
${ }^{8}$ Electrical stimulation of the FEF region in monkeys causes conjugate eye movements (e.g., Refs. [10,59,294]) (Fig. 22A). Eyelid blinking is evoked from the face area of the precentral motor strip of monkey (Fig. 22A [262]). Beevor and Horsely [11] stimulated the brain of an orangutan and found that conjugate eye movements (with no eyelid movements) were evoked from a region anterior to, and well-separated from, the motor strip ("FEF" in Fig. 22B). Eyelid blinking was evoked from the face area in the motor strip ("EBF", for eyelid blinking field, in Fig. 22B). A complex combination of head rotation, eye movement, and eyelid opening was also evoked within the motor strip itself, just medial to the blinking area ("MSEF", for motor strip eye field, in Fig. 22B). Leyton and Sherrington [144] confirmed all these findings in their subsequent study of orangutans, chimpanzees (Fig. 22C), and gorillas (Fig. 22D).

When neurosurgeons began stimulating the human brain, they found that the oculomotor layout of humans was similar to that of anthropoid apes. Rasmussen and Penfield [212] evoked eye movements from 48 stimulation sites in 31 patients and separated their eye movement sites into two groups. A posterior group consisted of 18 sites ( $37.5 \%$ of the total) on the lip of the central sulcus (Fig. 23A). Here, contraversive and as well as ipsiversive movements were often evoked. An anterior group consisted of 30 sites $(62.5 \%$ of the total) that were mostly rostral to the precentral sulcus (Fig. 23A). At these anterior sites, nearly all the evoked movements were contraversive. Comparing the two groups of eye movement sites with data from monkey and ape (cf. Fig. 22), it seems that the anterior group represents the FEF and that the posterior group represents the motor strip eye field. Rasmussen and Penfield also evoked eyelid movements from 27 sites in 18 patients. In contrast to the distribution of eye movement sites, the majority of eyelid sites ( $63 \%$ of the total) were on the lip of the central sulcus (Fig. 23B).

In order to summarize these results, we calculated the average locations of Rasmussen and Penfield's anterior eye field, posterior eye field, and eyelid field, depicting each field with an ellipse (Fig. 23C). The ellipses were constructed by scanning the original figures [212] into a computer graphics program, finding the $x-y$ location of each point, and drawing an ellipse to represent each field where the ellipse's center was at the mean $x-y$ location and the radii of the ellipses in the $x$ and $y$ direction equaled the standard deviations of the points in each direction. Rasmussen and Penfield's anterior eye field (FEF) is almost completely rostral to the precentral sulcus (and mostly within the middle frontal gyrus [193]). Note that this location is in excellent agreement with the location of Foerster's FEF (Fig. 1C). In contrast to the FEF, the eyelid field and posterior eye field are mostly within the motor strip.

${ }^{9}$ Mean $15 \pm$ S.D. $5^{\circ}$, range $7^{\circ}-25^{\circ}$; calculated from their Fig. 1 .
}

we suspect that blinking activations may have been canceled out in the study of Kawashima et al. [119] when control scans (fixation) were subtracted from the test scans.

Kawashima et al. [119] found that, although precentral sulcus activation was not significant, activation in the middle frontal gyrus was strong and bilateral (see their Tables 1 and 3). The location of this activation zone in Talairach space was $x=36.5 \pm 5.3, y=25.8 \pm 12.3$, and $z=29.3 \pm 7.7 .{ }^{10}$ Could this be within the true human FEF? Its location in the middle frontal gyrus [119] puts it within granular cortex (Fig. 23D) and within the mediodorsal thalamus-recipient zone (regio frontalis, Fig. 23E), making it anatomically homologous to the monkey FEF (see Section 2.2.1). The location of this putative FEF in Talairach space is about $3.5 \mathrm{~cm}$ anterior to the precentral sulcus and thus is well-removed from the primary motor strip. Furthermore, it is not within the dorsolateral prefrontal cortex as mapped by imaging investigators; rather, it lies about $1.1 \mathrm{~cm}$ posterior to it. ${ }^{11}$ This makes the putative human FEF location, as found by Kawashima et al. [119], homologous with monkey FEF in terms of gross location [70]. The idea, that human FEF is in the middle frontal gyrus, has very recently been supported using a method independent of functional imaging: transcranial magnetic stimulation combined with structural MRI (Fig. 23D,E; Ro et al. [215]).

Thus, human imaging studies are needed that explicitly control eyelid blinking so as to determine whether the human FEF is indeed located within the middle frontal gyrus. The oculomotor deficits that occur after damage to the precentral region in humans might in fact be due to damage of axons originating from the middle frontal gyrus. Finally, based on our analysis (see ${ }^{8}$ ), a third eye field might exist in the frontal lobe of monkeys, a motor-strip eye field, immediately adjacent to the face area within the precentral sulcus. In human imaging studies, this eye field may also contribute to biasing the FEF activity field caudally toward the motor cortex as subjects perform oculomotor tasks.

\footnotetext{
${ }^{10}$ Mean and standard deviations of their middle frontal gyrus activations, $n=4$. Note, left and right hemispheres combined, so absolute value of $x$ was used.

${ }^{11}$ Significantly different from the activity focus of prefrontal cortex imaging, $p=0.038$, Mann-Whitney rank sum test, from the dorsolateral prefrontal cortex mean location of $x=35.5 \pm 5.3, y=37.1 \pm 5.7, z=$ $23.7 \pm 7.4$ in Talairach coordinates; found by pooling 39 estimates of dorsolateral prefrontal cortex that were imaged during tasks that primarily involved working memory; right and left hemispheres combined (absolute value of $x$ used); values used only if authors indicate that the activation included at least part of Brodmann's area 46. Studies used: Cohen et al. [39,40]; Courtney et al. [44,45]; Goldberg et al. [83]; Haxby et al. [98]; McCarthy et al. [163]; Owen et al. [182-185]; Petrides et al. [200,201]; Smith et al. [260,261]
} 


\section{Discussion}

This review makes it evident that the organization and the functions of the DMFC and FEF for the most part are quite different. In what follows, we shall discuss the

A Eye Movements

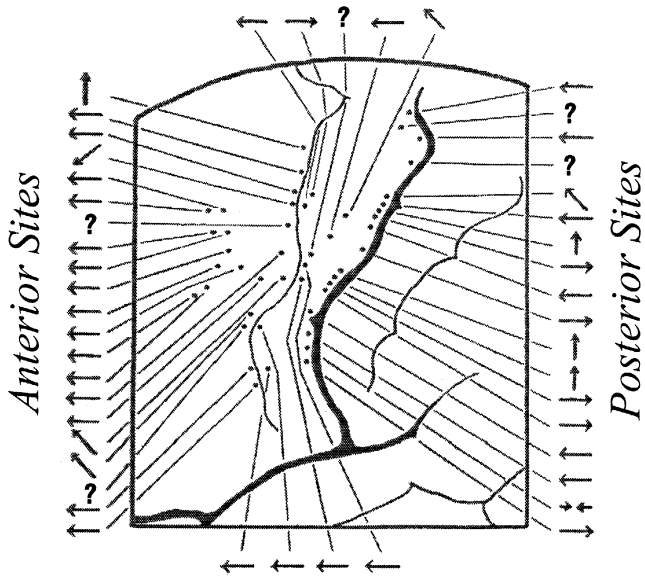

B Eyelid Movements

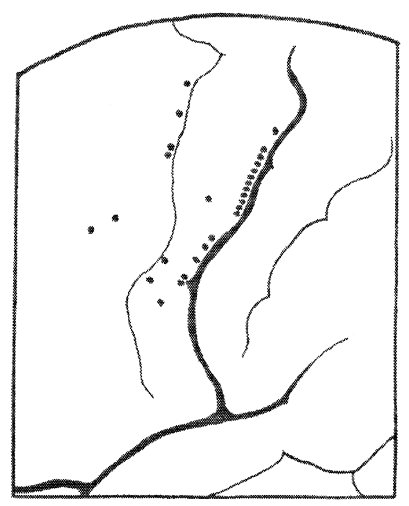

$\bigcirc$ Eye and Eyelid Fields

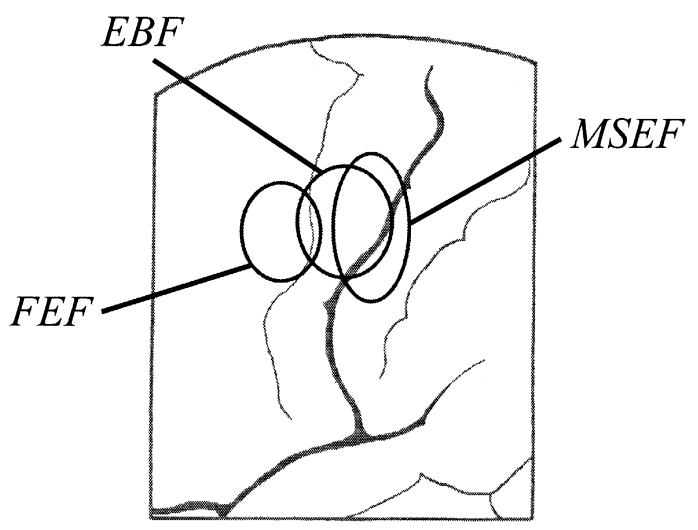

similarities and the differences that have been established between these two structures.

(1) The first difference between these structures is in the kinds of coding operations they perform. There is now compelling evidence to the effect that the FEF carries a

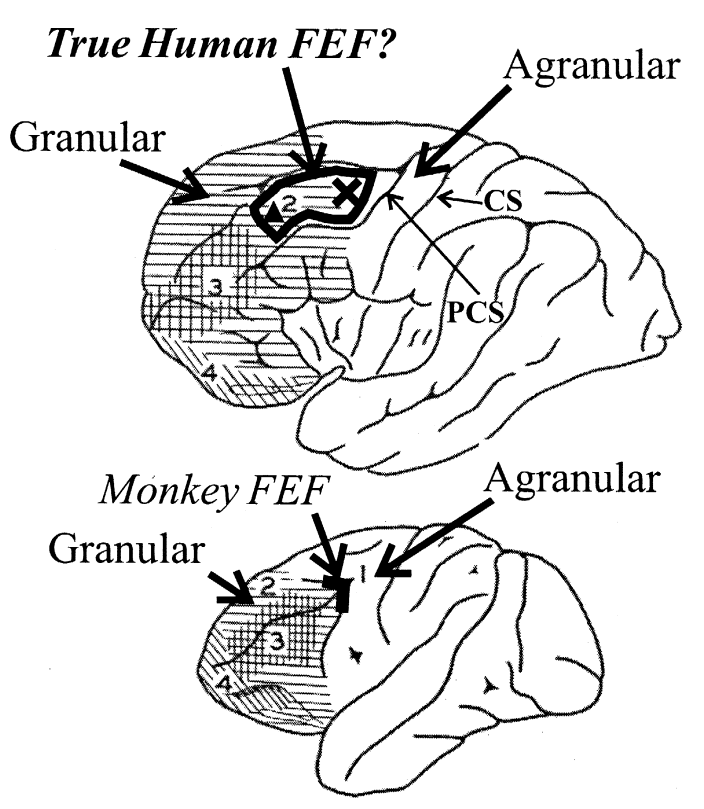

\section{$\mathrm{E}_{\text {Connections }}$}
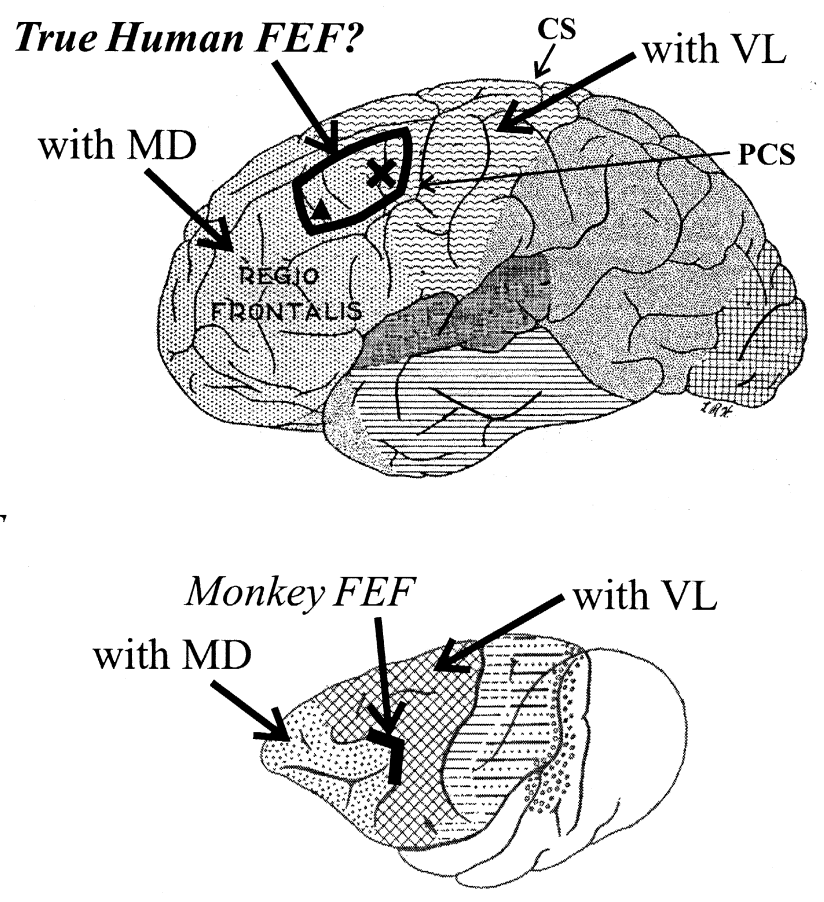
retinocentric code whereas the DMFC carries a craniocentric one. Two major lines of evidence support the existence of a retinocentric code in the FEF. (a) Electrical stimulation of the area evokes predominantly contraversive saccades of a specific size and direction irrespective of starting eye position [216]; there is topographic order in the layout within the FEF for different direction and amplitude saccadic eye movements. (b) Neurons in the FEF are tuned for specific directions and sizes of saccades made into contralateral space [31]; this arrangement corresponds with what has been reported with electrical stimulation. Supportive, if less compelling, is the evidence from lesion studies that show deficits in saccade execution associated with the execution of vectors [54,213,263].

Two major lines of evidence support the claim that the DMFC carries a craniocentric code. (a) Electrical stimulation of the DMFC at most sites drives the eyes to a particular orbital position and these orbital positions are topographically ordered in the DMFC [282]. (b) The response characteristics of single cells confirm this observation [139]. Lesion studies, again less compelling, are also in support of a craniocentric code in the DMFC; deficits have been reported in both monkeys and humans for the execution of saccades to two or more remembered target positions $[73,74,264]$; the deficit has been attributed to a failure to store the second or subsequent target positions in craniotopic coordinates [208].

(2) The second distinction between the two eye-movement areas in the frontal lobe is that the DMFC is less dedicated to the execution of saccadic eye movements than is the FEF. The DMFC contains a representation of the entire body; stimulation evokes oculomotor as well as skeletomotor responses (e.g., Mitz and Wise [166]); and many individual neurons in the DMFC respond both to eye and limb movements, which is not the case for FEF neurons $[37,38,173]$.

(3) The third difference between these two structures is revealed by the deficits that arise after ablation or reversible inactivation. Inactivation or lesions of the FEF produce deficits in saccadic latencies and velocities, in generating saccades to extinguished targets, in the selection of simultaneously presented targets, in the execution of sequences of saccadic eye movements to successive targets, and in pursuit eye movements; deficits in making saccades to extinguished targets in the selection of simultaneously presented targets, and in the execution of sequences of saccades are long-lasting. In contrast, DMFC inactivation and lesions produce virtually no deficits in saccades made to a single visual target or in pursuit eye movements; the deficits seen in initiating saccades to extinguished targets and in the execution of sequences of saccades are of small magnitude and recover rapidly.

In support of the FEF lesion work, physiological studies have reported neurons involved in pursuit eye movement in the FEF [154]. In conflict with the DMFC lesion work, however, is the finding that DMFC neurons are modulated during pursuit eye movements $[101,105]$ and that stimulation of the DMFC interferes with pursuit [102-104]. It is unclear whether this latter effect is due to direct interference with neural structures involved in the execution of pursuit eye movements. The effects reported could be due to interference produced by the stimulation that normally drives the eye to a termination zone.

The DMFC and the FEF are similar in having neurons that alter their responses as animals and humans learn new visuomotor tasks although such neurons are more preva-

\footnotetext{
Fig. 23. Results from intraoperative stimulation in humans, and anatomical implications of our human FEF hypothesis. Anterior is to the left in all the panels, and dorsal is to the top. Pictures in panels A and B were flipped in mirror image from the originals [212] so as to put anterior to the left. (A) Human Frontal lobe eye movement sites found by Rasmussen and Penfield [212]. They distinguished two groups separated by function and location, shown here as "Anterior Sites" (which includes the sites described by arrow diagrams at top and bottom) and "Posterior Sites". Arrows describe the directions of eye movements evoked at each site; leftward arrow = purely contraversive movement and rightward arrow = purely ipsiversive movement. Some movements have a vertical component as well, and some are purely vertical. Also, converging arrows $=$ convergence and ? = movement not described. (B) Frontal lobe eyelid movement sites found by Rasmussen and Penfield [212]. (C) Summary of the general locations of the FEF, the eyelid blinking field (EBF), and the motor strip eye field (MSEF), according to the data of Rasmussen and Penfield [212] (see ${ }^{8}$ for details of constructing the ellipses). (D) Basic cytoarchitecture of human frontal lobe, above, compared with monkey, below. Region 2 (horizontal lines) is the extent of granular frontal cortex, and caudal to that (but anterior to the central sulcus (CS)) is agranular frontal cortex. The region within the bold-outlined polygon is the general predicted location of the human FEF, lying in the middle frontal gyrus where neocortex changes from granular layer IV (rostrally) to agranular (caudally). A similar transition is seen in monkey FEF, lying in the bank of the arcuate sulcus (AS) where granular cortex changes to agranular cortex. Figures derived from Walker [301]. (E) Known connections of the human brain with respect to thalamus, above; compared with monkey, below. In human brain, the "regio frontalis" is connected primarily with the mediodorsal (MD) nucleus of the thalamus; the region caudal to that is connected primarily with the ventrolateral (VL) thalamic nucleus. Our predicted FEF region in the middle frontal gyrus is probably at a transition point, being connected with both thalamic zones. Similarly, FEF in monkey is also at a transition point where cortex changes from being more connected with MD thalamus (stippled) to being more connected with VL thalamus (cross-hatched). Human brain map is modified from Bailey and von Bonin [7]; monkey brain map is modified from Walker [300], chosen because he used similar methods (retrograde degeneration) as was used to derive the human map [65,165]. PCS, precentral sulcus. In both D and $\mathrm{E}$, the triangle shows the approximate mean location of middle frontal gyrus activation found by Kawashima et al. [119], and the (X) shows the approximate regions in two human subjects where transcranial magnetic stimulation delayed saccades (Ro et al. [215]; plotted with reference to anatomy of Yousry et al. [312]). For explanation of other notations and area fills in panels D and E, see the original papers.
} 
lent in the DMFC (Fig. 21; Chen and Wise [33,34]). In the DMFC, a frequently made observation is a decrease in the responses of neurons as proficiency is reached on a task. No such decrease has been reported so far for the FEF. Dopaminergic inputs to the DMFC are greater than those to the FEF. Whether this difference is functionally significant as it relates to learning is unclear.

Many outstanding issues pertaining to the functions of the DMFC and FEF remain to be addressed. Here we note three. First, it is not known what the magnitude is of the modifiability of DMFC and FEF neurons. At the present time, most unit recordings are limited to a time span of a few hours; changes that arise in the course of long-term learning have not been amenable to study. Second, it remains unclear as to what extent neurons in these areas play a role in memory functions. Does the execution of motor acts in the absence of direct sensory input rely on neural circuits within these structures or are they relayed to these areas from other regions? How are these structures engaged during task performance once overtraining has occurred? Third, the exact nature of the neural code in these areas needs to be clarified. While there is general agreement to the effect that the FEF carries a retinocentric code, the nature of the code in the DMFC is still under debate, as both retinocentric and craniocentric coding operations have been noted. Whether, in addition, other egocentric codes [205] or even allocentric codes [180] are operative in these or related areas needs to be assessed.

\section{Acknowledgements}

We would like to thank Andreas Tolias and David Leopold for comments on this review. This work was supported by NEI grant EY-08502 to P.H. Schiller.

\section{References}

[1] H. Aizawa, M. Inase, H. Mushiake, K. Shima, J. Tanji, Reorganization of activity in the supplementary motor area associated with motor learning and functional recovery, Exp. Brain Res. 84 (1991) 668-671

[2] G.E. Alexander, M.D. Crutcher, Preparation for movement: neural representation of intended direction in three motor areas of the monkey, J. Neurophysiol. 64 (1990) 133-150.

[3] G.E. Alexander, M.R. DeLong, P.L. Strick, Parallel organization of functionally segregated circuits linking basal ganglia and cortex, Annu. Rev. Neurosci. 9 (1986) 357-381.

[4] T.J. Anderson, I.H. Jenkins, D.J. Brooks, M.B. Hawken, R.S.J. Frackowiak, C. Kenard, Cortical control of saccades and fixations in man. A PET study, Brain 117 (1994) 1073-1084.

[5] T. Arikuni, K. Watanabe, K. Kubota, Connections of area 8 with area 6 in the brain of macaque monkey, J. Comp. Neurol. 277 (1988) 21-40.

[6] M. Azuma, H. Nakayama, Y. Sasaki, H. Suzuki, Relation between visual input and motor output for eye movements in monkey frontal eye field, Behav. Brain Res. 27 (1988) 93-98.

[7] P. Bailey, G. von Bonin, The Isocortex of Man, University of Illinois Press, Urbana, IL, USA, 1951.
[8] H. Barbas, D.N. Pandya, Architecture and frontal cortical connections of the premotor cortex (area 6) in the rhesus monkey, J. Comp. Neurol. 286 (1987) 211-228.

[9] W. Becker, O. Hoehne, K. Iwase, Bereitschaftpotential, prämotorische positivierung und andere hirnpotentiale bei sakkadischen augenbewegungen, Vision Res. 12 (1972) 421-436.

[10] C.E. Beevor, V. Horsley, A further minute analysis by electric stimulation of the so-called motor region of the cortex cerebri in the monkey (Macacus sinicus), Philos. Trans. R. Soc. London, Ser. B 179 (1888) 205-256.

[11] C.E. Beevor, V. Horsley, A record of the results obtained by electrical excitation of the so-called motor cortex and internal capsule in an orangoutang (Simia satyrus), Philos. Trans. R. Soc. London, Ser. B 181 (1890) 129-158.

[12] B. Berger, S. Trottier, P. Gaspar, C. Verney, C. Alvarez, Major dopamine innervation of the cortical motor areas in the cynomologus monkey. A radioautographic study with comparative assessment of serotonergic afferents, Neurosci. Lett. 72 (1986) 121-127.

[13] B. Berger, S. Trottier, C. Verney, P. Gaspar, C. Alvarez, Regional and laminar distribution of the dopamine and serotonin innervation in the macaque cerebral cortex: a radiographic study, J. Comp. Neurol. 273 (1988) 99-119.

[14] E. Bizzi, Discharge of frontal eye field neurons during saccadic and following eye movements in unanesthetized monkeys, Exp. Brain Res. 6 (1968) 69-80.

[15] E. Bizzi, P.H. Schiller, Single unit activity in the frontal eye field of unanesthetized monkeys during eye and head movement, Exp. Brain Res. 10 (1970) 151-158.

[16] S.T. Bok, Histonomy of the Cerebral Cortex, Elsevier, Amsterdam, 1959.

[17] L. Bon, C. Lucchetti, Neurons signalling the maintenance of attentive fixation in frontal area $6 \mathrm{a} \beta$ of macaque monkey, Exp. Brain Res. 82 (1990) 231-233.

[18] L. Bon, C. Lucchetti, Behavioural and motor mechanisms of dorsomedial frontal cortex of Macaca monkey, Int. J. Neurosci. 60 (1991) 187-193.

[19] L. Bon, C. Lucchetti, The dorsomedial frontal cortex of the Macaca monkey: fixation and saccade-related activity, Exp. Brain Res. 89 (1992) 571-580.

[20] L. Bon, C. Lucchetti, Ear and eye representation in the frontal cortex, area 8b, of macaque monkey: an electrophysiological study, Exp. Brain Res. 102 (1994) 259-271.

[21] L. Bon, C. Lucchetti, Attentional-related neurons in the supplementary eye field of the macaque monkey, Exp. Brain Res. 113 (1997) 180-185.

[22] K. Bötzel, H. Plendl, W. Paulus, M. Scherg, Bereitschaftpotential: is there a contribution of the supplementary motor area?, Electroencephalographr. Clin. Neurophysiol. 89 (1993) 187-196.

[23] V. Braitenberg, A. Schuz, Anatomy of the Cortex: Statistic and Geometry, Springer-Verlag, London, 1991.

[24] D. Braun, H. Weber, T.H. Mergner, J. Schulte-Monting, Saccadic reaction times in patients with frontal and parietal lesions, Brain 115 (1992) 1359-1386.

[25] C. Brinkman, Lesions in supplementary motor area interfere with a monkey's performance of a bimanual coordination task, Neurosci. Lett. 27 (1981) 267-270.

[26] C. Brinkman, Supplementary motor area of the monkey's cerebral cortex: short- and long-term deficits after unilateral ablation and the effects of subsequent callosal section, J. Neurosci. 4 (1984) 918-929.

[27] C. Brinkman, R. Porter, Supplementary motor area in the monkey: activity of neurons during performance of a learned motor task, J. Neurophyiol. 42 (1979) 681-709.

[28] K. Brodmann, Beitrage zur histologischen lokalisation der grosshirnrinde. Erste mitteilung: dei regio rolandica, J. Psychol. Neurol. 2 (1903) 79-107. 
[29] K. Brodmann, Beitrage zur histologischen lokalisation der grosshirnrinde: III. Mitteilung: die rhindenfelder der niederen afferen, J. Psychol. Neurol. Leipzig 4 (1905) 177-226.

[30] C.J. Bruce, M.E. Goldberg, Primate frontal eye fields: I. Single neurons discharging before saccades, J. Neurophysiol. 53 (1985) 603-635.

[31] C.J. Bruce, M.E. Goldberg, M.C. Bushnell, G.B. Stanton, Primate frontal eye fields: II. Physiological and anatomic correlates of electrically evoked eye movements, J. Neurophysiol. 54 (1985) 714-734.

[32] A.W. Campbell, Histological Studies on the Localization of Cerebral Function, Cambridge Univ. Press, 1905.

[33] L.L. Chen, S.P. Wise, Neural activity in the supplementary eye field during acquisition of conditional oculomotor associations, J. Neurophysiol. 73 (1995) 1101-1121.

[34] L.L. Chen, S.P. Wise, Supplementary eye field contrasted with the frontal eye field during acquisition of conditional oculomotor associations, J. Neurophysiol. 73 (1995) 1122-1134.

[35] Y.C. Chen, D. Thaler, P.D. Nixon, C.E. Stern, R.E. Passingham, The functions of the medial premotor cortex: II. The timing and selection of learned movements, Exp. Brain Res. 102 (1995) 461-473.

[36] D. Cheyne, H. Weinberg, Neuromagnetic fields accompanying unilateral finger movements: premovement and movement-evoked fields, Exp. Brain Res. 78 (1989) 604-612.

[37] I.-H. Chou, P.H. Schiller, Encoding of arm and eye movements in the dorsomedial frontal cortex (DMFC), Neural Control of Movement Abstract 2 (1997) 16.

[38] I.-H. Chou, P.H. Schiller, Single cell responses in dorsomedial frontal cortex (DMFC) to eye and arm movements, Soc. Neurosci. Abstr. 23 (1997) 1552.

[39] J.D. Cohen, S.D. Forman, T.S. Braver, B.J. Casey, D. ServanSchreiber, D.C. Noll, Activation of the prefrontal cortex in a non-spatial working memory task with functional MRI, Hum. Brain Mapp. 1 (1994) 293-304.

[40] J.D. Cohen, W.M. Perlstein, T.S. Braver, L.E. Nystrom, D.C. Noll, J. Jonides, E.E. Smith, Temporal dynamics of brain activation during a working memory task, Nature 386 (1997) 604-608.

[41] J.G. Colebatch, M.-P. Deiber, R.E. Passingham, K.J. Friston, R.S. Frackowiak, Regional cerebral blood flow during voluntary arm and hand movements in human subjects, J. Neurophysiol. 65 (1991) 1392-1401.

[42] M. Corbetta, F.M. Miezin, G.L. Shulman, S.E. Petersen, A PET study of visuospatial attention, J. Neurosci. 13 (1993) 1202-1226.

[43] S.M. Courtney, L. Petit, J.M. Maisog, L.G. Ungerleider, J.V. Haxby, An area specialized for spatial working memory in human frontal cortex, Science 279 (1998) 1347-1351.

[44] S.M. Courtney, L.G. Ungerleider, K. Keil, J.V. Haxby, Object and spatial visual working memory activates separate neural systems in human cortex, Cereb. Cortex 6 (1996) 39-49.

[45] S.M. Courtney, L.G. Ungerleider, K. Keil, J.V. Haxby, Transient and sustained activity in a distributed neural system for human working memory, Nature 386 (1997) 608-611.

[46] D.P. Crowne, C.H. Yeo, I.S. Russell, The effects of unilateral frontal eye field lesions in the monkey: visual-motor guidance and avoidance behaviour, Behav. Brain Res. 2 (1981) 165-187.

[47] D.G. Darby, A.C. Nobre, V. Thangaraj, R. Edelman, M.-M. Mesulam, S. Warach, Cortical activation in the human brain during lateral saccades using EPISTAR functional magnetic resonance imaging, Neuroimage 3 (1996) 53-62.

[48] L. Deecke, H.H. Kornhuber, W. Lang, M. Lang, H. Schreiber, Timing function of the frontal cortex in sequential motor and learning tasks, Hum. Neurobiol. 4 (1985) 143-154.

[49] L. Deecke, W. Lang, Generation of movement-related potentials and fields in the supplementary sensorimotor area and the primary motor area, in: H.O. Luders (Ed.), Advances in Neurology, Supple- mentary Sensorimotor Area, Vol. 70, Lippincott-Raven, Amsterdam, 1996.

[50] L. Deecke, P. Scheid, H.H. Kornhuber, Distribution of readiness potential, pre-motion positivity and motor potential of the human cerebral cortex preceding voluntary finger movements, Exp. Brain Res. 7 (1969) 158-168.

[51] M.-P. Deiber, R.E. Passingham, J.G. Colebatch, K.J. Friston, P.D. Nixon, R.S.J. Frackowiak, Cortical areas and the selection of movement: a study with positron emission tomography, Exp. Brain Res. 84 (1991) 393-402.

[52] S.Y. Deng, M.E. Goldberg, M.A. Segraves, L.G. Ungerleider, M. Mishkin, The effect of unilateral ablation of the frontal eye fields on saccadic performance in the monkey, in: E. Keller, D.S. Zee (Eds.), Adaptive Processes in the Visual and Oculomotor Systems, Pergamon, Oxford, 1986, pp. 201-208.

[53] C. Dettmers, G.R. Fink, R.N. Lemon, K.M. Stephan, R.E. Passingham, D. Sibersweig, A. Holms, M.C. Ridding, D.J. Brooks, R.S.J. Frackowiak, Relation between cerebral activity and force in the motor area of the human brain, J. Neurophysiol. 74 (1995) 802-815.

[54] E.C. Dias, M.A. Segraves, Muscimol-induced inactivation of the monkey frontal eye field: effects on visually and memory-guided saccades, J. Neurophysiol. 81 (1999) 2191-2214.

[55] F. Doricchi, D. Perani, C. Inococcia, F. Grassi, S.F. Cappa, V. Bettinardi, G. Galati, L. Pizzamiglio, F. Fazio, Neural control of fast-regular saccades and antisaccades: an investigation using positron emission tomography, Exp. Brain Res. 116 (1997) 50-62.

[56] R.P. Dum, P.L. Strick, The origin of corticospinal projections from the premotor areas in the frontal lobe, J. Neurosci. 11 (1991) 667-689.

[57] I. Evdokimidis, T. Mergner, C.H. Lucking, Dependence of presaccadic cortical potentials on the type of saccadic eye movement, Electroencephalogr. Clin. Neuropsychol. 83 (1992) 179-191.

[58] C. Evinger, K.A. Manning, J.J. Pellegrini, M.A. Basso, A.S. Powers, P.A. Sibony, Not looking while leaping: the linkage of blinking and saccadic gaze shifts, Exp. Brain Res. 100 (1994) 337-344.

[59] D. Ferrier, Experiments on the brains of monkeys - No. I, Proc. R. Soc. London 23 (1875) 409-432.

[60] O. Foerster, The cerebral cortex in man, Lancet 2 (1931) 309-312.

[61] O. Foerster, The motor cortex in man in the light of Hughlings Jackson's doctrines, Brain 59 (1936) 135-159.

[62] C. Fogarty, J.A. Stern, Eye movements and blinks: their relationship to higher cognitive processes, Int. J. Psychophysiol. 8 (1989) 35-42.

[63] S.L. Foote, J.H. Morrision, Development of the noradrenergic, serotonergic, and dopaminergic innervation of neocortex, Curr. Topics Dev. Biol. 21 (1987) 391-423.

[64] P.T. Fox, J.M. Fox, M.E. Raichle, R.M. Burde, The role of cerebral cortex in the generation of voluntary saccades: a positron emission tomographic study, J. Neurophysiol. 54 (1985) 348-369.

[65] W. Freeman, J.W. Watts, Retrograde degeneration of the thalamus following prefrontal lobotomy, J. Comp. Neurol. 86 (1947) 65-93.

[66] I. Fried, A. Katz, G. McCarthy, K.J. Sass, P. Williamson, S.S. Spencer, D. Spencer, Functional organization of human supplementary motor cortex studied by electrical stimulation, J. Neurosci. 11 (1991) 3656-3666.

[67] W. Fries, Cortical projections to the superior colliculus in the macaque monkey: a retrograde study using horseradish peroxidase, J. Comp. Neurol. 230 (1984) 55-76.

[68] G. Fritsch, E. Hitzig, Ueber die elektrische erregbarkeit des grosshirns, Archiv fur Anatomie, Physiologie, und Wissenschaftliche Medizin 37 (1870) 300-322.

[69] N. Fujii, H. Mushiake, M. Tamai, J. Tanji, Microstimulation of the supplementary eye field during saccade preparation, NeuroReport 6 (1995) 2565-2568.

[70] S. Funahashi, C.J. Bruce, P.S. Goldman-Rakic, Dorsolateral prefrontal lesions and oculomotor delayed-response performance: evi- 
dence for mnemonic "scotomas", J. Neurosci. 13 (1993) 1479 1497.

[71] P. Gaspar, B. Berger, A. Febvret, A. Vigny, J.P. Henry, Catecholamine innervation of the human cerebral cortex as revealed by comparative immunohistochemistry of tyrosine hydroxylase and dopamine- $\beta$-hydroxylase, J. Comp. Neurol. 279 (1989) 249-271.

[72] P. Gaspar, I. Stephniewska, J.H. Kaas, Topography and collateralization of the dopaminergic projections to motor and lateral prefrontal cortex in owl monkeys, J. Comp. Neurol. 325 (1992) 1-21.

[73] B. Gaymard, C. Pierrot-Deseilligny, S. Rivaud, Impairment of sequences of memory-guided saccades after supplementary motor area lesions, Ann. Neurol. 28 (1990) 622-626.

[74] B. Gaymard, S. Rivaud, C. Pierrot-Deseilligny, Role of the left and right supplementary motor areas in memory-guided saccade sequences, Ann. Neurol. 34 (1993) 404-406.

[75] H. Gemba, K. Sasaki, Studies on cortical field potentials recorded during learning processes of visually initiated hand movements in monkeys, Exp. Brain Res. 55 (1984) 26-32.

[76] M. Giguere, P.S. Goldman-Rakic, Mediodorsal nucleus: areal, laminar, and tangential distributions of afferents and efferents in the frontal lobe of rhesus monkeys, J. Comp. Neurol. 277 (1988) 195-213.

[77] M. Glickstein, Ferrier's mistake, Trends Neurosci. 8 (1985) 341344.

[78] J. Godoy, H. Lüders, D.S. Dinner, H.H. Morris, E. Wyllie, Versive eye movements elicited by cortical stimulation of the human brain, Neurology 40 (1990) 296-299.

[79] M. Godschalk, R.N. Lemon, H.G.J.M. Kuypers, H.K. Ronday, Cortical afferents and efferents of monkey postarcuate area: an anatomical and electrophysiological study, Exp. Brain Res. 56 (1984) 410-424

[80] M.E. Goldberg, C.J. Bruce, Primate frontal eye fields: III. Maintenance of spatially accurate saccade signal, J. Neurophysiol. 64 (1990) 489-508.

[81] M.E. Goldberg, M.C. Bushnell, Behavioral enhancement of visual responses in monkey cerebral cortex: II. Modulation in frontal eye fields specifically related to saccades, J. Neurophysiol. 46 (1981) 773-787.

[82] M.E. Golberg, M.C. Bushnell, C.J. Bruce, The effect of attentive fixation on eye movements evoked by electrical stimulation of the frontal eye fields, Exp. Brain Res. 61 (1986) 579-584.

[83] T.E. Goldberg, K.F. Berman, C. Randolph, J.M. Gold, D.R. Weinberger, Isolating the mnemonic component in spatial delayed response: a controlled PET ${ }^{15} \mathrm{O}$-labelled water regional cerebral blood flow study in normal humans, Neuroimage 3 (1996) 69-78.

[84] J.P. Gottlieb, C.J. Bruce, M.G. MacAvoy, Smooth eye movements elicited by microstimulation in the primate frontal eye field, J. Neurophysiol. 69 (1993) 786-799.

[85] J.P. Gottlieb, M.G. MacAvoy, C.J. Bruce, Neural responses related to smooth pursuit eye movements and their correspondence with electrically elicited smooth eye movements in the primate frontal eye field, J. Neurophysiol. 72 (1994) 1634-1653.

[86] H.J. Gould, C.G. Cusick, T.P. Pons, J.H. Kaas, The relationship of corpus callosum connections to electrical stimulation maps of motor, supplementary motor and frontal eye fields in owl monkeys, J. Comp. Neurol. 247 (1986) 297-325.

[87] S.T. Grafton, A.H. Fagg, R.P. Woods, M.A. Arbib, Functional anatomy of pointing and grasping in humans, Cereb. Cortex 6 (1996) 226-237.

[88] S.T. Grafton, E. Hazeltine, R. Ivry, Functional mapping of sequence learning in normal humans, J. Cognit. Neurosci. 7 (1995) 497-510.

[89] S.T. Grafton, J.C. Mazziotta, S. Presty, K.J. Friston, R.S.J. Frackowiak, M.E. Phelps, Functional anatomy of human procedural learning determined with regional cerebral blood flow and PET, J. Neurosci. 12 (1992) 2542-2548.

[90] S.T. Grafton, R.P. Woods, J.C. Mazziotta, Within-arm somatotopy in human motor areas determined by positron emission tomography imaging of cerebral blood flow, Exp. Brain Res. 95 (1993) 172-176.

[91] B. Grözinger, H.H. Kornhuber, J. Kriebel, Participation of mesial cortex in speech: evidence from cerebral potentials preceding speech production in man, in: O. Creutzfeldt, H. Scheich, C. Schreiner (Eds.), Hearing Mechanisms and Speech. Exp. Brain Res., Suppl. II, 1979, pp. 189-192.

[92] A.S.F. Grünbaum, C.S. Sherrington, Observations on the physiology of the cerebral cortex of anthropoid apes, Proc. R. Soc. London 72 (1903) 152-155.

[93] D. Guitton, H.A. Buchtel, R.M. Douglas, Frontal lobe lesions in man cause difficulties in suppressing reflexive glances and in generating goal-directed saccades, Exp. Brain Res. 58 (1985) 455472.

[94] U. Halsband, H.J. Freund, Premotor cortex and conditional motor learning in man, Brain 113 (1990) 207-222.

[95] U. Halsband, R.E. Passingham, Premotor cortex and the conditions for movement in monkeys (Macaca fascicularis), Behav. Brain Res. 18 (1985) 269-277.

[96] D.P. Hanes, K.G. Thompson, J.D. Schall, Relationship of presaccadic activity in frontal eye field and supplementary eye field to saccade initiation in macaque: Poisson spike train analysis, Exp. Brain Res. 103 (1995) 85-96.

[97] S. Hashimoto, H. Gemba, K. Sasaki, Analysis of slow cortical potentials preceding self-paced hand movements in the monkey, Exp. Neurol. 65 (1979) 218-229.

[98] J.V. Haxby, L.G. Ungerleider, B. Horwitz, S.I. Rapoport, C.L. Grady, Hemispheric differences in neural systems for face working memory, Hum. Brain Mapp. 3 (1995) 68-82.

[99] S.-Q. He, P.D. Richard, P.L. Strick, Topographic organization of corticospinal projections from the frontal lobe: motor areas on the lateral surface of the hemisphere, J. Neurosci. 13 (1993) 952-980.

[100] W. Heide, M. Blankenburg, E. Zimmermann, D. Kompf, Cortical control of double-step saccades: implications for spatial orientation, Ann. Neurol. 38 (1995) 739-748.

[101] S.J. Heinen, Single neuron activity in the dorsomedial frontal cortex during smooth pursuit eye movements, Exp. Brain Res. 104 (1995) 357-361.

[102] S.J. Heinen, Microstimulation in dorsomedial frontal cortex affects smooth pursuit eye movements, Soc. Neurosci. Abstr. 22 (1996) 968.

[103] S.J. Heinen, Miscrostimulation in dorsomedial frontal cortex inhibits smooth pursuit, Soc. Neurosci. Abstr. 23 (1997) 8.

[104] S.J. Heinen, A.N. Anbar, Stimulation of the supplementary eye fields affects saccade timing, Soc. Neurosci. Abstr. 24 (1998) 1147.

[105] S.J. Heinen, M. Liu, Single-neuron activity in the dorsomedial frontal cortex during smooth-pursuit movements to predictable target motion, Visual Neurosci. 14 (1997) 853-865.

[106] E. Hitzig, Ueber die galvanischen schwindelempfindungen und eine neue methode galvanischer reizung der augenmuskeln, Berliner Klinische Wochenschrift 11 (1870) 137-138.

[107] V. Horsley, E.A. Schäfer, A record of experiments upon the functions of the cerebral cortex, Philos. Trans. R. Soc. London, Ser. B 179 (1888) 1-45.

[108] M.F. Huerta, J.H. Kaas, Supplementary eye field as defined by intracortical microstimulation: connections in macaques, J. Comp. Neurol. 293 (1990) 299-330.

[109] M.F. Huerta, L.A. Krubitzer, J.H. Kaas, Frontal eye field as defined by intracortical microstimulation in squirrel monkeys, owl monkeys, and macaque monkeys: II. Cortical connections, J. Comp. Neurol. 265 (1987) 332-361.

[110] K.D. Hutchins, A.M. Martino, P.L. Strick, Corticospinal projections from the medial wall of the hemisphere, Exp. Brain Res. 71 (1988) 667-672.

[111] M. Jahanshahi, I.H. Jenkins, R.G. Brown, C.D. Marsden, R.E. Passingham, D.J. Brooks, Self-initiated versus externally triggered movements: I. An investigation using measurement of regional 
cerebral blood flow with PET and movement-related potentials in normal and Parkinson's disease subjects, Brain 118 (1995) 913933.

[112] I.H. Jenkins, D.J. Brooks, P.D. Nixon, R.S.J. Frackowiak, R.E. Passingham, Motor sequence learning: a study with positron emission tomography, J. Neurosci. 14 (1994) 3775-3790.

[113] E.G. Jones, T.P.S. Powell, An anatomical study of converging sensory pathways within the cerebral cortex of the monkey, Brain 93 (1970) 793-820.

[114] E.G. Jones, S.P. Wise, Size, laminar and columnar distribution of efferent cells in the sensory-motor cortex of monkeys, J. Comp. Neurol. 175 (1978) 391-438.

[115] M. Jueptner, C.D. Frith, D.J. Brooks, R.S.J. Frackowiak, R.E. Passingham, Anatomy of motor learning: II. Subcortical structures and learning by trail and error, J. Neurophysiol. 77 (1997) 13271337.

[116] M. Jueptner, K.M. Stephan, C.D. Frith, D.J. Brooks, R.S.J. Frackowiak, R.E. Passingham, Anatomy of motor learning: I. Frontal cortex and attention to action, J. Neurophysiol. 77 (1997) 13131324.

[117] R. Kawashima, P.E. Roland, B.T. O'Sullivan, Fields in human motor areas involved in preparation for reaching, actual reaching, and visuomotor learning: a positron emission tomography study, J. Neurosci. 14 (1994) 3462-3474.

[118] R. Kawashima, K. Satoh, H. Itoh, S. Ono, S. Furumoto, R. Gotoch, M. Koyama, S. Yoshioka, K. Takahashi, K. Takahiashi, T. Yanagisawa, H. Fukada, Functional anatomy of GO/NO-GO discrimination and response selection - a PET study in man, Brain Res. 728 (1996) 79-89.

[119] R. Kawashima, J. Tanji, K. Okada, M. Sugiura, K. Sato, S. Kinomura, K. Inoue, A. Ogawa, H. Fukuda, Oculomotor sequence learning: a positron emission tomography study, Exp. Brain Res. 122 (1998) $1-8$.

[120] E.G. Keating, Frontal eye field lesions impair predictive and visually guided pursuit eye movements, Exp. Brain Res. 86 (1991) 311-323.

[121] E.G. Keating, Lesions of the frontal eye field impair pursuit eye movements, but preserve the predictions driving them, Behav. Brain Res. 53 (1993) 91-104.

[122] E.G. Keating, A. Peirre, S. Chopra, Ablation of the pursuit area in the frontal cortex of the primate degrades foveal but not optokinetic smooth eye movements, J. Neurophysiol. 76 (1996) 637-641.

[123] K. Keizer, H.G.J.M. Kuypers, Distribution of corticospinal neurons with collaterals to the lower brain stem reticular formation in monkey (Macaca fascicularis), Exp. Brain Res. 74 (1989) 311318.

[124] M.A. Kennard, L. Ectors, Forced circling in monkeys following lesions of the frontal lobes, J. Neurophysiol. 65 (1938) 1243-1253.

[125] J. Kievit, H.G.J.M. Kuypers, Organization of the thalamocortical connections to the frontal lobe in the rhesus monkey, Exp. Brain Res. 29 (1977) 299-322.

[126] W. Klostermann, D. Klompf, W. Heide, R. Verleger, B. Wauschkuhn, T. Seyfert, The presaccadic cortical negativity prior to self-paced saccades with and without visual guidance, Electroencephalogr. Clin. Neuropsychol. 91 (1994) 219-228.

[127] H.H. Kornhuber, L. Deecke, Hirnpotentialänderungen bei willkürbewegungen und passiven bewegungen des menschen: bereitschaftpotential und reafferente potentiale, Pflügers Archiv für die Gesamte Physiologie 284 (1965) 1-17.

[128] H. Kunzle, An autoradiographic analysis of the efferent connections from premotor and adjacent prefrontal regions (area 6 and 9) in Macaca fascicularis, Brain Behav. Evol. 15 (1978) 185-234.

[129] H. Kunzle, Cortico-cortical efferents of primary motor and somatosensory regions of the cerebral cortex in Macaca fascicularis, Neuroscience 3 (1978) 25-39.

[130] K. Kurata, S.P. Wise, Premotor and supplementary motor cortex in rhesus monkeys: neuronal activity during externally and internally instructed motor tasks, Exp. Brain Res. 72 (1988) 237-248.

[131] D.D. Kurylo, A.A. Skavenski, Eye movements elicited by electrical stimulation of area PG in the monkey, J. Neurophysiol. 65 (1991) $1243-1253$.

[132] H.G.J.M. Kuypers, C.E. Catsman-Berrevoets, Frontal corticosubcortical projections and their cells of origin, in: F. Reinoso-Suarez, C. Ajmone-Marsan (Eds.), International Brain Research Organization Monograph Series, Cortical Integration: Basic, Archicortical, and Cortical Association Levels of Neural Integration, Vol. 11, Raven Press, New York, 1984, pp. 171-193.

[133] M. Lang, R. Beisteiner, G. Lindinger, L. Deecke, Changes of cortical activity when executing learned motor sequences, Exp. Brain Res. 89 (1992) 435-440.

[134] W. Lang, D. Cheyne, R. Kristeva, R. Beisteiner, G. Lindinger, L. Deecke, Three-dimensional location of SMA activity preceding voluntary movement: a study of electric and magnetic fields in a patient with infarction of the right supplementary motor area, Exp. Brain Res. 87 (1991) 688-695.

[135] M. Lang, A. Kornhuber, L. Deecke, H.H. Kornhuber, Human cerebral potentials and visuomotor learning, Eur. J. Physiol. 399 (1983) 342-344.

[136] W. Lang, H. Obrig, G. Lindinger, D. Cheyne, L. Deecke, Supplementary motor area activation while tapping bimanually different rhythms in musicians, Exp. Brain Res. 79 (1990) 506-514.

[137] W. Lang, L. Petit, P. Höllinger, U. Pietrzyk, N. Tzourio, B. Mazoyer, A. Berthoz, A positron emission tomography study of oculomotor imagery, NeuroReport 5 (1994) 921-924.

[138] K.-M. Lee, Electrophysiological characterization of the dorsomedial frontal cortex of the rhesus monkey, $\mathrm{PhD}$ thesis, Massachusetts Institute of Technology, Cambridge, 1992.

[139] K.-M. Lee, E.J. Tehovnik, Topographic distribution of fixation-related units in the dorsomedial frontal cortex of the rhesus monkey, Eur. J. Neurosci. 7 (1995) 1005-1011.

[140] G.R. Leichnetz, Afferent and efferent connections of the dorsolateral precentral gyrus (area 4, hand/arm region) in the macaque monkey, with comparisons to area 8, J. Comp. Neurol. 254 (1986) 460-492.

[141] G.R. Leichnetz, M.E. Goldberg, Higher centers concerned with eye movements and visual attention: cerebral cortex and thalamus, in: J.A. Büttner-Ennever (Ed.), Reviews of Oculomotor Research, Neuroanatomy of the Oculomotor System, Vol. 2, Elsevier, Amsterdam, 1988 , pp. 365-429.

[142] G.R. Leichnetz, D.L. Smith, R.F. Spencer, Cortical projections to the paramedian tegmental and basilar pons in the monkey, J. Comp. Neurol. 228 (1984) 388-408.

[143] D.A. Lewis, M.J. Campbell, S.L. Foote, M. Goldstein, J.H. Morrision, The distribution of tyrosine hydroxylase-immunoreactive fibres in primate neocortex is widespread but regionally specific, $\mathrm{J}$. Neurosci. 7 (1987) 279-290.

[144] A.S.F. Leyton, C.S. Sherrington, Observations on the excitable cortex of the chimpanzee, orangutan and gorilla, Q. J. Exp. Psychol. 11 (1917) 135-222.

[145] T. Ljungberg, P. Apicella, W. Schultz, Responses of monkey dopamine neurons during learning of behavioural reactions, J. Neurophysiol. 67 (1992) 145-163.

[146] M.-T. Lu, J.B. Preston, P.L. Strick, Interconnections between the prefrontal cortex and the premotor areas in the frontal lobe, J. Comp. Neurol. 341 (1994) 375-392.

[147] C. Lucchetti, F. Lui, L. Bon, Neglect syndrome for aversive stimuli in a macaque monkey with dorsomedial frontal cortex lesion, Neuropsychologia 36 (1998) 251-257.

[148] B. Luna, K.R. Thulorn, M.H. Strojwas, B.J. McCurtain, R.A. Berman, C.R. Genovese, J.A. Sweeney, Dorsal cortical regions subserving visually guided saccades in humans: an fMRI study, Cereb. Cortex 8 (1998) 40-47. 
[149] G. Luppino, M. Matelli, R. Camarda, G. Rizzolatti, Multiple representations of body movements in mesial area 6 and the adjacent cingulate cortex: an intracortical microstimulation study in the macaque monkey, J. Comp. Neurol. 311 (1991) 463-482.

[150] G. Luppino, M. Matelli, R. Camarda, G. Rizzolatti, Corticocortical connections of area F3 (SMA-Proper) and area F6 (Pre-SMA) in the macaque monkey, J. Comp. Neurol. 338 (1993) 114-140.

[151] G. Luppino, M. Matelli, R. Camarda, G. Rizzolatti, Corticospinal projections from mesial frontal and cingulate areas in the monkey, NeuroReport 5 (1994) 2545-2548.

[152] J.C. Lynch, Frontal eye field lesions in monkeys disrupt visual pursuit, Exp. Brain Res. 68 (1987) 437-441.

[153] J.C. Lynch, J.E. Hoover, P.L. Strick, Input to the primate frontal eye field from the substantia nigra, superior colliculus, and dentate nucleus demonstrated by transneuronal transport, Exp. Brain Res. 100 (1994) 181-186.

[154] M.G. MacAvoy, J.P. Gottlieb, C.J. Bruce, Smooth-pursuit eye movement representation in the primate frontal eye field, Cereb. Cortex 1 (1991) 95-102.

[155] C.D. MacKinnon, S. Kapur, D. Hussey, M.C. Verrier, S. Houle, W.G. Tatton, Contributions of the mesial frontal cortex to the premovement potentials associated with intermittent hand movements in humans, Hum. Brain Mapp. 4 (1996) 1-22.

[156] S.E. Mann, R. Thau, P.H. Schiller, Conditional task-related responses in monkey dorsomedial frontal cortex, Exp. Brain Res. 69 (1988) 460-468.

[157] R.T. Marrocco, Saccades induced by stimulation of the frontal eye fields: interaction with voluntary and reflexive eye movements, Brain Res. 146 (1978) 23-34.

[158] M. Matelli, G. Luppino, Thalamic input to mesial and superior area 6 in the macaque monkey, J. Comp. Neurol. 372 (1996) 59-87.

[159] M. Matelli, G. Luppino, G. Rizzolatti, Architecture of superior and mesial area 6 and the adjacent cingulate cortex in the macaque monkey, J. Comp. Neurol. 311 (1991) 445-462.

[160] M. Matsumura, K. Kubota, Cortical projection to hand-arm area from post-arcuate area in macaque monkeys: a histological study of retrograde transport of horseradish peroxidase, Neurosci. Lett. 11 (1979) 241-246

[161] Y. Matsuzaka, H. Aizawa, J. Tanji, A motor area rostral to the supplementary motor area (presupplementary motor area) in the monkey: neural activity during a learned motor task, J. Neurophysiol. 68 (1992) 653-662.

[162] Y. Matsuzaka, J. Tanji, Changing directions of forthcoming arm movements: neural activity in the presupplementary and supplementary motor area of monkey cortex, J. Neurophysiol. 76 (1996) $2327-2342$.

[163] G. McCarthy, A. Pruce, R.T. Constable, J.H. Krystal, J.C. Gore, P. Goldman-Rakic, Activation of human prefrontal cortex during spatial and non-spatial working memory tasks measured by functional MRI, Cereb. Cortex 6 (1996) 600-611.

[164] E. Melamed, B. Larsen, Cortical activation pattern during saccadic eye movements in humans: localization by focal cerebral blood flow increases, Ann. Neurol. 5 (1978) 79-88.

[165] A. Meyer, E. Beck, T. McLardy, Prefrontal leucotomy: a neuroanatomical report, Brain 70 (1947) 18-49.

[166] A.R. Mitz, S.P. Wise, The somatotopic organization of the supplementary motor area: intracortical microstimulation mapping, J. Neurosci. 7 (1987) 1010-1021.

[167] K. Miyashita, K. Sakai, O. Hikosaka, Anticipatory saccades in sequential procedural learning in monkeys, J. Neurosci. 76 (1996) 1361-1366.

[168] K. Miyashita, K. Sakai, O. Hikosaka, Effects of SMA and Pre-SMA inactivation on learning of sequential movements in monkey, Soc Neurosci. Abstr. 22 (1996) 1862.

[169] C.W. Mohler, M.E. Goldberg, R.H. Wurtz, Visual receptive fields of frontal eye field neurons, Brain Res. 61 (1973) 385-389.

[170] M.J. Morrow, J.A. Sharpe, Deficits of smooth pursuit eye move- ment after unilateral frontal lobe lesions, Ann. Neurol. 37 (1995) 443-451.

[171] R.M. Müri, O. Heid, A.C. Nirkko, C. Ozdoba, J. Felblinger, G. Schroth, C.W. Hess, Functional organization of saccades and antisaccades in the frontal lobe in humans: a study with echo planar functional magnetic resonance imaging, J. Neurol. Neurosurg. Psychiatry 65 (1998) 374-377.

[172] E.A. Murray, J.D. Coulter, Organization of corticospinal neurons in the monkey, J. Comp. Neurol. 195 (1981) 339-365.

[173] H. Mushiake, N. Fujii, J. Tanji, Visually guided saccade versus eye-hand reach: contrasting neural activity in the cortical supplementary and frontal eye fields, J. Neurophysiol. 75 (1996) 21872191.

[174] H. Mushiake, M. Inase, J. Tanji, Neural activity in the primate premotor, supplementary, and precentral motor cortex during visually guided and internally determined sequential movements, J. Neurophysiol. 66 (1991) 705-718.

[175] K. Nakamura, K. Sakai, O. Hikosaka, Neuronal activity in the medial frontal cortex during learning of sequential procedures, J. Neurophysiol. 80 (1998) 2671-2687.

[176] R. Neshige, H. Lüders, H. Shibasaki, Recording of movement-related potentials scalp and cortex in man, Brain 111 (1988) 719-736.

[177] J. Niemann, T. Winker, J. Gerling, B. Landwehrmeyer, R. Jung, Changes of slow cortical negative DC potentials during the acquisition of a complex finger motor task, Exp. Brain Res. 85 (1991) 417-422.

[178] G.A. O’Driscoll, N.M. Alpert, S.W. Matthysse, D.L. Levy, S.L. Rauch, P.S. Holzman, Functional anatomy of antisaccade eye movements investigated with positron emission tomography, Proc. Natl. Acad. Sci. U.S.A. 92 (1995) 925-929.

[179] K. Okano, J. Tanji, Neural activity in the primate motor fields of the agranular frontal cortex preceding visually triggered and selfpaced movement, Exp. Brain Res. 66 (1987) 155-166.

[180] C.R. Olson, S.N. Gettner, Object-centered direction selectivity in the macaque supplementary eye field, Science 269 (1995) 985-988.

[181] C.R. Olson, S.N. Gettner, Macaque SEF neurons encode objectcentered directions of eye movements regardless of the visual attributes of instruction cues, J. Neurophysiol. 81 (1999) 23402346.

[182] A.M. Owen, J. Doyon, M. Petrides, A.C. Evans, Planning and spatial working memory: a positron emission tomography study in humans, Eur. J. Neurosci. 8 (1996) 353-364.

[183] A.M. Owen, A.C. Evans, M. Petrides, Evidence for a two-stage model of spatial working memory processing within the lateral frontal cortex: a positron emission tomography study, Cereb. Cortex 6 (1996) 31-38

[184] A.M. Owen, B. Milner, M. Petrides, A.C. Evans, Memory for object features versus memory for object location: a positron emission tomography study of encoding and retrieval processes, Proc. Natl. Acad. Sci. U.S.A. 93 (1996) 9212-9217.

[185] A.M. Owen, C.E. Stern, R.B. Look, I. Tracey, B.R. Rosen, M. Petrides, Functional organization of spatial and non-spatial working memory processing within the human lateral frontal cortex, Proc. Natl. Acad. Sci. U.S.A. 95 (1998) 7721-7726.

[186] M. Pare, M. Crommelinck, D. Guitton, Gaze shifts evoked by stimulation of the superior colliculus in the head-free cat conform to the motor map but also depend on stimulus strength and fixation activity, Exp. Brain Res. 101 (1994) 123-139.

[187] H.B. Parthasarathy, J.D. Schall, A.M. Graybiel, Distributed but convergent ordering of corticostriatal projections: analysis of the frontal eye field and the supplementary eye field in the macaque monkeys, J. Neurosci. 12 (1992) 4466-4488.

[188] R.E. Passingham, Two cortical systems for directing movement. Motor Areas of the Cerebral Cortex, Ciba Foundation Symposium 132, Wiley, New York, 1987, pp. 151-164.

[189] T. Paus, Location and function of the human frontal eye field: a selective review, Neuropsychologia 34 (1996) 475-483. 
[190] T. Paus, M. Kalina, L. Patockova, Y. Anterova, R. Cerny, P. Mecir, J. Bauer, P. Krabec, Medial vs. lateral frontal lobe lesions and differential impairment of central-gaze fixation maintenance in man, Brain 114 (1991) 2051-2067.

[191] T. Paus T, S. Marrett, K.J. Worsley, A.C. Evans, Extra-retinal modulation of cerebral blood flow in the human visual cortex: implications for saccadic suppression, J. Neurophysiol. 74 (1995) 2179-2184.

[192] T. Paus, M. Petrides, A.C. Evans, E. Meyer, Role of human anterior cingulate cortex in the control of oculomotor, manual and speech responses: a positron emission tomography study, J. Neurophysiol. 70 (1993) 453-469.

[193] W. Penfield, E. Boldrey, Somatic motor and sensory representation in the cerebral cortex of man as studied by electrical stimulation, Brain 60 (1937) 389-443.

[194] W. Penfield, H. Jasper, Epilepsy and the Functional Anatomy of the Human Brain, Little, Brown, and Co., Boston, 1954.

[195] W. Penfield, T. Rasmussen, The Cerebral Cortex of Man. A Clinical Study of Localization of Function, MacMillan, New York, 1950.

[196] W. Penfield, K. Welch, The supplementary motor area of the cerebral cortex, Arch. Neurol. Psychiatry 66 (1951) 289-317.

[197] L. Petit, V.P. Clark, J. Ingehom, J.V. Haxby, Dissociation of saccade-related and pursuit-related activation in human frontal eye fields as revealed by fMRI, J. Neurophysiol. 77 (1997) 3386-3390.

[198] L. Petit, C. Orssaud, N. Tzourio, F. Crivelli, A. Berthoz, B. Mazoyer, Functional anatomy of a prelearned sequence of horizontal saccades in humans, J. Neurosci. 16 (1996) 3714-3728.

[199] L. Petit, C. Orssaud, N. Tzourio, G. Salamon, B. Mazoyer, A. Berthoz, PET study of voluntary saccadic eye movements in humans: basal ganglia-thalamocortical system and cingulate cortex involvement, J. Neurophysiol. 69 (1993) 1009-1017.

[200] M. Petrides, B. Alivisatos, A.C. Evans, E. Meyer, Dissociation of human mid-dorsolateral from posterior dorsolateral frontal cortex in memory processing, Proc. Natl. Acad. Sci. U.S.A. 90 (1993) 873-877.

[201] M. Petrides, B. Alivisatos, A.C. Evans, E. Meyer, Functional activation of the human frontal cortex during performance of verbal working memory tasks, Proc. Natl. Acad. Sci. U.S.A. 90 (1993) 873-882.

[202] M. Petrides, D.N. Pandya, Projections to the frontal cortex from the posterior parietal region in the rhesus monkey, J. Comp. Neurol. 228 (1984) 105-116.

[203] M. Petrides, D.N. Pandya, Comparative architectonic analysis of the human and the macaque frontal cortex, in: F. Boller, J. Grafman (Eds.), Handbook of Neuropsychology, Vol. 9, Elsevier, Amsterdam, 1994, pp. 17-58.

[204] N. Picard, P.L. Strick, Motor areas of the medial wall: a review of their location and functional activation, Cereb. Cortex 6 (1996) 342-353.

[205] C. Pierrot-Deseilligny, I. Israël, A. Berthoz, S. Rivaud, B. Gaymard, Role of the difference frontal lobe areas in the control of the horizontal component of memory-guided saccades in man, Exp. Brain Res. 95 (1993) 166-171.

[206] C. Pierrot-Deseilligny, S. Rivaud, B. Gaymard, Y. Agid, Cortical control of memory-guided saccades in man, Exp. Brain Res. 83 (1991) 607-617.

[207] C. Pierrot-Deseilligny, S. Rivaud, B. Gaymard, Y. Agid, Cortical control of reflexive visually guided saccades, Brain 114 (1991) 1473-1485.

[208] C. Pierrot-Deseilligny, S. Rivaud, B. Gaymard, R. Muri, A.-I. Vermersch, Cortical control of saccades, Ann. Neurol. 37 (1995) 557-567.

[209] E.D. Playford, I.H. Jenkins, R.E. Passingham, J. Nutt, R.S.J. Frackowiak, D.J. Brooks, Impaired medial frontal and putamen activation in Parkinson's disease: a positron emission tomography study, Ann. Neurol. 32 (1992) 151-161.

[210] L.J. Porrino, P.S. Goldman-Rakic, Brainstem innervation of prefrontal and anterior cingulate cortex in the rhesus monkey revealed by retrograde transport of HRP, J. Comp. Neurol. 205 (1982) 63-76.

[211] T.M. Preuss, P.S. Goldman-Rakic, Myelo- and cytoarchitecture of the granular frontal cortex and surrounding regions in the strepsirhine primate, Galago and the anthropoid primate, Macaca, J. Comp. Neurol. 310 (1991) 429-474.

[212] T. Rasmussen, W. Penfield, Movement of the head and eyes from stimulation of human frontal cortex, Res. Publ. -Assoc. Res. Nerv. Ment. Dis. 27 (1948) 346-361.

[213] S. Rivaud, R.M. Muri, B. Gaymard, A.I. Vermersch, C. Pierrot-Deseilligny, Eye movement disorders after frontal eye field lesions in humans, Exp. Brain Res. 102 (1994) 110-120.

[214] G. Rizzolatti, M. Matelli, G. Pavesi, Deficits in attention and movement following the removal of postarcuate (area 6) and prearcuate (area 8) cortex in macaque monkeys, Brain 106 (1983) $655-673$.

[215] T. Ro, S. Cheifet, H. Ingle, R. Shoup, R. Rafal, Localization of the humans frontal eye fields and motor hand area with transcranial magnetic stimulation and magnetic resonance imaging, Neuropsychologia 37 (1999) 225-231.

[216] D.A. Robinson, A.F. Fuchs, Eye movements evoked by stimulation of frontal eye fields, J. Neurophyiol. 32 (1969) 637-648.

[217] A.J. Rockel, R.W. Hiorns, T.P.S. Powell, The basic uniformity in structure of the neocortex, Brain 103 (1980) 221-244.

[218] P.E. Roland, B. Larsen, N.A. Lassen, E. Skinhoj, Supplementary motor area and other cortical areas in organizing voluntary movements in man, J. Neurophysiol. 43 (1980) 118-136.

[219] P.E. Roland, K. Zilles, Functions and structures of the motor cortices in humans, Curr. Opin. Neurobiol. 6 (1996) 773-781.

[220] R. Romo, H. Merchant, A. Zainos, A. Hernandez, Categorical perception of somesthetic stimuli: psychophysical measurements correlated with neural events in primate medial premotor cortex, Cereb. Cortex 7 (1997) 317-326.

[221] E.M. Rouiller, A. Babalian, O. Kazennikov, V. Moret, X.-H. Yu, M. Wiesendanger, Transcallosal connections of the distal forelimb representations of the primary and supplementary motor cortical areas in macaque monkeys, Exp. Brain Res. 102 (1994) 227-243.

[222] G.S. Russo, C.J. Bruce, Effect of eye position within the orbit on electrically elicited saccadic eye movements: a comparison of the macaque monkey's frontal and supplementary eye fields, J. Neurophysiol. 69 (1993) 800-818.

[223] G.S. Russo, C.J. Bruce, Neurons in the supplementary eye field of rhesus monkeys code visual targets and saccadic eye movements in an oculocentric coordinate system, J. Neurophysiol. 76 (1996) $825-848$.

[224] K. Sakai, O. Hikosaka, S. Miyauchi, R. Takino, Y. Sasaki, B. Putz, Transition of brain activation from frontal to parietal areas in visuomotor sequence learning, J. Neurosci. 18 (1998) 1827-1840.

[225] K. Sasaki, H. Gemba, Development and change of cortical field potentials during learning of visually initiated hand movements in monkey, Exp. Brain Res. 48 (1982) 429-437.

[226] K. Sasaki, H. Gemba H, Compensatory motor function of the somatosensory cortex for the motor cortex temporarily impaired by cooling in the monkey, Exp. Brain Res. 55 (1984) 60-68.

[227] K. Sasaki, H. Gemba, Effects of premotor cortex cooling upon visually initiated hand movements in the monkey, Brain Res. 374 (1986) 278-286.

[228] J.D. Schall, Neural activity related to visually guided saccadic eye movements in the supplementary motor area of rhesus monkeys, J. Neurophysiol. 66 (1991) 530-558.

[229] J.D. Schall, Neuronal activity related to visually guided saccades in 
the frontal eye fields of rhesus monkeys: comparison with supplementary eye fields, J. Neurophysiol. 66 (1991) 559-579.

[230] Schall, J.D., Visuomotor areas of the frontal lobe, in: K.S. Rockland, J.H. Kaas, A. Peters (Eds.), Cerebral Cortex: Extrastriate Cortex in Primates, Vol. 12, 1997, pp. 527-637.

[231] J.D. Schall, A. Morel, J.H. Kaas, Topography of supplementary eye field afferents to frontal eye field in macaque: implications for mapping between saccade coordinate systems, Visual Neurosci. 10 (1993) 385-393.

[232] J.D. Schall, A. Morel, D.J. King, J. Bullier, Topography of visual cortex connections with frontal eye field in macaque: convergence and segregation of processing streams, J. Neurosci. 15 (1995) 4464-4487.

[233] P.H. Schiller, The effect of superior colliculus ablation on saccades elicited by cortical stimulation, Brain Res. 122 (1977) 154-156.

[234] P.H. Schiller, I. Chou, The effects of frontal eye field and dorsomedial frontal cortex lesions on visually guided eye movements, Nat. Neurosci. 1 (1998) 248-253.

[235] P.H. Schiller, I. Chou, The effects of anterior arcuate and dorsomedial frontal cortex lesions on visually guided eye movements in the rhesus monkey: I. Single and sequential targets, submitted.

[236] P.H. Schiller, I. Chou, The effects of anterior arcuate and dorsomedial frontal cortex lesions on visually guided eye movements in the rhesus monkey: I. Paired and multiple targets, submitted.

[237] P.H. Schiller, J.H. Sandell, Interactions between visually and electrically elicited saccades before and after superior colliculus and frontal eye field ablations in the rhesus monkey, Exp. Brain Res. 49 (1983) 381-392.

[238] P.H. Schiller, J.H. Sandell, J.H.R. Maunsell, The effect of frontal eye field and superior colliculus lesions on saccadic latencies in the rhesus monkey, J. Neurophysiol. 57 (1987) 1033-1049.

[239] P.H. Schiller, S.D. True, J.L. Conway, Paired stimulation of the frontal eye fields and the superior colliculus of the rhesus monkey, Brain Res. 179 (1979) 162-164.

[240] P.H. Schiller, S.D. True, J.L. Conway, Deficits in eye movements following frontal eye field and superior colliculus ablations, J. Neurophysiol. 44 (1980) 1175-1189.

[241] M. Schlag-Rey, N. Amador, H. Sanchez, J. Schlag, Antisaccade performance predicted by neural activity in the supplementary eye field, Nature 390 (1997) 398-401.

[242] J. Schlag, M. Schlag-Rey, Unit activity related to spontaneous saccades in frontal dorsomedial cortex of monkey, Exp. Brain Res. 58 (1985) 208-211.

[243] J. Schlag, M. Schlag-Rey, Evidence for a supplementary eye field, J. Neurophysiol. 57 (1987) 179-200.

[244] J. Schlag, M. Schlag-Rey, I. Pigarev, Supplementary eye field: influence of eye position on neural signals of fixation, Exp. Brain Res. 90 (1992) 302-306.

[245] G. Schlaug, U. Knorr, R.J. Seitz, Intersubject variability of cerebral activations in acquiring a motor skill: a study with positron emission tomography, Exp. Brain Res. 98 (1994) 523-534.

[246] W. Schultz, P. Apicella, T. Ljungberg, Responses of monkey dopamine neurons to reward and conditioned stimuli during successive steps of learning a delayed response task, J. Neurosci. 13 (1993) 900-913.

[247] M.A. Segraves, Activity of monkey frontal eye field neurons projecting to oculomotor regions of the pons, J. Neurophysiol. 68 (1992) 1967-1985.

[248] M.A. Segraves, M.E. Goldberg, Functional properties of corticotectal neurons in the monkey's frontal eye field, J. Neurophysiol. 58 (1987) 1387-1419.

[249] M.A. Segraves, K. Park, The relationship of monkey frontal eye field activity to saccadic dynamics, J. Neurophysiol. 69 (1993) $1880-1889$.

[250] J. Sergent, E. Zuck, S. Terriah, B. MacDonald, Distributed neural network underlying musical sight-reading and keyboard performance, Science 257 (1992) 106-109.
[251] D. Shi, H.R. Friedman, C.J. Bruce, Deficits in smooth pursuit eye movements after muscimol inactivation within the primate's frontal eye field, J. Neurophysiol. 80 (1998) 458-464.

[252] H. Shibasaki, G. Barrett, E. Halliday, A.M. Halliday, Components of the movement-related cortical potential and their scalp topography, Electroencephalogr. Clin. Neurophysiol. 49 (1980) 213-226.

[253] H. Shibutani, H. Sadata, J. Hyvarinen, Saccade and blinking evoked microstimulation of the posterior parietal association cortex of the monkey, Exp. Brain Res. 55 (1984) 1-88.

[254] K. Shima, H. Mushiake, N. Saito, J. Tanji, Role for cells in the presupplementary motor area in updating motor plans, Proc. Natl. Acad. Sci. U.S.A. 93 (1996) 8694-8698.

[255] K. Shima, J. Tanji, Both supplementary and presupplementary motor areas are crucial for the temporal organization of multiple movements, J. Neurophysiol. 80 (1998) 3247-3260.

[256] B.L. Shook, M. Schlag-Rey, J. Schlag, Direct projection from the supplementary eye field to the nucleus raphe interpositus, Exp. Brain Res. 73 (1988) 215-218.

[257] B.L. Shook, M. Schlag-Rey, J. Schlag, Primate supplementary eye field: I. Comparative aspects of mesencephalic and pontine connections, J. Comp. Neurol. 301 (1990) 618-642.

[258] B.L. Shook, M. Schlag-Rey, J. Schlag, Primate supplementary eye field: II. Comparative aspects of connections with the thalamus, corpus striatum, and related forebrain nuclei, J. Comp. Neurol. 307 (1991) 562-583.

[259] J.J. Sloper, T.P.S. Powell, A study of the axon initial segment and proximal axon of neurons in the primate motor and somatic sensory cortices, Philos. Trans. R. Soc. London, Ser. B 285 (1979) 123-139.

[260] E.E. Smith, J. Jonides, R.A. Keoppe, E. Awh, E.H. Schumacher, S. Minoshima, Spatial versus object working memory: PET investigations, J. Cognit. Neurosci. 7 (1995) 337-356.

[261] E.E. Smith, J. Jonides, R.A. Koeppe, Dissociating verbal and spatial working memory using PET, Cereb. Cortex 6 (1996) 11-20.

[262] W.K. Smith, The frontal eye fields, in: P.C. Bucy (Ed.), The Precentral Motor Cortex, University of Illinois Press, Urbana, IL, USA, 1949, pp. 307-342.

[263] M.A. Sommer, E.J. Tehovnik, Reversible inactivation of macaque frontal eye field, Exp. Brain Res. 116 (1997) 229-249.

[264] M.A. Sommer, E.J. Tehovnik, Reversible inactivation of macaque dorsomedial frontal cortex, Exp. Brain Res. 124 (1999) 429-446.

[265] M.A. Sommer, R.H. Wurtz, Frontal eye field neurons orthodromically activated from the superior colliculus, J. Neurophysiol. 80 (1998) 3331-3333.

[266] D.L. Sparks, L.E. Mays, Spatial localization of saccade targets: I. Compensation for stimulation-induced perturbations in eye position, J. Neurophysiol. 49 (1983) 45-63.

[267] G.B. Stanton, S.-Y. Deng, M.E. Goldberg, N.T. McMullen, Cytoarchitectural characteristics of the frontal eye fields in macaque monkeys, J. Comp. Neurol. 282 (1989) 415-427.

[268] G.B. Stanton, M.E. Goldberg, C.J. Bruce, Frontal eye field efferents in the macaque monkey: I. Subcortical pathways and topography of striatal and thalamic terminal fields, J. Comp. Neurol. 271 (1988) 473-492.

[269] K.M. Stephan, G.R. Fink, R.E. Passingham, D. Sibersweig, A.O. Ceballos-Bbaumann, C.D. Frith, R.S.J. Frackowaik, Functional anatomy of the mental representation of upper extremity movements in healthy subjects, J. Neurophysiol. 73 (1995) 373-386.

[270] H. Suzuki, A. Azuma, H. Yumiya, Stimulus and behavioural factors contributing to the activation of monkey prefrontal neurons during gazing, Jpn. J. Physiol. 29 (1979) 471-489.

[271] H. Suzuki, M. Azuma, Topographic studies on visual neurons in the dorsomedial prefrontal cortex of the monkey, Exp. Brain Res. 53 (1983) 47-58.

[272] J.A. Sweeney, M.A. Mintun, S. Kwee, M.B. Wiseman, D.L. Brown, D.R. Rosenberg, J.R. Carl, Positron emission tomography study of voluntary saccadic eye movements and spatial working memory, J. Neurophysiol. 75 (1996) 454-468. 
[273] J. Talairach, P. Tournoux, Co-Planar Stereotaxic Atlas of the Brain, Thieme Medical Publishers, New York, 1988.

[274] J. Tanji, New concepts of the supplementary motor area, Curr. Opin. Neurobiol. 6 (1996) 782-787.

[275] J. Tanji, K. Kurata, Comparison of movement-related activity in two cortical motor areas of primates, J. Neurophysiol. 48 (1982) 633-653.

[276] J. Tanji, K. Kurata, Contrasting neuronal activity in supplementary and precentral motor cortex of monkeys: I. Responses to instructions determining motor responses to forthcoming signals of different modalities, J. Neurophysiol. 53 (1985) 129-141.

[277] J. Tanji, H. Mushiake, Comparison of neural activity in the supplementary motor area and primary motor cortex, Cognit. Brain Res. 3 (1996) 143-150.

[278] J. Tanji, K. Okano, K. Sato, Neuronal activity in cortical motor areas related to ipsilateral, contralateral, and bilateral digit movements of the monkey, J. Neurophysiol. 60 (1988) 325-343.

[279] J. Tanji, K. Shima, Role for supplementary motor area cells in planning several movements ahead, Nature 371 (1994) 413-416.

[280] E.J. Tehovnik, The dorsomedial frontal cortex: eye and forelimb fields, Behav. Brain Res. 67 (1995) 147-163.

[281] E.J. Tehovnik, Electrical stimulation of neural tissue to evoke behavioural responses, J. Neurosci. Methods 65 (1996) 1-17.

[282] E.J. Tehovnik, K.-M. Lee, The dorsomedial frontal cortex of the rhesus monkey. Topographic representation of saccades evoked by electrical stimulation, Exp. Brain Res. 96 (1993) 430-442.

[283] E.J. Tehovnik, K.-M. Lee, P.H. Schiller, Stimulation-evoked saccades from the dorsomedial frontal cortex of the rhesus monkey following lesions of the frontal eye fields and superior colliculus, Exp. Brain Res. 98 (1994) 179-190.

[284] E.J. Tehovnik, W.M. Slocum, P.H. Schiller, Behavioural conditions affecting saccadic eye movements elicited electrically from the frontal lobes of primates, Eur. J. Neurosci. 11 (1999) 2431-2443.

[285] E.J. Tehovnik, W.M. Slocum, A.S. Tolias, P.H. Schiller, Saccades induced electrically from the dorsomedial frontal cortex: evidence for a head-centered representation, Brain Res. 795 (1998) 287-291.

[286] E.J. Tehovnik, M.A. Sommer, Electrically evoked saccades from the dorsomedial frontal cortex and frontal eye fields: a parametric evaluation reveals differences between areas, Exp. Brain Res. 117 (1997) 369-378.

[287] E.J. Tehovnik, M.S. Sommer, Effective spread and time-course of neural inactivation caused by lidocaine injection in monkey cerebral cortex, J. Neurosci. Methods 74 (1997) 17-26.

[288] D. Thaler, Y.C. Chen, P.D. Nixon, C.E. Stern, The functions of the medial premotor cortex: I. Simple learned movements, Exp. Brain Res. 102 (1995) 445-460

[289] H. Tokuno, M. Takada, A. Nambu, M. Inase, Somatotopical projections from the supplementary motor area to the red nucleus in the macaque monkey, Exp. Brain Res. 106 (1995) 351-355.

[290] A.S. Tolias, T. Moore, S.M. Smirnakis, E.J. Tehovnik, A.G. Siapas, P.H. Schiller, Modulation of spatial sensitivity of V4 neurons during eye movements, submitted.

[291] J. van der Steen, I.S. Russell, G.O. James, Effects of unilateral frontal eye field lesions on eye-head coordination in monkey, J. Neurophysiol. 55 (1986) 696-714.

[292] H. van Mier, L.W. Tempel, J.S. Perlmutter, M.E. Raichle, S.E. Petersen, Changes in brain activity during motor learning measured with PET: effects of hand on performance and practice, J. Neurophysiol. 80 (1998) 2177-2199.

[293] F. Viallet, J. Massion, R. Massarino, R. Khalil, Coordination between posture and movements in a bimanual load-lifting task: putative role of a medial frontal region including the supplementary motor area, Exp. Brain Res. 88 (1992) 674-684.

[294] C. Vogt, O. Vogt, Zur Kenntnis der elektrisch erregbaren hirnrindengebiete bei den säugetieren, Journal für Psychologie und Neurologie Leipzig 8 (1907) 277-456.

[295] C. Vogt, O. Vogt, Allgemeinere ergebnisse unserer hirnforschung, Journal für Psychologie und Neurologie Leipzig 25 (1919) 279-462.

[296] C. Vogt, O. Vogt, Die vergleichend-architektonische und die vergleichend-reizphysiologische felderung der groâhirnrinde unter besonderer berücksichtigung der menschlichen, Naturwissenschaften 14 (1926) 1190-1194.

[297] G. von Bonin, P. Bailey, The Neocortex of Macaca Mulatta, University of Illinois Press, Urbana, 1947, p. 136.

[298] M. von Cranach, R. Schmid, M.W. Vogel, Über einige bedingungen des zusammenhanges von lidschlag und blickwendung, Psychologische Forschung 33 (1969) 68-78.

[299] C.F. von Economo, G.N. Koskinas, Die Cytoarchitektonik der Hirnrinde des erwachsenen Menschen, Springer, Berlin, 1925.

[300] A.E. Walker, The Primate Thalamus, University of Chicago Press, Chicago, 1938.

[301] A.E. Walker, A cytoarchitectural study of the prefrontal area of the macaque monkey, J. Comp. Neurol. 73 (1940) 59-86.

[302] A.E. Walker, Stimulation and ablation. Their role in the history of cerebral physiology, J. Neurophysiol. 20 (1957) 435-449.

[303] Y. Watanabe, T. Fujita, J. Gyoba, Investigation of the blinking contingent upon saccadic eye movement, Tohuku Psychologia Folia 39 (1980) 121-129.

[304] K. Welch, P. Stuteville, Experimental production of unilateral neglect in monkeys, Brain 81 (1958) 341-347.

[305] M. Wiesendanger, Recent developments in studies of the supplementary motor areas of primates, Rev. Physiol. Biochem. Pharmacol. 103 (1986) 1-59.

[306] M. Wiesendanger, The riddle of supplementary motor area function, in: N. Mano, I. Hamada, M.R. DeLong (Eds.), Role of the Cerebellum and Basal Ganglia in Voluntary Movement, Elsevier, 1993, pp. 253-266.

[307] R.H. Wilkins, The electrical excitability of the cerebrum, J. Neurosurg. 20 (1963) 904-916, (translation of original paper by Fritsch and Hitzig, published in 1870).

[308] S.P. Wise, J. Tanji, Supplementary and precentral motor cortex: contrast in responsiveness to peripheral input in the hindlimb area of the anaesthetized monkey, J. Comp. Neurol. 195 (1981) 433-442.

[309] C.N. Woolsey, Organization of somatic sensory and motor areas of the cerebral cortex, in: H.F. Harlow, C.N. Woolsey (Eds.), Biological and Biochemical Bases of Behavior, University of Wisconsin Press, Madison, WI, USA, 1958, pp. 63-81.

[310] C.N. Woolsey, T.C. Erickson, W.E. Gilson, Localization in somatic sensory and motor areas of human cerebral cortex as determined by direct recording of evoked potentials and electrical stimulation, J. Neurosurg. 51 (1979) 476-506.

[311] C.N. Woolsey, P.H. Settlage, D.R. Meyer, W. Spencer, T.P. Hamuy, A.M. Travis, Patterns of localization in precentral and "supplementary" motor areas and their relation to the concept of a premotor area, Res. Publ. Assoc. Nerv. Ment. Dis. 30 (1952) 238-264.

[312] T.A. Yousry, U.D. Schmid, H. Alkadhi, D. Schmid, A. Peraud, A. Buettner, P. Winkler, Localization of the motor hand area to a knob on the precentral gyrus. A new landmark, Brain 120 (1997) 141157. 